\title{
Consumer Durables and Risky Borrowing: the Effects of Bankruptcy Protection*
}

\author{
Marina Pavan ${ }^{\dagger}$
}

May 2005

\begin{abstract}
This paper estimates a dynamic model of durable and non-durable consumption choice and default behavior in an economy where risky borrowing is allowed and bankruptcy protection is regulated by law. I exploit the substantial difference in the generosity of bankruptcy exemptions across the U.S. states to assess the role of durable goods as both informal collateral for unsecured debt and self-insurance against bad shocks to earnings. The model accounts for the equilibrium effects of bankruptcy protection on both consumer saving behavior and the credit market. In addition to providing reasonable estimates of the discount rate and risk aversion, I find that the generosity of bankruptcy protection does change both the incentives and the ability of households to accumulate durable wealth. The more generous the bankruptcy regulation, the lower the net durable wealth held by households in the first half of the life cycle before retirement. In order to minimize the default rate bankruptcy protection should be removed. The optimal level of exemption is positive but low.
\end{abstract}

*This paper is my doctoral thesis at the University of Pennsylvania. I am especially grateful to Jesús Fernández-Villaverde, Antonio Merlo, Victor Rios-Rull and Kenneth Wolpin for all their guidance and encouragement. I also benefited from conversations with Aldo Colussi, Marco Cozzi, Peter Gottschalk, Matteo Iacoviello, Makoto Nakajima, Elena Pastorino and Nicholas Souleles. All errors are mine.

${ }^{\dagger}$ Boston College. All comments are welcome at pavanma@bc.edu. 


\section{Introduction}

In this paper, I analyze the effects of personal bankruptcy protection on household saving behavior, focusing attention on the accumulation of net durable wealth. In particular, I exploit variation in the level of bankruptcy protection across U.S. states to assess the role of durable wealth as both informal collateral and self-insurance against future bad shocks to earnings.

In the U.S., a person that files for bankruptcy under Chapter 7 is repossessed of all assets in excess of an exempted value, which depends on the state of residence. ${ }^{1}$ All unsecured debt is discharged and the person keeps all exempted assets (mostly durables) and future income, thus enabling a "fresh start". There are substantial differences in the generosity of these exemption levels across the U.S. states. The homestead exemption (the amount of one's home equity that can be kept in bankruptcy) ranges from a few hundred dollars to $\$ 100,000$, and can be unlimited in some states. Cross-state variation in exemption levels provides the appropriate environment to exploit in order to assess the impact of bankruptcy protection on consumer behavior.

The major components (above 80\%) of exempted assets are durable goods, namely home equity and cars. ${ }^{2}$ The minimum consumption floor guaranteed by the exemption is conditional on the individual holding some assets. We thus expect exemption levels to influence the incentives to hold durable wealth, at least for households that are willing to borrow.

Moreover, bankruptcy protection affects both the demand and supply of credit. On the one hand, it provides insurance that permits an agent to better smooth consumption over time and states. The greater the exemption level, the smaller the risk of impoverishment upon default, and, thus, the higher the demand for borrowed funds. On the other hand, the higher the exemption level, the higher the probability and magnitude of losses on loans, and, thus, the smaller the supply of credit. This effect on supply can lead to higher interest rates on loans and tighter credit limits. The theoretical model in this work, and the empirical work based on it, account for both of these effects.

I develop a dynamic life cycle model of durable and non-durable consumption choice in an economy with incomplete markets where bankruptcy is regulated by law. The household, facing idiosyncratic shocks to earnings, can borrow or save in a competitive credit market. Risk-neutral banks provide a risk-free return on deposits, but issue loans at interest rates that depend, in equilibrium, on observable components of the agents. Given uncertainty about future earnings, households cannot commit to repaying debt. Borrowing constraints are derived endogenously from the equilibrium condition of the banking sector.

\footnotetext{
${ }^{1}$ The new Bankruptcy Bill approved in April 2005 (S. 256) directs higher-income debtors into repayment plans. Before this reform, there was no such a means test and anybody could file for bankruptcy under Chapter 7 .

${ }^{2}$ Home equity is defined as the market value of the occupied house net of the remaining mortgage payments. Bankruptcy protection affects only house equity. Debts which are collateralized - mortgages, home equity loans and automobile loans - cannot be discharged unless debtors give up the collateral.
} 
The fact that households can borrow at the risk of default and that a minimum consumption is always guaranteed by the exemption level can explain why households are observed to accumulate debt and durable goods at the same time. In the model, the optimal choice of durable and non-durable consumption depends not only on lifetime resources (as would be the case in a standard certainty-equivalence life cycle model), but also on the expected growth of income and on the borrowing constraints faced by the individual at different ages.

Bankruptcy regulation affects the household's credit conditions and incentives to accumulate durable goods in the following way. Given any level of debt, durables in excess of the exempted value serve as informal collateral that is used to lower the cost of borrowing, since it increases the expected returns to the banks. Instead, durable assets below the level of exemption provide insurance against future bad shocks to earnings as they can be saved in bankruptcy. Through these effects, a higher exemption level should increase the incentive to hold durables. On the other hand, the higher are the borrowing constraints and the higher is the probability of default induced by a high exemption, the more households will save in financial assets rather than durable wealth, for precautionary motives. The overall impact of bankruptcy protection on the accumulation of durables depends on which of these two effects prevails.

The empirical work combines information on exemption levels with longitudinal data on married couples from Panel Study of Income Dynamics (PSID) on bankruptcies and on the life cycle pattern of accumulation of durable and nondurable wealth. The data reveal some difference in the accumulation of durable and non-durable wealth of households who reside in low vs. high exemption states. Although net durable and non-durable wealth increase throughout the life-cycle in both (at least up to age 60), they are greater in high exemption states, after conditioning on age and other household characteristics. Bankruptcies, as reported in the PSID, are relatively rare; only $2.11 \%$ of the married couples used in the analysis had ever filed for bankruptcy.

Estimation is by maximum likelihood and involves iterating between the likelihood function and the solution of the optimization problem. A novel feature of the estimation procedure is that it allows for biased reporting in bankruptcy filings, which have been noted to be severely underreported in the PSID.

The paper makes the following contributions. First, there have been few attempts to estimate the preference parameters of a life cycle model of consumer behavior that incorporates endogenous borrowing constraints and savings in both durable and financial assets. Gourinchas and Parker (2002), for instance, structurally estimate a model of optimal life cycle consumption expenditures. In their model, individuals never choose to borrow because there is a strictly positive probability that income will be close to zero and Inada conditions hold. Under the same assumptions, this is not true when it is possible both to default and to hold savings in durable wealth. The fitted model matches the durable and non-durable net wealth life cycle profiles, and default behavior, observed in the data. I find reasonable estimates of the preference parameters. The average household has a discount rate of $7.3 \%$ and a coefficient of relative risk aversion of about 1.65 . 
Second, the estimated model provides an evaluation of the impact of bankruptcy protection on the accumulation of durable goods without using data on interest rates which are difficult to observe. In this context, a reduced form analysis that failed to account for the endogeneity of the borrowing interest rate would be misspecified, and would lead to biased estimates of the effect of the exemption level. ${ }^{3}$ Structural estimation allows me to derive both the equilibrium interest rate function and the (also unobserved) credit restrictions faced by individuals in a coherent theoretical framework. I find a strong impact of bankruptcy regulation on credit supply: the estimated default risk premium charged on borrowing interest rates in equilibrium is on average about $12 \%$.

Since the solution of the model consists in explicit decision rules, I can quantify the effect on decisions of altering the parameters that describe the bankruptcy regulation. In particular, the estimated model allows to separately compute the effect of bankruptcy as insurance and the effect of bankruptcy through the changed credit market conditions. These two effects are symmetric and increasing with the level of exemption, and they almost cancel each other. On one hand, the tighter credit constraints (higher borrowing interest rates and/or lower credit limits) induced by a high exemption level are found to reduce the accumulation of durables and increase precautionary saving in nondurable wealth, especially in the first half of the life cycle before retirement. On the other hand, the insurance provided by a high exemption gives agents the incentive to borrow and buy more durables especially at high levels of exemption, and it decreases precautionary saving. Overall, net durable wealth is decreasing in the value of the exemption, even if in a non-linear fashion. The results from a reduced form analysis are found to be driven by unobserved heterogeneity among states, and therefore misleading.

Third, structural estimation permits welfare analysis, allowing the computation of the expected lifetime utility under different bankruptcy regulations. Simple counterfactual experiments show that the default rate would be minimized if the possibility of bankruptcy were to be eliminated. However, the optimal level of exemption would be low (about $\$ 5,000$ ), even if with a relatively small welfare gain.

There exists a small, but growing, literature that uses an equilibrium approach to characterize the quantitative features of an economy in which agents have the option to default. Athreya $(2002,2005)$ evaluates the welfare consequences of new proposals from the National Bankruptcy Review Commission and the Bankruptcy Reform Act of 1999. Li and Sarte (2005) explore the effects of the proposed Bankruptcy Reform H.R. 333 (2002), explicitly modeling the choice between Chapter 7 and Chapter 13 bankruptcy filing in a general equilibrium model. In all these models, however, all agents borrow at the same interest rate, so banks can increase their profits by reducing the credit limits. Chatterjee, Corbae, Nakajima and Rios-Rull (2002) prove the existence of a competitive equilibrium for an incomplete markets, infinitely lived agents econ-

\footnotetext{
${ }^{3}$ Given the opposing effects of the exemption level on the demand of durables described above, it is not possible to determine the direction of the bias a-priori.
} 
omy with unsecured consumer credit and the possibility of default. Their main goal is to match the main quantitative facts about bankruptcy and unsecured credit in the U.S. (the percentage of defaulters, the fraction of borrowers in the market, the volume of debt). Livshits, MacGee and Tertilt (2004) focus their attention on the comparison between the "Fresh Start" bankruptcy and a Wage Garnishment rule. They are interested above all on the effect these different institutions have on labor supply. This paper differs from this literature in a number of important dimensions. I address a different question and explicitly model the effect of bankruptcy protection on durable wealth. Moreover, I use micro data to estimate the parameters of the model. ${ }^{4}$

Several empirical papers analyze individuals' incentives to file for bankruptcy. Other studies assess the impact of bankruptcy law on the default rate and credit conditions. Gropp, Scholz and White (1997) estimate the effects of different exemption levels on credit supply and demand. Their main finding is that the higher a state's exemption level, the more likely it is that lenders will turn down credit applicants, especially those in the bottom quartile of the wealth distribution. ${ }^{5}$ The effects of the exemption levels on the credit market are also addressed in Berkowitz and Hynes (1999) and Lin and White (2000), who study the relationship between mortgage interest rates and bankruptcy law, but get opposite results. ${ }^{6}$ It is worth noting here that any analysis of the impact of bankruptcy regulation on the credit market necessarily finds an obstacle in the unobservability of the interest rates and credit limits that each individual faces.

To the best of my knowledge, there exists just one attempt to evaluate the effects of bankruptcy exemptions on the accumulation of wealth (Repetto (1998)). From a reduced form analysis using PSID data, Repetto's main finding is that bankruptcy protection discourages the accumulation of positive financial wealth, while raises the amount of home equity individuals are willing to hold. Although Repetto does include interest rates into the analysis, these are state specific rates on secured loans, while the correct variable to use would be the individual interest rate on unsecured debt, which is unobserved. The results obtained from the structural estimation of a dynamic behavioral model lead to the conclusion that a reduced form analysis could be misleading.

The paper is organized as follows. The next section describes bankruptcy law in the U.S.. The theoretical model is presented in section 3, while section 4 contains an illustration of the micro data used in estimation. Section 5 de-

\footnotetext{
${ }^{4}$ At a theoretical level, it is worth mentioning the papers by Dubey, Geanakoplos and Shubik (1994, revised 2000) and Zame (1993). They show how the default option can promote efficiency in an incomplete markets environment, since it replaces the existing contracts with more "desired" or appropriate contracts.

${ }^{5}$ Their results are based on reduced form regressions using the Survey of Consumer Finances dataset of 1983 .

${ }^{6}$ Berkowitz and Hynes (1999) find that large exemptions drive down the interest rates, since there is more secured versus unsecured debt (meaning there is a greater supply of mortgages). Lin and White (2000) take the opposite view: a higher exemption level does not increase the supply of mortgages, but actually increases by $2 \%$ the probability of being turned down for a mortgage (they use Home Mortgage Disclosure Act data for 1992 through 1997).
} 
scribes the estimation methodology and section 6 presents the results. Section 7 contains possible extensions and concluding remarks. Some technical details and all tables and figures are relegated to the Appendix.

\section{Personal Bankruptcy in the U.S.}

Personal Bankruptcy law is intended to help people who cannot pay their debts. Individuals that file for bankrutpcy in the U.S. can choose to do so either under Chapter 7, "Straight Bankruptcy", or under Chapter 13, "Wage Earners Plan".

Under Chapter 7, the individual is required to give up all his non-exempted assets to a trustee for the benefit of his creditors, in exchange for which he will be discharged from all his unsecured debt. ${ }^{7}$ The bankrupt person does not have to sacrifice any of his future nor current (if not paid yet) income to debt repayment, which is why this type of bankruptcy is also called "Fresh Start".

Under Chapter 13, the debtor presents a plan in which he surrenders all of his disposable income to creditors over several years (typically three to five). ${ }^{8}$ In the case of a Chapter 13 filing, the creditors receive an amount that is at least as much as they would have received in a Chapter 7 filing. ${ }^{9}$

Around $70 \%$ of all personal bankruptcy filings occur under Chapter $7 .{ }^{10}$ Given the close relationship between Chapter 7 and Chapter 13 bankruptcy filings, I ignore the distinction between them and model just Chapter 7 bankruptcy, following Gropp, Scholz and White (1997) and many others in the literature.

There exists a large empirical research that focuses on the factors that lead to personal bankruptcy. Not surprisingly, the main reasons seem to be an unexpected loss of income, due to unemployment, large medical bills or divorce, together with poor debt management, i.e. a high debt to income ratio (Sullivan, Warren and Westbrook $(1989,2000))$. However, some studies also underline the role of a decrease in the so called "stigma" effect attached to bankruptcy in increasing the propensity to default. According to Fay, Hurst and White (2002), households' bankruptcy decisions are influenced by the average bankruptcy filing rate in the localities where they live, which is a proxy for stigma. Similar conclusions in favor of a "stigma" explanation of the increased bankruptcy rate are in Gross and Souleles (1999), who use a very exclusive dataset, composed of several hundred thousand individual credit card accounts, from different issuers.

\footnotetext{
${ }^{7}$ Some debt survives the bankruptcy, such as alimony and child support, taxes and educational loans. Secured debt must also be paid in full, or the debtor will lose the collateral that secured the loan (Sullivan, Warren and Westbrook (2000)).

${ }^{8}$ Disposable income is defined as all the income in excess of necessary living expenses (determined by the court - Hynes (1997)).

${ }^{9}$ Most (around 65\%) Chapter 13 cases fail before all the promised payments have been made. When that happens, either the case is dismissed (and debtors will have to file again or to struggle on without bankruptcy relief) or the case may be converted into a Chapter 7 liquidation (Sullivan, Warren and Westbrook (2000)).

${ }^{10}$ See Kowalewski (2000).
} 
Personal bankruptcy law became more favorable to debtors with the Bankruptcy Reform Act of 1978 (BRA78). Before 1978, the exemptions were specified by the states and were in general very low. ${ }^{11}$ The BRA78 specified a uniform (Federal) bankruptcy exemption of $\$ 7,500$ for equity in "homesteads" (owneroccupied principal residences) and $\$ 4,000$ for non-homestead property, with the exemption values doubled when married couples filed for bankruptcy. However, the act permitted states to opt out of the Federal exemption by adopting their own bankruptcy exemptions. By 1983 all states had done so, although 12 states allowed debtors to choose between the state and the Federal bankruptcy exemptions. The result is quite a heterogenous set of exemption levels, ranging from a few hundred dollars to an unlimited amount for the homestead exemption (Gropp, Scholz and White (1997)). ${ }^{12}$ With the Bankruptcy Reform Act of 1994 the Congress doubled the Federal Bankruptcy exemption, which had not been adjusted for inflation since 1978.

A bankruptcy reform has been pushed by the credit card industry and very much debated in Congress for several years. The very recent Bankruptcy Bill S. 256 (April 2005) is meant to make it more difficult for debtors to file for bankruptcy under Chapter 7. In particular, the bill establishes a means test to determine whether a debtor earns more than the median income of the debtor's state and has the funds to repay at least a portion of the debts. If the debtor has enough income (after subtracting living and other expenses) to repay at least $\$ 6,000$ over five years, the test requires filing for protection under Chapter 13 and developing a plan to repay creditors. The bill also introduces a cup of $\$ 125,000$ to the exemption level allowed by the states.

Exemptions are of several kinds. The most significant exemption (at least for home owner debtors) is certainly the homestead exemption, which entitles the debtor to exempt his home equity up to a certain amount. ${ }^{13}$ States can give an additional detailed list of other kinds of exemptions, including clothing, jewelry, home furnishings, sports equipment, vehicles, food and books. The list of personal property exemptions can be very specific, and does not always contain a dollar value, but instead lists quantities, or limitations based on "necessity", so that the exemption is quite difficult to quantify. There is also a "wild card" exemption, which allows the debtor to choose the object of the exemption up to a certain dollar amount (usually not very high). On average, about $80 \%$ of exempted assets are durable goods (home equity and cars).

Moreover, often exemptions depend on the characteristics of the debtors: some states allow married couples who file for bankruptcy to each claim a homestead exemption (so that the effective exemption level is doubled). Other states

\footnotetext{
${ }^{11}$ The first exemption in the U.S. was created in Texas in 1839 (Hynes (1997)).

${ }^{12} \mathrm{I}$ am not aware of studies that analyze the underlying differences that brought to such disparate choices of exemptions. Figures 1 and 2 show the scatter plots of exemptions and average real Gross State Products (GSP) per capita for 1978-1983 (the years in which the state bankruptcy laws were passed). Even eliminating the three outsiders and the unlimited exemption states, the correlation between exemptions and per capita GSP is equal to 0.27.

${ }^{13}$ Some states have an "unlimited" homestead exemption. In reality, this is not actually "unlimited", since it usually contains a limit on the lot size (eg. in Arkansas a debtor can claim an unlimited exemption only if his homestead is under $1 / 4$ of an acre).
} 
offer increased exemptions to senior citizens. ${ }^{14}$

A list of states and relative exemptions in two sample years, 1984 and 1992, is given in Table 1 in the Appendix. ${ }^{15}$ Given the objective difficulty of quantifying the exact value of the overall exemption level, to calculate it I use the sum of homestead exemption, motor vehicle and wild card exemptions, which are readily available and comparable for each state. ${ }^{16}$ For the states that give the possibility of opting for the Federal law, I impute the highest of the two exemption levels. I double the exemption in states where it is permitted for married couples filing jointly to do so, since my micro data sample consists of married heads of households (see below for a description of the data used in estimation). Thus calculated, exemptions range from an average value of $\$ 2,700$ over the period 1984-1992 (in Delaware) to a maximum average value of $\$ 87,000$ (in Nevada), to unlimited in eight states.

Exemption levels did not vary much in nominal terms over the years 1984 to 1994 . They actually decreased in real terms because they were not often adjusted for inflation. The average national exemption level was $\$ 25,400$ in 1984 , and $\$ 24,000$ in 1992. Only three states experienced sizeable changes in their exemption levels between 1984 and 1994. Exemptions in Idaho increased from $\$ 6,400$ to $\$ 75,200$ (in real terms), Iowa changed from a mere $\$ 4,500$ to an unlimited exemption regime, while the opposite happened in South Dakota, where exemptions went from unlimited to $\$ 25,200$. If a household in the PSID dataset is a resident of any of these three states, it is included in the sample used for estimation only for the period in which exemptions stay stable (e.g. if a household is married over the whole period 1984 to 1994, but resides in Idaho, it enters the sample only for the years 1984 to 1989, with an exemption of $\$ 6,400$, and is excluded from the sample in 1994). I therefore exploit in this work the cross sectional differences in exemptions, disregarding the time series dimension. I do this on the ground of two considerations. First, as noted, there is no much variation of exemptions over time (at least for the period of observation). Second, my dynamic model implicitly assumes the economy is in a steady state (in which bankruptcy law is exogenously given). Any change in exemption is therefore thought of as an unforeseen event in the life of an individual, and the re-optimization due to such a change is not analyzed.

For estimation, I will need to simulate histories of households' choices at each level of education, age at marriage and exemption level. For computational reasons, I simplify and divide the U.S. states into four different groups of exemptions, according to their distribution. The first group comprises all states with an average exemption below $\$ 15,000$ over the period $1984-1994$, and is assigned an exemption level of $\$ 9,800$, which is the average value over the period

\footnotetext{
${ }^{14}$ There are also various anti-abuse provisions that limit the possibility that the debtor borrows from unsecured creditors to accumulate more exempt assets. If a court finds behavior of this kind, it can deny the bankruptcy petition on the grounds that it was fraudulent.

${ }^{15}$ Exemption levels are as reported by Elias, Renauer and Leonard (several years). All values are in real 1984 dollars.

${ }^{16}$ In the effort to have as comprehensive a definition of exemption level as possible, the wild card component is included on the assumption that it is used to exempt additional durable assets.
} 
in that group of states. The second group includes all states with an exemption between $\$ 15,000$ and $\$ 40,000$, whose average exemption is $\$ 22,900$. The third group is that of the states with exemptions between $\$ 40,000$ and $\$ 87,000$, with average value $\$ 64,500$, while the fourth group is characterized by an unlimited exemption regime. For exemption levels and groups of states, refer to Table 1 in the Appendix.

\section{The Model}

Since the motives for saving or borrowing can vary widely over the life cycle (see Gourinchas and Parker (2002)), the equilibrium effects of bankruptcy regulations might strongly depend on an individual's age. Therefore, the framework used here is a discrete-time, life cycle model of household consumption behavior.

To keep the model as parsimonious as possible, there is just one good produced in the economy, whose price is normalized to one. All transactions are in terms of that good, which can be used as durable or non-durable consumption, or can be saved. A durable good differs from a non-durable good only in two dimensions. First, the durable good not only provides utility in the current period but also constitutes a source of liquidity for the future. Second, the durable good can be used as an informal form of collateral for borrowing.

Each period the agent faces idiosyncratic uncertainty in the labor endowment and in a shock to preferences. Since I am interested in analyzing the insurance role of bankruptcy, I assume that markets are incomplete, in the sense that it is not possible to make the repayment of the loans contingent on the future realization of the shocks. Moreover, I focus the attention on the effects of individual characteristics (especially durable wealth) on credit conditions. Therefore, I model the credit market as perfectly competitive, with risk neutral banks that provide a risk-free return on deposits and supply loans at individual-specific interest rates. Naturally, a key feature of the model is the lack of commitment of the agent in the contract with the bank. Bankruptcy regulation is taken as exogenous.

In the following, first the individual problem is formalized. The equilibrium is then defined, followed by a brief description of the computational solution method, whose details are relegated to the Appendix.

\subsection{Individual Problem}

The basic unit of analysis is the head of the household, characterized by his age at marriage $a$, his education level $s$, and the exemption level $e$ of his state of residence. The decision process starts at age $a+1$ and ends at $T$, before retirement. ${ }^{17}$ For computational tractability, each period is assumed to be fiveyear long. ${ }^{18}$ Choices of education, residence and marriage are not modeled, and

\footnotetext{
${ }^{17}$ In estimation, each state is discretized. See the Appendix for details.

${ }^{18}$ As it will be clearer below, this assumption is also consistent with bankruptcy law.
} 
these variables are not allowed to change over the life cycle. ${ }^{19}$ The analysis is restricted to married households in order to be able to estimate the model using a sample of individuals with similar preferences towards durable goods. A change in marital status (i.e. a divorce) would indeed alter a household's preferences with respect to durables. In the model, such a change, or moving to another state, are implicitly assumed unforeseen and unexpected events in the life of an individual.

Despite the estimation being applied to a homogenous sample, it is unlikely that preference parameters, expected endowments and initial wealth at marriage are the same for everyone. One standard approach to deal with this unobserved heterogeneity, and the one I adopt, is to assume there exists a finite mixture of types, say $K$ types, each comprising a fixed proportion $\pi_{k}(k=1, . ., K)$ of the population. ${ }^{20}$ At marriage, the agent holds debt $d_{a+1}$ (debt if positive, savings if negative) and durable goods $h_{a}$, which are assumed to depend on the individual's type, education, and age at marriage plus a random component, according to the following linear functions:

$$
\begin{gathered}
h_{a}=\psi_{0}+\psi_{a} a+\psi_{s} s+\sum_{k=2}^{K} \psi_{k} I\{k\}+\varepsilon_{h}, \\
d_{a+1}=\beta_{0}+\beta_{a} a+\beta_{s} s+\sum_{k=2}^{K} \beta_{k} I\{k\}+\varepsilon_{d},
\end{gathered}
$$

where $I\{k\}$ is an indicator equal to one if the individual belongs to type $k$, while $\varepsilon_{h}$ and $\varepsilon_{d}$ are normally distributed, with mean 0 , variances $\sigma_{h}^{2}$ and $\sigma_{d}^{2}$ respectively, and covariance $\sigma_{h d}{ }^{21}$

At each age $t$, the type- $k$ household receives a labor endowment $y_{t}^{k}$ according to the following function:

$$
y_{t}^{k}=\exp \left(\alpha_{t}+\alpha_{s} s+\sum_{k=2}^{K} \alpha_{k}^{T} I\{k\}\right) \epsilon_{t}^{y},
$$

\footnotetext{
${ }^{19}$ The implicit assumption is that bankruptcy regulation does not affect these choices. In particular, it seems plausible that the state of residence is selected on the basis of family or work location, even if there could exist a few cases of auto-selection into high exemption states (see Elul and Subramanian (2001)). These cases are limited by anti-abuse provisions that allow individuals to file for bankruptcy only in the state where they have been resident for at least two years. In the model, this auto-selection is treated as unobserved and corresponds to the existence of different types distributions across states, as described in the text below.

${ }^{20}$ Unobserved heterogeneity can arise in several places - in different preference parameters or shocks, or in the endowment process. I limit the heterogeneity to the risk aversion coefficient, the utility cost of default, the expected earnings, and initial durable and non-durable wealth, for tractability (although somewhat arbitrary). See below for the specification of the types probability distribution.

${ }^{21}$ In the text I will often refer to $d_{t}$ as "non-durable wealth" to distinguish it from "durable" wealth $h_{t}$. Although durable and non-durable wealth are continuous state variables, in computation I use a finite support with well-defined lower and upper bounds (see Appendix for details).
} 
where $\alpha_{t}$ represents the agent's age-specific labor productivity, while $\alpha_{s}$ is the marginal effect of one extra year of schooling on $\log \left(y_{t}^{k}\right)$. Expected endowments are assumed also to be dependent on the household's type ( $I\{k\}$ is the indicator function that is equal to 1 if the type is $k$ ). The shock to earnings $\epsilon_{t}^{y}$ is realized at $t$ and lognormally distributed, $\epsilon_{t}^{y} \sim L N\left(0, \sigma_{y}^{2}\right)$, at any $t$. Shocks are serially independent over time, assumption that seems quite plausible given that the decision period is assumed to be five-year long. Therefore, persistence in the earnings process is assumed to be purely deterministic, and is given by education and type.

A point is worth noting. Given the specified earning process, the endowment can never be zero but can be very close to zero with a strictly positive probability. ${ }^{22}$ With a zero lower bound for the income process and a utility function satisfying the Inada condition $\lim _{c \rightarrow 0} u^{\prime}(c)=\infty$, a finite life-cycle model of only non-durable consumption behavior without the possibility of default (nor dying in debt) would imply a self-imposed liquidity constraint equal to zero, or, in other terms, individuals would never choose to borrow (see Ayagari (1994), or Gourinchas and Parker (2002)). Allowing for durable goods accumulation and default with bankruptcy protection, this model accounts for the fact that individuals hold durable wealth and debt at the same time.

The individual derives utility from consumption of the non-durable good, $c \geq 0$, and from the services of the net stock of durables owned, $h \geq 0$. The per period utility of the agent is continuous, strictly increasing and strictly concave in both arguments, and obeys Inada conditions for non-durable consumption.

Following Fernandez-Villaverde and Krueger (2004), the utility takes the following CRRA functional form applied to a Cobb-Douglas aggregator function of the consumption services from durables and non-durables :

$$
u_{k}\left(c_{t}, h_{t}, \varepsilon_{t}^{c}\right)=\frac{\left[\varepsilon_{t}^{u}\left(c_{t}\right)^{\theta}\left(h_{t}+\xi\right)^{(1-\theta)}\right]^{\left(1-\sigma_{k}\right)}}{1-\sigma_{k}},
$$

where the coefficient of relative risk aversion for type $k$ is $\sigma_{k}>0$, the consumption share is $\theta \in(0,1)$ and $\varepsilon_{t}^{u}$ is a shock to preferences, lognormally distributed, $\varepsilon_{t}^{u} \sim L N\left(0, \sigma_{u}^{2}\right)$, and uncorrelated with the shock to earnings. This random component to preferences can be thought of as unobserved and changing household characteristics over the life cycle, which affect the intertemporal rate of substitution of (durable and non-durable) consumption. The shock to preferences has two roles. First, it constitutes another type of uncertainty, the one over future preferences, which the individual must take into consideration (along with the uncertainty over future income) when taking decisions today. Second, this unobserved shock (together with measurement error) helps to explain different observed behavior in the data conditional on the same observed initial state vector (age, durable wealth, earnings, etc.). As in Fernandez-Villaverde

\footnotetext{
${ }^{22}$ Very few married households in the PSID sub-sample are observed having zero labor earnings over five year periods. Those households have been excluded from the sample used in estimation.
} 
and Krueger (2004), $\xi$ is a small number that is irrelevant for the quantitative solution but that makes the utility finite at $h_{t}=0$, to allow for durable goods not to be a necessity (apart from accounting for the observation that a few households hold zero durable wealth).

It must be clarified here that in order to be consistent with bankruptcy law the variable $h_{t}$ represents the value of durable goods net of secured debt. Indeed, the exemption applies only to the latter definition of durable wealth. ${ }^{23}$ I will refer to the variable $h_{t}$ as durable wealth for simplicity, but its definition should be kept in mind. The functional form for utility implies that the household benefits only from the services of that part of the durable good that it really owns. This is of course a simplification, but it is necessary to keep the model tractable: distinguishing between the stock of durables and unsecured debt would mean to include one additional choice variable (unsecured debt), which would make computation extremely burdensome. ${ }^{24}$

At each $t$, after having observed the realization of shocks to earnings and preferences, the household chooses the quantity $c_{t}$ of non-durable goods to consume and the stock $h_{t}$ of durables. The latter depreciate at a rate $\delta \in \Re$. Notice that the depreciation rate is allowed to be negative: $(1-\delta)$ can be interpreted as the value of a durable good in terms of a non-durable good, which is assumed to be constant and known. ${ }^{25}$

Moreover, the agent can decide whether to save or borrow at a bank an amount $b_{t} \in \Re$, where $b_{t}$ is positive if he borrows, and negative if he lends. Saving $b_{t}<0$ gives the right to receive $d_{t+1}=R b_{t}$ the following period, where $R>1$ is the risk-free gross interest rate. Borrowing $b_{t}>0$ entails an individualspecific debt $d_{t+1}$ to be paid in $t+1$, determined in equilibrium as explained below. The contract with the bank is therefore characterized by $\left(b_{t}, d_{t+1}\right)$ at any period $t$ (the banking sector is described in detail in the following section).

The household, however, does not commit to repay its debt. At the beginning of each period $t$, the agent chooses whether to repay the debt $d_{t}$ (if any) or not. In the latter case, he decides to default and file for bankruptcy. Under Chapter 7 filing, the individual can keep all his current (if not paid yet) and future wages: the punishment falls only on assets. Therefore, the agent is assumed to be able to keep all his wages, but the bank will repossess all the defaulter's durables $\left((1-\delta) h_{t}\right)$ in excess of the exempted level, $e$. A further punishment to the agent that defaults is his inability to borrow in the period of default. In that period, he can only save and buy durables. His life goes back to normal in the period after he defaulted (he can borrow again, and default again). ${ }^{26}$

\footnotetext{
${ }^{23}$ More precisely, in the data the variable $h_{t}$ is the sum of home equity and cars (net of secured debt). As described above, the exemption is the sum of homestead exemption (or exempted home equity), wild card and vehicles.

${ }^{24}$ Furthermore, there is no rental market for durable goods in the model. Even if the existence of a rental market would be of some importance, the role of durables as insurance and informal collateral limits the theoretical role of such a market. I can justify the absence of a rental market by assuming that there exist very high agency costs.

${ }^{25}$ It would not be possible in the model to separately identify the price of the durable good (in terms of non-durable consumption) and the depreciation rate.

${ }^{26}$ In the U.S., you cannot file for bankruptcy for 6 years after a prior bankruptcy. By
} 
The bankrupt person is also assumed to incur a "stigma" or "psyche" cost of defaulting, i.e. a loss in utility $\Omega_{k}$, dependent on his type. The existence and importance of a "stigma" in bankruptcy is well documented in the empirical literature (see Gross and Souleles (1999)).

The budget constraint of an individual that does not default is

$$
c_{t}+h_{t}=y_{t}^{k}+(1-\delta) h_{t-1}-d_{t}+b_{t}
$$

with borrowing constraint

$$
\begin{gathered}
b_{t}=\frac{d_{t+1}}{R} \quad \text { if } d_{t+1} \leq 0 \\
b_{t} \leq \bar{b}\left(h_{t}, d_{t+1}\right) \quad \text { if } \quad d_{t+1}>0
\end{gathered}
$$

where $\bar{b}\left(h_{t}, d_{t+1}\right)$ is the maximum borrowing allowed by the bank to the individual that chooses to hold durables $h_{t}$ and have a debt $d_{t+1}$ in $t+1$. This borrowing constraint is derived endogenously from the equilibrium condition of the banking sector (see next section), and will hold with equality.

For a person that defaults the budget constraint is

$$
\begin{gathered}
c_{t}+h_{t}=\min \left\{(1-\delta) h_{t-1}, e\right\}+y_{t}^{k}+\frac{d_{t+1}}{R} \\
\text { with } d_{t+1} \leq 0
\end{gathered}
$$

as he is able to keep the exempted durables (or all the durables, if the value of these is less than the exemption level), and can only save.

Each period, the individual first observes the realization of the shocks to earnings and preferences and decides whether to default (if he is a net debtor). After that, he buys durables, borrows or saves and consumes.

In the last period of life the individual chooses whether to default (if he is a debtor), how much to consume and how many durables and savings (negative $d_{T+1}$ ) to leave for retirement (he cannot borrow). The additional value of carrying over wealth $h_{T}$ and $d_{T+1}$ into the retirement period is represented by the simple function

$$
g\left(h_{T}, d_{T+1}\right)=\alpha_{h}\left[h_{T}-\alpha_{d} d_{T+1}\right]
$$

construction, in the model an individual will be able to file for bankruptcy no sooner than two periods after having first defaulted, which is perfectly consistent with the law.

The assumption that the household can borrow again starting from the period after default is not a standard one in the literature. Chatterjee and al. (2002), for example, assume the individual that defaults cannot get any new loan for at least one period (one year, in their model) after default. In this model, the punishment actually lasts five years, so that it is reasonable to assume that the individual has full access to the credit market after that. Moreover, borrowing is entirely determined endogenously in the model (i.e. the individual who didn't pay his debts is very likely to start the next period with very low durable wealth, thus possibly facing non-favorable credit conditions). 
i.e. it is assumed to be linear in both durable and non-durable wealth.

Let $\beta \in(0,1)$ be the individual discount factor. Then the overall expected utility of the agent at marriage is given by:

$U\left(\left\{c_{t}, h_{t}, \varepsilon_{t}^{u}\right\}_{t=a+1}^{T} ; k\right)=E_{a+1}\left[\sum_{t=a+1}^{T} \beta^{t-a-1} u_{k}\left(c_{t}, h_{t}, \varepsilon_{t}^{u}\right)+\beta^{T-a-1} g\left(h_{T}, d_{T+1}\right)\right]$

where $E_{a+1}$ denotes the expectation at the period after marriage, taken over the stream of future random shocks.

Lastly, the probability of belonging to type $k$ is assumed to depend on one's education and state of residence according to the following logit function:

$$
\pi_{k}=\frac{\exp \left(\gamma_{0 k}+\gamma_{s k} \cdot s+\sum_{e x=2}^{E X} \gamma_{e x, k} I\{e=e x\}\right)}{1+\sum_{l=1}^{K} \exp \left(\gamma_{0 l}+\gamma_{s l} \cdot s+\sum_{e x=2}^{E X} \gamma_{e x, l} I\{e=e x\}\right)}
$$

for $k=1, \ldots, K-1$, and

$$
\sum_{k=1}^{K} \pi_{k}=1
$$

where $I\{e=e x\}$ is an indicator function equal to one if the exemption level is equal to $e x$, zero otherwise, and $E X$ is the total number of existing exemptions. ${ }^{27}$ In particular, the fact that the distribution of types differs by exemption wants to account both for the possibility that self-selection of individuals into states with different levels of bankruptcy protection is not observed and for the existence of possibly many other unobserved differences among states apart from their bankruptcy regulations.

\subsection{Credit sector}

The competitive banks are assumed to have access to an international credit market in which they can borrow or lend as much as needed at a gross risk-free interest rate $R$, constant and exogenous.

As mentioned above, each agent's contract with a bank specifies the loan $b_{t}>0$ from that bank (or the deposit $b_{t}<0$ into that bank), and the repayment $d_{t+1}$ (or withdrawal of savings, if negative). ${ }^{28}$

Banks maximize their expected profits every period. They observe age, state of residence, education and age at marriage of individuals, and their current

\footnotetext{
${ }^{27}$ In computation, as noted, $E X$ is set to four. The number of types is two.

${ }^{28} \mathrm{I}$ restrict the attention to just one contract, although this could represent the sum of many loans arrangements, $\left(b_{t}^{n}, d_{t+1}^{n}\right)_{n=1}^{N}$.
} 
stock of durables, $h_{t}$. However, they do not know the individual's type. Perfect competition implies that in equilibrium the expected profits derived from each individual-specific contract are zero (where expectations are taken over types and future shocks). Thus in equilibrium banks perfectly discriminate among borrowers (up to the unobserved type) through the interest rate.

As mentioned above, the assumption that $d_{t+1}$ is not made contingent on the realization of the shock to earnings is embedded in the formulation of the contract $\left(b_{t}, d_{t+1}\right)$. In other words, markets are incomplete, since it is not possible for the agent to perfectly insure himself against future shocks to earnings and preferences. The kind of standard debt contracts considered here is quite consistent with the contracts observed in practice, and can be justified by the existence of important transaction and agency costs. Moreover, as mentioned above, the interest is here in analyzing the insurance effect of bankruptcy protection, which wouldn't have any role if markets were complete. Rather, in a world of non-contingent contracts the default option improves efficiency by allowing agents to lower the amount that they must repay to the bank by filing for bankruptcy. The latter point is made by Dubey, Geanakoplos and Shubik (1994 - revised).

The uncertainty of future earnings, together with the implicit assumption that the agent does not commit to the contract with the bank, are sufficient conditions to allow the possibility that the individual defaults. ${ }^{29}$ Banks, on the other hand, are supposed to commit to the contracts with the agent, so that saving is always riskless.

For each contract $\left(b_{t}, d_{t+1}\right)$, the actual repayment made to the bank will be equal to $d_{t+1}$ if there is no default, and to the value of non exempt durables, as long as positive and less than the debt $d_{t+1}$, in case of default. Clearly, the repayment made to the bank in $t+1$ does depend on the quantity of durables and debt chosen by the individual at age $t$, on the unobserved type, and on the shocks $\varepsilon_{t+1}^{y}$ and $\varepsilon_{t+1}^{u}$.

The zero expected profits condition determines the borrowing $\bar{b}_{t}$ allowed at each level of debt and durable wealth:

$\bar{b}_{t}\left(h_{t}, d_{t+1}\right)=\left\{\begin{array}{c}\frac{d_{t+1}}{R} \quad \text { if } d_{t+1} \leq \max \left\{(1-\delta) h_{t}-e, 0\right\} \\ \frac{1}{R}\left\{\left[1-\mu_{t}\left(h_{t}, d_{t+1}\right)\right] d_{t+1}+\mu_{t}\left(h_{t}, d_{t+1}\right) \max \left\{(1-\delta) h_{t}-e, 0\right\}\right\} \\ \text { otherwise }\end{array}\right.$

If the debt is smaller than the non exempted durable assets, then the bank will be able to recover the borrowed funds in full, so that the borrowing allowed will simply be the discounted value of $d_{t+1}$. I denote with $\mu_{t}\left(h_{t}, d_{t+1}\right)$ the

\footnotetext{
${ }^{29}$ The lack of commitment argument, with the uncertainty on future earnings, is just one possible source of a positive probability of default (Hart and Moore (1994), Kocherlakota (1996)). Asymmetric information and moral hazard could be some of the alternative assumptions to generate default in the economy (Green (1987), Thomas and Worrall (1989)).
} 
probability that a person with deterministic state $\left(h_{t}, d_{t+1}\right)$ defaults in $t+1$. Implicitly, $\mu_{t}\left(h_{t}, d_{t+1}\right)$ is a function of $(a, e, s)$ as well, as those are known to the bank. If the debt is higher than the non exempted assets, the bank will be fully repaid only with probability $\left[1-\mu_{t}\left(h_{t}, d_{t+1}\right)\right]$, while with probability $\mu_{t}\left(h_{t}, d_{t+1}\right)$ the bank will repossess the non exempted assets, $(1-\delta) h_{t}-e$, if positive. The borrowing allowed is the discounted value of the expected repayment. The default probability conditional on each state is calculated taking expectations over types and future shocks to preferences and endowments.

Notice that the individual specific (gross) interest rate on the loan is simply the ratio between $d_{t+1}$ and $\bar{b}_{t}\left(h_{t}, d_{t+1}\right)$, and therefore depends on the debt and on durable wealth held by the household, and on its probability of default.

\subsection{The problem in recursive formulation}

The problem of the agent can be written in recursive form.

The state variables at age $t$ are $\left(a, e, s, h_{t-1}, d_{t}, \varepsilon_{t}^{y}, \varepsilon_{t}^{u} ; k\right)$. Trivially, age is also a state.

Let $\left(a, e, s, h_{t-1}, d_{t}, \varepsilon_{t}^{y}, \varepsilon_{t}^{u} ; k\right)=\left(\underline{x}_{t}, \underline{\varepsilon}_{t} ; k\right)$, where $\underline{x}_{t}=\left(a, e, s, h_{t-1}, d_{t}\right)$ is the deterministic state, while $\varepsilon_{t}$ is the vector of the realizations of shocks at $t$.

The control variables at age $t$ are $\left(h_{t}, d_{t+1}, b_{t}, c_{t}, I_{t}^{d}\right)$, where $I_{t}^{d}=1$ if the agent defaults, 0 otherwise. The decisions $b_{t}$ and $c_{t}$ are uniquely determined by the constraints and $\left(h_{t}, d_{t+1}, I_{t}^{d}\right)$.

Given his education $s$, age at marriage $a$ and exemption level $e$, the type $k$ agent solves the following problem:

$\forall(a+1) \leq t<T$

$V_{t}\left(\underline{x}_{t}, \underline{\varepsilon}_{t} ; k\right)=\left\{\begin{array}{cc}\max _{I_{t}^{d} \in\{0,1\}}\left\{\left(1-I_{t}^{d}\right) V_{t}^{0}\left(\underline{x}_{t}, \underline{\varepsilon}_{t} ; k\right)+I_{t}^{d} V_{t}^{1}\left(\underline{x}_{t}, \underline{\varepsilon}_{t} ; k\right)\right\} & \text { if } d_{t}>0 \\ V_{t}^{0}\left(\underline{x}_{t}, \underline{\varepsilon}_{t} ; k\right) & \text { otherwise }\end{array}\right.$

The value of not defaulting is given by:

$$
\begin{gathered}
V_{t}^{0}\left(\underline{x}_{t}, \underline{\varepsilon}_{t} ; k\right)= \\
\max _{c_{t}, h_{t}, b_{t}, d_{t+1}}\left\{u_{k}\left(c_{t}, h_{t}, \varepsilon_{t}^{u}\right)+\beta E_{t}\left(V_{t+1}\left(\underline{x}_{t+1}, \underline{\varepsilon}_{t+1} ; k\right)\right)\right\} \\
\text { s.t. }\left\{\begin{array}{c}
c_{t}+h_{t}=y_{t}^{k}+(1-\delta) h_{t-1}-d_{t}+b_{t} \\
b_{t} \leq \overline{b_{t}}\left(h_{t}, d_{t+1}\right) \\
h_{t} \geq 0, c_{t} \geq 0, d_{t+1} \in R
\end{array}\right.
\end{gathered}
$$

where $\bar{b}_{t}\left(h_{t}, d_{t+1}\right)$ is derived from (1). As mentioned above, this constraint holds with equality in equilibrium. 
The value of defaulting is

$$
\begin{gathered}
V_{t}^{1}\left(\underline{x}_{t}, \underline{\varepsilon}_{t} ; k\right)= \\
\max _{c_{t}, h_{t}, d_{t+1}}\left\{u_{k}\left(c_{t}, h_{t}, \varepsilon_{t}^{u}\right)-\Omega_{k}+\beta E_{t}\left(V_{t+1}\left(\underline{x}_{t+1}, \underline{\varepsilon}_{t+1} ; k\right)\right)\right\} \\
\text { s.t. }\left\{\begin{array}{c}
c_{t}+h_{t}=\min \left\{(1-\delta) h_{t-1}, e\right\}+y_{t}^{k}+\frac{d_{t+1}}{R} \\
h_{t} \geq 0, c_{t} \geq 0, d_{t+1} \leq 0
\end{array}\right.
\end{gathered}
$$

At each period $t$, expectations are taken over the joint distribution of the stochastic shocks $\underline{\varepsilon}_{t+1}$.

In period $T$ the value $V_{T}\left(\underline{x}_{T}, \underline{\varepsilon}_{T} ; k\right)$ is the greatest of:

$$
\begin{gathered}
V_{T}^{0}\left(\underline{x}_{T}, \underline{\varepsilon}_{T} ; k\right)=\max _{c_{T}, h_{T}, d_{T+1}}\left\{u_{k}\left(c_{T}, h_{T}, \varepsilon_{T}^{u}\right)+\beta g\left(h_{T}-d_{T+1}\right)\right\} \\
\text { s.t. }\left\{\begin{array}{c}
c_{T}+h_{T}=(1-\delta) h_{T-1}+y_{T}^{k}-d_{T}+\frac{d_{T+1}}{R} \\
h_{T} \geq 0, c_{T} \geq 0, d_{T+1} \leq 0
\end{array}\right.
\end{gathered}
$$

and

$$
\begin{gathered}
V_{T}^{1}\left(\underline{x}_{T}, \underline{\varepsilon}_{T} ; k\right)=\max _{c_{T}, h_{T}, d_{T+1}}\left\{u_{k}\left(c_{T}, h_{T}, \varepsilon_{T}^{u}\right)-\Omega_{k}+\beta g\left(h_{T}-d_{T+1}\right)\right\} \\
\text { s.t. } \quad\left\{\begin{array}{c}
c_{T}+h_{T}=\min \left\{(1-\delta) h_{T-1}, e\right\}+y_{T}^{k}+\frac{d_{T+1}}{R} \\
h_{T} \geq 0, c_{T} \geq 0, d_{T+1} \leq 0
\end{array}\right.
\end{gathered}
$$

A solution to the dynamic optimization problem is given by optimal decision rules for durable goods $h_{t}\left(\underline{x}_{t}, \underline{\varepsilon}_{t} ; k\right) \in \Re_{+}$, borrowing/saving contracts $\left(b_{t}\left(\underline{x}_{t}, \underline{\varepsilon}_{t} ; k\right), d_{t+1}\left(\underline{x}_{t}, \underline{\varepsilon}_{t} ; k\right)\right) \in \Re^{2}$, consumption $c_{t}\left(\underline{x}_{t}, \underline{\varepsilon}_{t} ; k\right) \in \Re_{+}$and default $I_{t}^{d}\left(\underline{x}_{t}, \underline{\varepsilon}_{t} ; k\right) \in\{0,1\}$, for any state $\left(\underline{x}_{t}, \underline{\varepsilon}_{t} ; k\right) \in\{0, . ., 8\} \times\{1, . ., e x\} \times\{1, . ., 4\} \times$ $\Re_{+} \times \Re \times \Re_{+}^{2} \times\{1, . ., K\}$, for any period $t=a+1, \ldots T$.

\subsection{Equilibrium}

Given the risk-free gross interest rate $R$, a Recursive Competitive Equilibrium is a set of value functions $V_{t}\left(\underline{x}_{t}, \underline{\varepsilon}_{t} ; k\right)$, policy functions $h_{t}\left(\underline{x}_{t}, \underline{\varepsilon}_{t} ; k\right)$, $d_{t+1}\left(\underline{x}_{t}, \underline{\varepsilon}_{t} ; k\right), b_{t}\left(\underline{x}_{t}, \underline{\varepsilon}_{t} ; k\right), c_{t}\left(\underline{x}_{t}, \underline{\varepsilon}_{t} ; k\right)$ and $I_{t}^{d}\left(\underline{x}_{t}, \underline{\varepsilon}_{t} ; k\right)$, for $k=1, . ., K$, a probability of default function $\mu_{t}\left(\underline{x}_{t+1}\right)$ and a borrowing constraint function $\overline{b_{t}}\left(\underline{x}_{t+1}\right)$ such that: 
1) at each $t$, the policy functions solve the agent's optimization problem with corresponding value function $V_{t}$;

2) $\overline{b_{t}}\left(\underline{x}_{t+1}\right)$ is determined by the zero expected profits condition of the banks, at each $t$ and for each $\underline{x}_{t+1}$;

3 ) at each $t$, for each $\underline{x}_{t+1}$, the probability of default is given by

$$
\mu_{t}\left(\underline{x}_{t+1}\right)=\sum_{k=1}^{K} \pi_{k} E_{t}\left[I_{t+1}^{d}\left(\underline{x}_{t+1}, \underline{\varepsilon}_{t+1} ; k\right)\right] .
$$

where expectations are taken over future shocks $\underline{\varepsilon}_{t+1}$.

\subsection{The solution method}

The solution to the model is not analytic, and has to be numerically computed. Having to deal with two continuous deterministic states, two continuous random shocks and three choices (durables, debt and default), the problem is particularly burdensome. The main difficulty is in evaluating two dimensional integrals at each of the many state points, at each period.

Because the policies at each age (solutions of the dynamic problem) are functions of the continuous shocks, they are impossible to store in a computer. However, in order to be able to evaluate the value function and the optimal choice at any state and age, it is sufficient to know the expected values $E_{t} V_{t+1}\left(\underline{x}_{t+1}, \underline{\varepsilon}_{t+1} ; k\right)$ and $\overline{b_{t}}\left(\underline{x}_{t+1}\right)$ (as in (1) above, $\overline{b_{t}}\left(\underline{x}_{t+1}\right)$ also involves an expectation, since it depends on the probability of default). I therefore consider a solution of the model to consist of the set of

$$
E_{t-1}\left(V_{t}\left(\underline{x}_{t}, \underline{\varepsilon}_{t} ; k\right)\right) \equiv E M A X\left(\underline{x}_{t}, t ; k\right)
$$

and

$$
\bar{b}_{t-1}\left(\underline{x}_{t}\right) \equiv \sum_{k=1}^{K} \operatorname{EBOR}\left(\underline{x}_{t}, t-1 ; k\right)
$$

as functions of each state $\underline{x}_{t}$ and age $t, t=a+2, \ldots, T$, where $E B O R\left(\underline{x}_{t}, t-\right.$ $1 ; k)$ is the discounted value (at $R$ ) of the expected repayment by a type $k$ household that borrows at age $(t-1)$.

Both the EBOR and EMAX functions correspond to double integrals over the distribution of shocks $\underline{\varepsilon}_{t}=\left(\varepsilon_{t}^{y}, \varepsilon_{t}^{u}\right)$, and must be computed for each permanent state $(k, e, a, s)$.

I use Monte Carlo integration to evaluate the required integrals at all state points, as in Keane and Wolpin (1994). After having evaluated the EMAX and EBOR functions, life-cycle profiles of the decisions of consumption, stock of durables, borrowing/saving and default can be simulated. See the Appendix for a description of the algorithm used for computation. 


\section{Data}

The data are a sub-sample of the Panel Study of Income Dynamics (PSID), which is a longitudinal study started in 1968 with a sample of 5,000 families, with individuals followed -whether or not in the same family unit - every year until 1997, and every other year since then. This dataset contains all relevant information on durable and non-durable wealth, labor income, household's characteristics, and, most importantly, states of residence and bankruptcy filings. In particular, the PSID asked specific questions on one person's bankruptcy history only in one wave, in 1996.

Information on wealth is collected only at five waves: 1984, 1989, 1994, 1999 and 2001. However, I restrict attention to the period 1984 to 1994 since there has been an important reform in bankruptcy law in 1994, while there have not been salient changes before that (see Section 2).

In order to obtain a high quality sample with the required information, I drop a significant portion of the data. I follow all the heads of household, that are between the ages of 20 and 64, as long as they had no changes in marital status or in the state of residence for at least one full 5-year period of the three periods under consideration (between 1982 and 1986, between 1987 and 1991, and between 1992 and 1996, each period being centered at a year for which information on wealth is available). The final sample is composed of 4,790 individuals. For details on the sample selection, refer to Table 2 in the Appendix. Individual characteristics of the sample are presented in Table 3.

To match the time spans of the model, I aggregate the head's and wife's after-tax labor income over five years. ${ }^{30}$ The value of durable wealth consists of the sum of home equity (market value of the house net of mortgages) and the value of vehicles (net of secured debt) owned by the household. The value of nondurable net wealth is the sum of saving and checking accounts, mutual funds, retirement accounts, money market funds, stocks, bonds, farms or business, land and other real estate, less credit card and other unsecured debts, and matches the $b$ variable in the model.

One issue with the data is worth mentioning. In the PSID, those respondents that do not report an exact amount of a wealth component are asked to provide a brackets range for its value. For all these respondents an exact value is then imputed on the basis of the distribution of amounts from respondents who reported exact values and which fell within the range of the same bracket. Both bracket ranges and imputed values are publicly available. My estimation methodology allows me to avoid using the imputed values and directly compute the likelihood of the brackets ranges for those individuals that didn't report the exact amounts. ${ }^{31}$

All data are converted in real 1984 dollars using the CPI deflator. Given the relatively short time-series, and the underlying supposition of an economy

\footnotetext{
${ }^{30}$ The implicit assumption is that all the resources of the family unit are pooled, and decisions about their allocation are made by the head of the household.

${ }^{31}$ Values are imputed also for individuals that didn't report neither exact values nor bracket ranges. I exclude these observations from the sample.
} 
in steady state, I implicitly assume there are no cohort nor time effects in the sample. Therefore a household is characterized by its state of residence, the age at marriage, education group and age of its head, but not by the year of the interview. All statistics are therefore computed aggregating over these characteristics.

Figure 3 shows household earnings over 5 years, durable wealth, and nondurable net wealth sample averages at each of the nine age groups, starting from age 20 to 24 . Household earnings profiles show the typical humped shape over the life cycle. Both durable and non-durable net wealth increase until at least the age of 60, with the average stock of durables (net of secured debt) being significantly higher than non-durable net wealth until age 45: young households hold most of their wealth in durables, while other types of assets gain importance in later periods of life.

Only 101 households, or $2.11 \%$ of the whole sample used for estimation, have filed for bankruptcy during the observation period. Default behavior is aggregated over 5 year periods (a person participating in the sample in 1984 is considered a defaulter if he/she filed for bankruptcy in any of the years between 1982 and 1986, a person participating in the sample in 1989 is considered a defaulter if he/she filed for bankruptcy in any of the years from 1987 to 1991, and so on). The typical individual that files for bankruptcy is about 35 years old, white, with a high school degree, owns about $\$ 17,000$ worth of durable assets (over the 5 years period of default), and almost no non-durable wealth. His family labor income is below the average income of a household his age, but not extremely low.

Notice that it is difficult to compare the PSID default rates to the ones observed at the national level, since the latter are not calculated by individual characteristics (age, marital status). However, if anything, it is very likely that these rates are underestimated, since bankruptcy filings are found to be underreported in the PSID, as documented by Fay, Hurst and White (2000). In fact, the overall PSID filing rate is only about half as high as the national rate (the correlation between the two rates is 0.67 , reported in FHW). I take the underreporting into account by assuming that default is observed with error, as described in the next section.

\section{Estimation Method}

I estimate all the 47 parameters of the model by maximum likelihood. Each individual in the sample is assumed to be solving the optimization problem described above. At each age after marriage, given the deterministic state of durables and debt/savings, and shocks to earnings and preferences, the person chooses the stock of durables to own, the net borrowing or saving, and whether to default or not. Conditional on the deterministic state, the solution of the dynamic programming problem allows me to evaluate the probability that the agent is observed to make a certain choice as the product of the conditional type probabilities and a two dimensional integral over the vector of shocks such 
that that particular choice is the optimal one. The likelihood function is the product, over time and individuals, of these probabilities.

In the present context, however, the traditional approach of using smooth probability simulators (as the GHK simulator, or the one developed by McFadden (1989)) to evaluate conditional choice probabilities is not feasible, because the short dimension of the panel implies that only a few endogenous state variables are observed. In particular, the great majority of individuals in the sample are observed many years after marriage. Calculating the conditional probabilities of their observed choices would mean to have to "integrate out" all possible choice sequences that they may have followed, which would consist in evaluating very high dimensional integrations. This computation would be very cumbersome. I therefore use the same simulated maximum likelihood estimation algorithm as in Keane and Wolpin (2001). This algorithm is shown to be computationally practical and to have good small sample properties (see Keane and Sauer (2005) for a discussion), and allows one to avoid the computation of conditional probabilities. Rather, only unconditional probabilities are computed.

At each trial parameter vector $\xi$, and for each permanent state $(e, s, a)$, I simulate outcome histories of initial states $\widetilde{h}_{a k}^{n}$ and $\widetilde{d}_{a+1, k}^{n}$, earnings $\left\{\widetilde{y}_{t, k}^{n}\right\}_{t=a+1}^{T}$ and choices $\left\{\widetilde{h}_{t, k}^{n}, \widetilde{b}_{t, k}^{n}, \widetilde{I}_{t, k}^{d, n}\right\}_{t=a+1}^{T}$, for each type $k=1, . ., K$, for $n=1, . ., N$, according to the functional forms and error processes assumed in the model, and the related decision rules. ${ }^{32}$ Denote a simulated history by

$$
\widetilde{X}_{k}^{n}=\left\{\widetilde{X}_{t, k}^{n}\right\}_{t=a+1}^{T}=\left\{\widetilde{y}_{t, k}^{n}, \widetilde{h}_{t, k}^{n}, \widetilde{b}_{t, k}^{n}, \widetilde{I}_{t, k}^{d n}\right\}_{t=a+1}^{T}, \quad n=1, \ldots, N, k=1, . ., K
$$

The key assumption that is required to form the likelihood is that the observed data on initial states, choice variables and labor earnings are measured with error. In this way, the observed outcome history for individual $j$

$$
X_{j}=\left(h_{a, j}, d_{a+1, j},\left\{y_{t, j}, h_{t, j}, b_{t, j}, I_{t, j}^{d}\right\}_{t=a+1}^{T}\right)
$$

in the data has a positive probability of being generated by any simulated history $\widetilde{X}_{k}^{n}{ }^{n} 33$

The probability of the observed history $X_{j}$ conditional on the simulated history $\widetilde{X}_{k}^{n}, \operatorname{Pr}\left\{X_{j} \mid \widetilde{X}_{k}^{n}\right\}$, is simply the product of the measurement error

\footnotetext{
${ }^{32}$ I simulate $N=1,500$ histories for each type and permanent state.

${ }^{33}$ Notice that the first period of observed data is individual specific. In particular, each agent is observed for at most three consecutive age groups between marriage and retirement. Here, for convenience, I describe the history of observations as if known at each age between $(a+1)$ and $T$.
} 
densities for the continuous variables and the classification error rates for the discrete choices that are needed to make $X_{j}$ and $\widetilde{X}_{k}{ }^{n}$ consistent. ${ }^{34}$

Simulating $N$ histories, I obtain the unbiased simulator of the probability of $X_{j}$ :

$$
\operatorname{Pr}\left\{X_{j} \mid\left(e_{j}, s_{j}, a_{j}\right), \xi\right\}=\frac{1}{K N} \sum_{k=1}^{K} \sum_{n=1}^{N} \operatorname{Pr}\left\{X_{j} \mid \widetilde{X}_{k}^{n}\right\} \frac{\pi_{k / s_{j}, e_{j}}}{N}
$$

where $\pi_{k / s_{j}, e_{j}}$ denotes the probability of being type $k$ conditional on individual $j$ 's education and state of residence. Notice that each conditional probability is weighted by the ratio of the proportion of type $k$ according to the model, $\pi_{k / s_{j}, e_{j}}$, to the proportion of type $k$ in the simulator, $N$.

The likelihood function to maximize over the parameter vector $\xi$ is then

$$
L\left(\xi,\left\{X_{j}\right\}_{j}\right)=\prod_{j} \operatorname{Pr}\left\{X_{j} \mid\left(e_{j}, s_{j}, a_{j}\right), \xi\right\}
$$

Finally, it is necessary to describe the specific assumptions for the measurement error processes. First, the measurement error in labor earnings is assumed to be multiplicative, i.e. $y_{t}=\widetilde{y}_{t} \eta_{t}^{y}$, where $\eta_{t}^{y}$ is lognormally distributed. The measurement errors in net durable and non-durable wealth are additive, i.e. $h_{t}=\widetilde{h}_{t}+\eta_{t}^{h}$ and $b_{t}=\widetilde{b}_{t}+\eta_{t}^{b}$ respectively, where $\eta_{t}^{h}$ and $\eta_{t}^{b}$ are normally distributed. These errors are assumed to be serially indipendent and indipendent of each other. ${ }^{35}$

The bankruptcy variable is assumed to be subject to classification error. Simply, there is a probability that the reported answer on default is not true. In order to take into account the fact that bankruptcies are very likely to be underreported in the PSID, I allow for biased classification error. That means that the probability a person is observed to file for bankruptcy is actually not equal to the true probability of that person defaulting. ${ }^{36}$

The optimization method used is a simplex algorithm (since the likelihood function is not smooth). I instead use a smoothing algorithm to construct standard errors using the BHHH algorithm. See the Appendix for details on estimation and on the measurement and classification errors processes.

Lastly, a brief discussion on identification of the model parameters. There is actually no general method to check the conditions for identification prior to

\footnotetext{
${ }^{34}$ As an example, let the measurement error be $\eta=x-\widetilde{x}$, where $\widetilde{x}$ is the true (simulated) value, while $x$ is the observed variable. Then the contribution to the computation of the likelihood is simply $f(\eta)$, where $f$ denotes the probability density function of $\eta$.

If instead than observing the exact value $x$, only the brackets range $[\underline{x}, \bar{x}]$ is known (as discussed in the previous section), then the probability of the observed interval conditional on the simulated $\widetilde{x}$ is given by $F(\bar{x}-\widetilde{x})-F(\underline{x}-\widetilde{x})$, with $F$ being the cumulative distribution function of the measurement error.

${ }^{35} \mathrm{I}$ assume that the measurement error variance is proportional to the value of the true variable. See the Appendix for details.

${ }^{36}$ The permanent state $(e, s, a)$ of each individual is assumed to be observed with certainty.
} 
estimation. However, in the model there are several sources of exogeneity which are possible sources of identification, such as the exemption level, age, education and history of earnings realizations. In practice, I compute the information matrix and determine whether there is an identification problem from looking at how the likelihood function varies with the parameters. The likelihood function is sensitive to the change in each parameter value (keeping all the others constant). ${ }^{37}$

\section{Results}

\subsection{Estimated parameters and sample fit}

Table 4 in the Appendix contains the point estimates of the parameters and the related standard errors. ${ }^{38}$ All parameter values are tightly estimated. Households discount the future at an annual factor of $93.2 \%$, which corresponds to an estimated annual discount rate of $7.3 \%$. The estimated annual risk-free interest rate is $1.8 \%$.

The discount rate is within a reasonable range. Using information on the elasticity of assets with respect to uncertainty, Carroll and Samwick (1997) estimate a discount rate in the interval of $10-15 \%$, while Gourinchas and Parker (2002) estimate a discount rate just above four percent. The interest rate estimated here, on the other hand, is quite low if compared to the average real return on bonds for the period under consideration, about 3.4\%. However, the PSID does not over-sample very rich people, so that it seems plausible for individuals in this sample to face on average low returns on savings.

It is also worth noting that what really matters is the ratio between discount rate and risk-free rate. The profiles of durable and non-durable wealth are very sensitive to this ratio. The higher the discount rate with respect to the return on savings, the more impatiently households behave, being more willing to borrow and consume in both durable and non-durable goods early in life, and saving only later, for retirement. In the context of the present model, impatience makes individuals more sensitive to the effects of bankruptcy regulations on the credit market and thus explain the effect of these regulations on individual behavior (especially in the first half of the life-cycle).

A key preference parameter is the CRRA coefficient. The large strand of the literature that calibrates the life-cycle model from macro data or from existing studies tends to use for this parameter a value between 1 and 5. Studies that estimate this parameter from micro data typically find lower values, between 0.5 and 2 (Attanasio and Weber (1993) and Laitner and Silverman (2005), among

\footnotetext{
${ }^{37}$ It's to be noted that the exact specifications for most of the functional forms in the model were chosen to begin with for their economic interpretation and correspondence to the existing literature. However, as estimation proceeded, these specifications were subject to changes driven by their ability to fit some aspects of the data, or due to identification problems.

${ }^{38}$ For the parameters that are transformed, the delta method has been used to obtain the standard error.
} 
others). Gourinchas and Parker (2002) estimate a CRRA coefficient between 0.5 and 1.4. I estimate a very reasonable CRRA coefficient of about 1.65 for both types of households. The relatively low risk aversion (with respect to the one used in similar but calibrated models) indicates that households are indeed willing to borrow at the risk of default.

The estimated consumption share $\theta$ is $97.8 \%$. This value is very high if compared with the 0.81 value used by Fernandez-Villaverde and Krueger (2004), who use the same utility functional form (their value is calibrated together with the discount factor in order to obtain a steady-state interest rate of $4 \%$ ). I attribute this difference to the fact that the measure of durable wealth that enters the utility function used here is net of secured debt, implicitly assuming that agents receive utility only from that part of the stock of durable assets that they really own. That is a necessary simplification in order to have as durable wealth variable the one consistent with the exemption regulations (see Section 3.1 for a discussion).

The estimated earning process is consistent with the evidence that mean labor earnings over the working life cycle are hump-shaped (see Figure 5), increasing in education. The standard deviation of the i.i.d. shock to earnings is estimated to be 0.38 in a period of 5 years, or about 0.08 per year. This number is quite low if compared with similar numbers in the literature: Storesletten, Telmer and Yaron (2004) find for example that the unconditional standard deviation of log earnings ranges from 0.3 to 0.64 , in a model in which persistence is found to be very high. The difference is probably due to the fact that I aggregate earnings over five years, and I consider the joint earnings of head and wife, while most of the studies use yearly individual labor income. My estimate is more in line with the results by Keane and Wolpin (1997), who find that the fraction of lifetime uncertainty resolved by skill heterogeneity is $90 \%$. The estimated parameters of the earnings process in my model suggest in fact an important role of education and possibly unobserved skills (type) in determining one's earnings, so that a lot of the variability of income would be attributed to the deterministic persistence rather than the transitory shocks.

The two unobserved types of households are characterized by virtually the same CRRA coefficient but by very different "stigma" costs of defaulting: $\Omega$ is estimated to be four times higher for type 1 than for type 2 . The second type has a lower expected value of earnings, and lower durable and non-durable assets at marriage. Overall, type 2 is the most likely to default. The probability of being of the first type is increasing in education, as expected, and increasing in the exemption level, except for the unlimited exemption. In other words, a higher concentration of type 2 individuals is estimated to be living in the low and in the unlimited exemption states. ${ }^{39}$

\footnotetext{
${ }^{39}$ The percentage of type 2 households in the states are as follows: $68 \%$ in the low exemption state $(\$ 9,800), 40 \%$ in the medium exemption $(\$ 22,900)$, only $9 \%$ in the high exemption $(\$ 64,500)$ and $72 \%$ in the unlimited one. Both the wide difference in these distributions of types and the fact that the probability of being type 2 is similar in the low and the unlimited exemption states goes against the interpretation of unobserved heterogeneity as self-selection into states with different generosity in the bankruptcy regulations. It's instead a signal that
} 
Of interest is also the probability that a non-default is reported in the PSID conditional on the individual having actually filed for bankruptcy, which appears to be extremely high, at $85 \%$, supporting the evidence that bankruptcy filings are underreported in the PSID (Fay, Hurst and White (2000)).

With these estimates, I can address how well the model fits the data on durable and non-durable net wealth accumulation, default rates and household income. Table 5 presents some summary statistics and Figure 4 compares the actual and simulated distributions of the key variables. The model matches particularly well the distribution of durable wealth (at the bottom of Figure 4), and satisfactorily replicates the distribution of non-durable net wealth (which is usually quite a difficult task, at the centre in the Figure). As for simulated earnings, the model fit is not very good: it overstates the number of people at the bottom of the distribution (at the top in Figure 4). Apart from this feature and despite its simplicity, the model does a good job at fitting the distributions of earnings, durable and non-durable net wealth. As for characteristics of the households that file for bankruptcy, these are characterized by lower mean earnings, durable and non-durable wealth than the population averages both in the model and in the data. ${ }^{40}$

Simulated and actual life-cycle profiles of mean durable and non-durable wealth, labor earnings and default rates are presented in Figure 5. Average durable and non-durable net wealth from the simulated model track the actual increasing profiles very closely at least until age 50-54. The model fit is not very good at the end of the decision periods, probably due to the very simplified retirement motive in the model. Average labor earnings over the working life cycle are also very close to the actual means, even if the standard deviation is over-estimated (on average $\$ 145,000$ over age in the model, $\$ 110,000$ in the data). Simulated and actual default rates show the same decreasing pattern.

The model also predicts interest rates on unsecured debt. The predicted equilibrium borrowing interest rate is equal to $13.7 \%$, quite credible if compared to the rates on credit cards or personal loans observed in practice. Notice that the predicted rate implies a quite high default risk-premium, of about $11.9 \%$.

Tables 6 and 7 present in detail the simulated and actual means for the key variables over the life-cycle for the four education groups and the four exemption groups, respectively. ${ }^{41}$ The model correctly predicts that both durable and non-durable wealth increase with the number of years of school, while the probability of default is higher for high school drop-outs. Comparing the simulated outcomes of the estimated model with the data by exemption level, results are again good at least until age 50, a bit less satisfactory for the last ages, especially for the states with an exemption higher than $\$ 15,000$ (and limited). In

there exists an unobserved heterogeneity among states that is not captured by the model.

${ }^{40} \mathrm{By}$ construction, agents that default in the model have a negative non-durable net wealth. In the data this is not necessarily true since default is a one-time event in a period that lasts five years, so that individuals that file for bankruptcy in this period can also hold positive net wealth.

${ }^{41}$ The statistics are computed over five age groups rather than the nine in the model to have a significant number of observations per cell in the data. 
particular, the model consistently overstates mean non-durable net wealth after 50 years old. As noted above, it's a very difficult task to try and match wealth data, and the problem at the last ages might be due to the very simple retirement motive function adopted here. It's also worth noting here that all these comparisons between simulated and actual data are made taking into consideration the compositions of the population in the four groups of states along the dimensions only of education, age at marriage and exemption, and the estimated distribution of unobserved types, disregarding many other potential sources of heterogeneity among the groups of states.

Lastly, as a way of summarizing the data, it's possible to use the simulated results to estimate a regression of durable wealth on the key state variables according to the theoretical model, and compare the coefficients of that regression with the estimated ones from the data. The results are presented in Table 8. The regressors are the years of shooling, age at marriage, age and age squared, the exemption level and a dummy variable for the unlimited exemption. ${ }^{42}$ The simulated regression captures quite correctly the effect of each variable on the accumulation of durables. In particular, the effect of the exemption level on durables has a positive sign for the limited values and is nul for the unlimited exemption. The estimated regression under-estimates the coefficient for the limited exemption level, which is probably due to sources of heterogeneity other than the ones considered here.

In summary, the very parsimonious model is found to match relatively well the life-cycle profiles of earnings, wealth accumulation and default behavior observed in the data, and the relation between exemptions and durable wealth, here the main object of interest.

\subsection{Discussion}

A simple exercise allows us to conduct a more rigorous analysis of the effect of the exemption level on the individual accumulation of durable and non-durable net wealth over the life-cycle. The exercise consists in simulating shocks and choices of 3,000 households that are equal in all respects except the exemption level, and take averages. For the results of the exercise not to be driven by the distribution of unobserved types in a particular state, in simulation the probability of being each type is calculated conditional only on education, not on the state of residence. Table 9 presents average durable and non-durable net wealth, default behavior and welfare for each of the levels of exemption used in computation: low $(\$ 9,800)$, medium $(\$ 22,900)$, high $(\$ 64,500)$ and unlimited. Tables 10 to 13 show the results for each of the two types, two selected education groups (high school and college) and two selected exemptions, $\$ 9,800$ and $\$ 64,500 .^{43}$

\footnotetext{
${ }^{42}$ All variables are transformed so that they are consistent with the numerical solution of the model (i.e. age is age group, the average exemption for each of the four groups of states, etc.).

${ }^{43}$ The groups are selected so that they are representative of a low and a high education level, and a low and a high exemption. Results for the other groups are not shown for brevity
} 
As underlined above, the effect of bankruptcy protection is twofold. On one hand, the exemption corresponds to insurance for the borrower. On the other, the level of protection of the borrowers has an effect on the credit constraints faced by individuals. The estimated model allows to isolate these two effects. First, I simulate choices of individuals with an exemption level set equal to zero (i.e. no insurance), and I compute the endogenous borrowing interest rates in this economy. In order to capture the effect of bankruptcy protection as insurance (the insurance effect), I then simulate the choices in an economy with a positive exemption but an interest rates schedule fixed at the one computed in the previous exercise, as if the credit market didn't react to the higher consumer's protection. The effect of the change in credit conditions due to the introduction of a positive exemption level (the credit constraints effect) is then calculated as a residual.

A first somewhat surprising result is that allowing for a positive exemption leads to a net lower accumulation of durables, at least in the first half of the life cycle (before retirement). The household between 20 and 29 years old, for instance, accumulates on average $\$ 4,500$ less durables in an economy where the exemption is $\$ 9,800$ than in one in which the exemption is nul. Moreover, this negative effect is non-linear: the decrease in the stock of durables is $\$ 7,600$ for an exemption of $\$ 22,900$, but $\$ 8,000$ for the two highest exemptions. This result leads to the conclusion that the positive impact estimated with the regression presented in the section above must be due to the unobserved heterogeneity among states, and therefore quite misleading.

Non-durable net wealth increases with the exemption, again especially in the first half of the life cycle. A household between 30 and 39 years old saves $\$ 7,700$ more on average if the exemption is $\$ 9,800$ relative to the case of no insurance (zero exemption). Again, the effect is non-linear: the increase in non-durable net wealth is about $\$ 13,000$ for the medium exemption, but only about $\$ 14,000$ for the two highest exemptions.

Default rates are increasing with the exemption level, with at most 1.2 percentage points increase (with respect to the zero exemption default rate) if the exemption is unlimited.

Overall, the introduction of a positive exemption is welfare improving. In terms of consumption equivalent variation, the household living in a world without insurance would be willing to forgo $1.2 \%$ of its consumption every period (that is, every 5 years) in order to live in an economy with an exemption equal to $\$ 9,800$. However, the gain from insurance is less for higher levels of protection $(0.9 \%$ of consumption every period for each of the other three exemption levels), suggesting that the higher the exemption, the higher is also the welfare loss due to tighter credit constraints.

The last two columns of each of the Tables 9 to 13 show the two separate effects of insurance and credit constraints, for each exemption level. It is interesting to notice how these vary widely across exemption levels, substantially

and are available upon request. The net effect of the exemption seems to be non linear, since there is practically no difference in average behavior between a $\$ 64,500$ exemption and the unlimited case. 
increasing in magnitude for the high exemptions, even when the net effects are similar across states. The effect on durable wealth due to the change in credit constraints when a positive exemption is introduced is always negative, ranging from a few thousand dollars for the lowest exemption to about $\$ 70,000$ for the unlimited exemption: the higher the protection of the borrower the tighter the credit constraints faced by individuals, and thus the lower their capability to buy durables. On the other hand, tighter credit limits and/or higher borrowing interest rates induce higher precautionary saving, increasing non-durable net wealth, again especially in the first ages, by about $\$ 6,000$ in a low exemption state and by more than $\$ 30,000$ in the high exemption states. Lastly, higher borrowing interest rates decrease the default rate (by even 4.4 percentage points in the unlimited exemption state). The welfare loss due to the credit constraints effect is large in the two highest exemptions: $15 \%$ and $28 \%$ in terms of consumption equivalent variation in the highest limited exemption and the unlimited one, respectively, while the loss is relatively small in the low and medium exemption states (1.6\% and $5.6 \%$, respectively).

The sign and magnitude of the insurance effect on durables varies with the level of exemption: it's positive and high for the highest levels, positive and low for the medium exemption $(\$ 22,900)$ and negative and small for the $\$ 9,800$ level. On the one hand, the possibility of saving a higher value of your durable assets upon default increases the incentive to accumulate durables at least by the borrowers (the higher the exemption level, the higher this incentive). On the other hand, however, the introduction of additional insurance induces less precautionary saving, both in durable and non-durable wealth (in fact nondurable net wealth accumulation decreases upon the introduction of insurance). At a low level of exemption, the latter seems to be the prevailing effect: as a consequence of allowing a positive exemption level, durable wealth decreases (by small amounts, ranging from a few hundred dollars to about $\$ 2,000$ ). As the protection increases, instead, it becomes more and more attractive to hold durables (and borrow to buy them), so that durable wealth accumulation increases with respect to the case of zero exemption, by about $\$ 1,000$ to $\$ 2,500$ in the medium exemption, but by more than $\$ 10,000$ in the high exemption, and by up to $\$ 60,000$ in the unlimited exemption state. The introduction of insurance has a large crowding-out effect on savings in the high and unlimited states: the decrease in non-durable net wealth in these states ranges between $\$ 18,000$ and $\$ 25,000$ in the first half of the life cycle. ${ }^{44}$

As expected, the introduction of insurance would increase default rates (at most by 5.5 percentage points in the unlimited exemption state). Lastly, higher borrowers' protection induces welfare gains that are symmetric and higher in absolute value than the welfare losses due to the tighter credit constraints. Overall, the household would be on average better off with some level of bankruptcy

\footnotetext{
${ }^{44}$ The only puzzling result is for the unlimited exemption, at the last age, when the credit constraints effect is negative and large (almost $\$ 84,000$ ), and the insurance effect is positive (also big: \$86,000). At the end of the life cycle, individuals are clearly less concerned with precautionary motives, and they save for retirement. Therefore, these effects could be due to a re-optimization of life-time resources before retirement.
} 
protection. ${ }^{45}$

Analyzing these effects on different education levels and different types (Tables 10 to 13), the main conclusions described above do not change. In general, for all levels of exemption, the high school graduates seem to have a stronger incentive to accumulate durables as insurance (there is less crowding-out of precautionary saving due to the introduction of borrower's protection), and suffer more from the tighter borrowing constraints. They gain more from the positive exemption than college graduates do. As for the two types of individuals, the second type, the more likely to default, would in fact increase his "strategic" accumulation of durables (higher positive insurance effect) and suffer the most from the worsening of the credit conditions.

Motivated by the observation that the welfare gain from bankruptcy protection is higher for the lowest exemption used in computation, I conduct a counterfactual experiment to identify what the "optimal" level of exemption is. I simulate the estimated model in an economy with the same characteristics as the benchmark used for estimation but under different regimes, increasing the exemption from zero up to an unlimited value. ${ }^{46}$ Default rates, equilibrium borrowing interest rates and percentage of net borrowers in the economy, as well as welfare comparisons in terms of consumption equivalent variation are presented in Table 14.

The default rate is minimized when there is no bankruptcy: it would be 0.8 percentage points lower than in the benchmark model. As for credit market, the percentage of net debtors in the economy would decrease with the exemption, while the equilibrium borrowing interest rate would be only $3.3 \%$ in a world with a zero exemption level, very low if compared with the $13.7 \%$ found from the original estimated model.

In the benchmark economy households would be willing to forgo $0.4 \%$ of their 5-year consumption to be able to live in a world with a level of exemption equal to $\$ 5,000$, the "optimal" exemption, since for higher levels the gain would be much less (or would even be a loss). Overall, it seems that the gains from a high level of insurance are reduced by the effect of tighter credit constraints, so that the net effects of a change in exemption are actually very small.

\section{Conclusions}

This article contributes to the analysis and understanding of the effects of bankruptcy regulations on household saving and default behavior, estimating a dynamic model that accounts for the equilibrium effects of bankruptcy protection

\footnotetext{
${ }^{45}$ Simulated average consumption over the life cycle does not change very much with the exemption. It might seem a little bit of a puzzle that households are better off in a world where they accumulate less durables and they consume the same. However, in this economy households give a value to non-durable net wealth too, for the retirement motive, so that they benefit from a higher accumulation of assets (and less borrowing) in the higher exemption states.

${ }^{46}$ The same distribution of unobserved types by state is used in simulation than in the benchmark estimated model.
} 
on the accumulation of durable and non-durable net wealth, and on the credit conditions faced by individuals.

The model is able to replicate the main features of the data, namely the increasing profiles of durable and non-durable wealth, the hump-shaped labor earnings and the decreasing default rates over the life cycle, as well as the differences in the patterns of these variables across different education and exemption groups. The estimated preference parameters are credible. Households discount the future at an annual rate of $7.3 \%$, and have a coefficient of risk aversion equal to 1.65 . An individual default risk premium of about $12 \%$ is incorporated into the cost of borrowing.

The estimates allow me to evaluate the overall impact of bankruptcy protection on durable wealth using a coherent theoretical framework to derive the credit constraints which are actually unobserved in the data. Moreover, I can separate the effect of the exemption as insurance for the borrowers from the effect of the exemption on the credit conditions faced by individuals. Due to the latter, a positive exemption leads to tighter credit constraints (higher borrowing interest rates and/or lower credit limits), reducing the accumulation of durables and increasing precautionary saving in non-durable wealth. On the other hand, the introduction of a positive insurance gives agents the incentive to borrow and buy more durables especially at high levels of exemption, and it decreases precautionary saving. The effect of the exemption level on durable wealth is overall negative, but households would be better off with a positive small exemption of about $\$ 5,000$.

The model here estimated is very parsimonious and would need to be extended along various dimensions. As an example, a possible extension would be to incorporate the distinction between secured and unsecured loans. This work has treated the value of durables as net of secured debt (i.e., home equity), and has disregarded the households' choice of the kind of debt they hold. This was done because secured debt is senior to bankruptcy exemptions, i.e. the value of the house that is collateralized can never be saved in bankruptcy. However, the existence of a protection for unsecured debt might influence the supply and demand of secured debt as well, as documented with somewhat divergent results in the empirical work by Berkowitz and Hynes (1999) and Lin and White (2000).

Moreover, a more realistic environment would also distinguish between Chapter 7 and Chapter 13, taking into consideration their potential impact (especially of the latter) on labor supply and as a consequence on the level of uncertainty faced by households. ${ }^{47}$ Such a setting would also allow a better understanding of the equilibrium effects of the very recent Bankruptcy Reform (S. 256), which introduces a means test to exclude higher income individuals from the possibility to file for bankruptcy under Chapter 7, prompting them to use the repayment plan required by Chapter 13 . The analysis of the equilibrium effects of bankruptcy protection in these settings is an important question for future

\footnotetext{
${ }^{47}$ Very recent interesting work by Meh and Terajima (2005) explores the effects of U.S. bankruptcy protection on entrepreneurship.
} 
work. 


\section{Appendix}

\subsection{Computation}

\subsubsection{Algorithm}

In computation, each state is discretized. The following four categories of education are considered: no high school $(s=9)$, high school degree $(s=12)$, some college $(s=14)$ and college degree $(s=16)$. Exemption levels are also divided into four groups (described in Section 2): $\$ 9,800, \$ 22,900, \$ 64,500$ and unlimited, for which a value of $\$ 300,000$ is used in computation (that's the maximum value of durable goods that can be chosen). Age can range from 1 (20-24 years old) until 9 (60-64 years old). Accordingly, age at marriage goes from 0 (younger than 20 years old) to 8 (55-59 years old). The value of debt $d_{t}$ at each age $t$ is restricted to lie in the interval $[-75,50]$ (where all variables are divided by $\$ 10,000)$. The value of durable goods $h_{t}$ belongs to the interval $[0,30]$. Intervals were chosen both in consideration of observed values in the data and such that they do not bind simulated choices. Initial conditions are also restricted to lie in the above intervals.

In brief, the algorithm I use is the following:

1) corresponding to a parameters value, compute

$$
E_{T-1}\left\{V_{T}\left(\underline{x}_{T}, \underline{\varepsilon}_{T} ; k\right)\right\}=E M A X\left(\underline{x}_{T}, T ; k\right)
$$

and the borrowing allowed $\bar{b}_{T-1}\left(\underline{x}_{T}\right) \equiv \sum_{k=1}^{K} \operatorname{EBOR}\left(\underline{x}_{T}, T-1 ; k\right)$ as in (1), at each $\underline{x}_{T}$, using Monte Carlo simulation (see below);

2) recursively, using Monte Carlo simulations, calculate $E M A X$ and $E B O R$ for all $\underline{x}_{t+1}$, for $t=T-2, \ldots, a+1$;

3) simulate the optimal decisions of the $j^{\text {th }}$ agent characterized by $(a, s, e, k)$, generating shocks $\left\{\varepsilon_{t j}^{y}, \varepsilon_{t j}^{u}\right\}_{t=1}^{T}$, for $j=1, \ldots, 1,500$, assigning initial endowments $\left(h_{a j}, d_{a+1, j}\right)$, and using the $E M A X$ and $E B O R$ calculated above to find the stream of choices and utility values.

\subsubsection{Monte Carlo Integration}

The two random i.i.d. shocks are the following:

$$
\begin{gathered}
\varepsilon_{t}^{y} \sim L N\left(0, \sigma_{y}^{2}\right) \quad \forall t \\
\varepsilon_{t}^{u} \sim L N\left(0, \sigma_{u}^{2}\right) \quad \forall t
\end{gathered}
$$

Use Cholesky decomposition:

$$
\ln \left(\epsilon_{t}^{y}\right)=\alpha_{1} u_{1 t}
$$




$$
\ln \left(\varepsilon_{t}^{u}\right)=\alpha_{2} u_{2 t}
$$

where $u_{1 t} \sim N(0,1), u_{2 t} \sim N(0,1)$, i.i.d. $\forall t$.

Then $\sigma_{y}^{2}=\alpha_{1}^{2}$ and $\sigma_{u}^{2}=\alpha_{2}^{2}$.

The Monte Carlo simulation proceeds as follows.

Given all deterministic states and type, at any value of choices $\underline{x}_{t+1}$, I generate two random numbers $u_{1 t+1}^{m}$ and $u_{2 t+1}^{m}$, from standard normal distributions (i.i.d), for $m=1, \ldots, M$ ( $M=25$ has proved to be sufficient), and I perform the following transformation:

$$
\begin{aligned}
& \epsilon_{t+1}^{y, m}=\exp \left(\alpha_{1} u_{1 t+1}^{m}\right) \\
& \epsilon_{t+1}^{u, m}=\exp \left(\alpha_{2} u_{2 t+1}^{m}\right)
\end{aligned}
$$

The value of no default $V^{0, m}\left(\underline{x}_{t+1}, \underline{\varepsilon}_{t+1}^{m} ; k\right)$ and the value of default $V^{1, m}\left(\underline{x}_{t+1}, \underline{\varepsilon}_{t+1}^{m} ; k\right)$ are evaluated at each vector of shocks $\underline{\varepsilon}_{t+1}^{m}$, for $m=1, \ldots M$.

The value function $V^{m}\left(\underline{x}_{t+1}, \underline{\varepsilon}_{t+1}^{m} ; k\right)$ at each $\underline{\varepsilon}_{t+1}^{m}$ is then given by the highest of the no-default value and the default value, and the default rule $I_{t+1}^{d, m}\left(\underline{x}_{t+1}, \underline{\varepsilon}_{t+1}^{m} ; k\right)$ is derived from that.

Then,

$$
\begin{gathered}
E_{t}\left\{V_{t+1}\left(\underline{x}_{t+1}, \underline{\varepsilon}_{t+1} ; k\right)\right\} \approx \frac{1}{M} \sum_{m=1}^{M} V_{t+1}^{m}\left(\underline{x}_{t+1}, \underline{\varepsilon}_{t+1}^{m} ; k\right)= \\
=E M A X\left(\underline{x}_{t+1}, t ; k\right)
\end{gathered}
$$

and (from (1))

$$
\begin{gathered}
\bar{b}_{t}\left(\underline{x}_{t+1}\right) \approx \frac{1}{R} \sum_{k=1}^{K} \pi_{k}\left\{\frac { 1 } { M } \sum _ { m = 1 } ^ { M } \left[d_{t+1}\left(1-I_{t+1}^{d, m}\left(\underline{x}_{t+1}, \underline{\varepsilon}_{t+1}^{m} ; k\right)\right)+\right.\right. \\
\left.\left.+I_{t+1}^{d, m}\left(\underline{x}_{t+1}, \underline{\varepsilon}_{t+1}^{m} ; k\right) \max \left\{(1-\delta) h_{t}-e, 0\right\}\right]\right\}= \\
=\sum_{k=1}^{K} \pi_{k} \operatorname{EBOR}\left(\underline{x}_{t+1}, t ; k\right)
\end{gathered}
$$




\subsection{Estimation}

\subsubsection{Parameters to estimate}

Parameters to estimate (47):

- Preference parameters: $\theta, \alpha_{h}, \alpha_{d}$, and $\sigma_{1}, \sigma_{2}$

- Discount factor $\beta$

- Depreciation rate of durables $\delta$

- Risk-free Gross Interest Rate $R$

- Age-specific components in earnings process, $\left\{\alpha_{i}\right\}_{i=1, \ldots, 9}$

- Coefficient for schooling in earnings process, $\alpha_{s}$

- Coefficient for type 2 in earnings process, $\alpha_{2}^{T}$

- Variance of shocks to earnings, $\sigma_{y}^{2}$

- Variance of shocks to preferences, $\sigma_{u}^{2}$

- "Psyche" cost of default for each type, $\Omega_{1}$ and $\Omega_{2}$

- Initial states function coefficients, $\psi_{0}, \psi_{a}, \psi_{s}, \psi_{2}, \beta_{0}, \beta_{a}, \beta_{s}, \beta_{2}, \sigma_{h}, \sigma_{d}, \sigma_{h d}$

- Types distribution coefficients: $\gamma_{01}, \gamma_{s 1}, \gamma_{21}, \gamma_{31}, \gamma_{41}$

- Parameters of Measurement and Classification Errors (see below):

$$
\sigma_{\eta^{h} 0}, \sigma_{\eta^{h} 1,} \sigma_{\eta^{b} 0}, \sigma_{\eta^{b} 1,} \sigma_{\eta^{y} 0}, \sigma_{\eta^{y} 1}, \varphi_{0}, \varphi_{1}
$$

\subsubsection{Measurement and Classification Error}

The observed initial states, choice variables and labor earnings are assumed to be measured with error.

- Measurement error in durables:

$$
\begin{gathered}
h_{t}=\widetilde{h}_{t}+\eta_{t}^{h} \\
\eta_{t}^{h} \sim N\left(0, \sigma_{\eta^{h}, t}^{2}\right) \\
\sigma_{\eta^{h}, t}=\left|\sigma_{\eta^{h} 0}+\sigma_{\eta^{h} 1} \widetilde{h}_{t}\right|
\end{gathered}
$$

(the variance of the measurement error is proportional to the true - simulated - value $\left.\widetilde{h}_{t}\right)$. 
- Measurement error in non-durable wealth:

$$
\begin{gathered}
b_{t}=\widetilde{b}_{t}+\eta_{t}^{b} \\
\eta_{t}^{b} \sim N\left(0, \sigma_{\eta^{b}, t}^{2}\right) \\
\sigma_{\eta^{b}, t}=\left|\sigma_{\eta^{b} 0}+\sigma_{\eta^{b} 1} \widetilde{b}_{t}\right|
\end{gathered}
$$

(the variance of the measurement error is proportional to the true - simulated - value $\left.\widetilde{b}_{t}\right)$.

Measurement error in the initial states $\left(h_{a}, d_{a+1}\right)$ is assumed to be characterized by analogous distributions as above.

- Measurement error in household labor income:

$$
\begin{gathered}
y_{t}=\widetilde{y}_{t} \eta_{t}^{y} \\
\eta_{t}^{y} \sim L N\left(0, \sigma_{\eta^{y, t}}^{2}\right) \\
\sigma_{\eta^{y}, t}=\left|\sigma_{\eta^{y} 0}+\sigma_{\eta^{y} 1} \ln \left(\widetilde{y}_{t}\right)\right|
\end{gathered}
$$

(the variance of the measurement error is proportional to the logarithm of the true - simulated - value, $\ln \left(\widetilde{y}_{t}\right)$ ).

- Since bankruptcy filings have been noted to be severely underreported in the PSID (Fay, Hurst and White (2000)), the classification error for bankruptcy is assumed to be biased (i.e. the probability a person is observed to file for bankruptcy is not equal to the true probability that the person files for bankruptcy).

The biased classification error scheme is characterized by the following index function: ${ }^{48}$

$$
l_{i t}=\varphi_{0}+\varphi_{1} \widetilde{I}_{i t}^{d}+\omega_{i t}
$$

with $\omega_{i t}$ logistically distributed. If $l_{i t}>0$ then $I_{i t}^{d}=1, I_{i t}^{d}=0$ otherwise.

\footnotetext{
${ }^{48}$ See Keane and Sauer (2003) for a discussion. Here, I do not allow persistence in misreporting since by construction the bankruptcy decision is not possible every five years.
} 


$$
\begin{gathered}
\operatorname{Pr}\left\{I_{i t}^{d}=1 \mid{\widetilde{I_{i t}}}^{d}=1\right\}=\frac{\exp \left(\gamma_{0}+\gamma_{1}\right)}{1+\exp \left(\gamma_{0}+\gamma_{1}\right)} \\
\operatorname{Pr}\left\{I_{i t}^{d}=1 \mid \widetilde{I}_{i t}^{d}=0\right\}=\frac{\exp \left(\gamma_{0}\right)}{1+\exp \left(\gamma_{0}\right)}
\end{gathered}
$$

All measurement errors are assumed to be independent and serially uncorrelated. 


\section{References}

[1] Athreya K. [2002], "Welfare Implications of The Bankruptcy Reform Act of 1999", Journal of Monetary Economics, vol. 49, pp. 1567-1595;

[2] Athreya K. [2005], "Fresh Start or Head Start? Uniform Bankruptcy Exemptions and Welfare", Journal of Economic Dynamics and Control, forthcoming;

[3] Attanasio O. and Weber G. [1993], "Consumption Growth, the Interest Rate and Aggregation", Review of Economic Studies 60, pp. 631-649;

[4] Ayagari R. [1994], "Uninsured Idiosyncratic Risk and Aggregate Savings", Quarterly Journal of Economics, 109, pp. 659-684;

[5] Berkowitz J. and Hynes R. [1999], "Bankruptcy Exemptions and the Market for Mortgage Loans", Journal of Law and Economics, 42 (2), pp.809830

[6] Carroll C.D. and Samwick A.A. [1997], "The Nature of Precautionary Wealth", Journal of Monetary Economics, 40 (1);

[7] Chatterjee S., Corbae D., Nakajima M. and Rios-Rull J.V. [2002], "A Quantitative Theory of Unsecured Consumer Credit with Risk of Default", CAERP Working Paper n.2;

[8] Dubey P., Geanakoplos J. and Shubik M. [1994 - revised], "Default in a General Equilibrium Model with Incomplete Markets", Cowles Foundation Discussion Paper \#773;

[9] Elias S., Renauer A. and Leonard R. [1986, 1992], How to file for Bankruptcy, Berkeley, CA: Nolo Press;

[10] Elul, R. and Subramanian, N. [2001], "Forum-Shopping and Personal Bankruptcy", Working Paper;

[11] Fay S., Hurst E. and White M. [2000], "The Household Bankruptcy Decision", American Economic Review, vol. 92 (3), pp. 708-718;

[12] Fernandez-Villaverde J. and Krueger D. [2004], "Consumption and Saving over the Life Cycle: How important are Consumer Durables?", Federal Reserve Bank of Minneapolis Working Paper;

[13] Gourinchas P.O. and Parker J.A. [2002], "Consumption over the Life Cycle", Econometrica, vol. 70, pp. 47-89;

[14] Green E.J. [1987], "Lending and the Smoothing of Uninsurable Income", in Contractual Arrangements for Intertemporal Trade (Prescott E.C. and Wallace N. Ed.s), Minnesota Press, Minnesota; 
[15] Gropp R., Scholz J.K. and White M. [1997], "Personal Bankruptcy and Credit Supply and Demand", The Quarterly Journal of Economics, vol. 112, pp. 217-252;

[16] Gross D.B. and Souleles N [1999], "What caused the recent increase in bankruptcy and delinquency: stigma or risk-composition?", Proceedings, Federal Reserve Bank of Chicago, issue 0, pp. 298-301;

[17] Hart O. and Moore J. [1994], " A Theory of Debt Based on the Inalienability of Human Capital", Quarterly Journal of Economics, vol. 109-4, pp. 841879

[18] Hynes R., "Three essays on consumer bankruptcy and exemptions" [1997], Univ. of Pennsylvania Ph.D. Dissertation;

[19] Keane M.P. and Sauer R.M. [2005], "A Computationally Practical Simulation Estimation Algorithm for Dynamic Panel Data Models with Unobserved Endogenous State Variables", Working Paper;

[20] Keane M.P. and Wolpin K.I. [1994], "The Solution and Estimation of Discrete Choice Dynamic Programming Models by Simulation and Interpolation: Monte Carlo Evidence", The Review of Economics and Statistics, vol. 76, Issue 4, pp. 648-672;

[21] Keane M.P. and Wolpin K.I. [1997], "The Career Decisions of Young Men", Journal of Political Economy, vol. 105 (3), pp. 473-522;

[22] Keane M.P. and Wolpin K.I. [2001], "The Effect of Parental Transfers and Borrowing Constraints on Educational Attainment", International Economic Review, vol. 42, No. 4, pp.1051-1104;

[23] Kocherlakota N.R. [1996], "Implications of Efficient Risk Sharing without Commitment", The Review of Economic Studies, vol. 63-4, pp. 595-609;

[24] Kowalewski K. [2000], "Personal Bankruptcy: a Literature Review", Congressional Budget Office;

[25] Laitner J. and Silverman D. [2005], "Estimating Life-Cycle Parameters from Consumption Behavior at Retirement", NBER Working Paper \# W11163;

[26] Li W. and Sarte P.D. [2005], "U.S. Consumer Bankruptcy Choice: The Importance of General Equilibrium Effects", Journal of Monetary Economics, forthcoming;

[27] Lin E.Y. and White M.J. [2000], "Bankruptcy and the Market for Mortgage and Home Improvement Loans", Michigan Law and Economics Research Paper No. 00-013;

[28] Livshits I., MacGee J. and Tertilt M. [2004], "Consumer Bankruptcy: A Fresh Start", Federal Reserve Bank of Minneapolis Working Paper; 
[29] McFadden D. [1989], "A Method of Simulated Moments for Estimation of Discrete Response Models without Numerical Integration", Econometrica, vol. 57 (5), pp. 995-1026;

[30] Meh C. A. and Terajima Y. [2005], "Housing, Personal Bankruptcy and Entrepreneurship", Bank of Canada Working Paper;

[31] Repetto, A., [1998], "Personal Bankruptcies and Individual Wealth Accumulation", M.I.T. Dissertation;

[32] Storesletten K., Telmer C.I. and Yaron A. [2004], "Consumption and Risk Sharing over the Life Cycle", Journal of Monetary Economics, vol. 51, pp. 609-633;

[33] Sullivan T.A., Warren E. and Westbrook J.L [1989], As We Forgive Our Debtors: Bankruptcy and Consumer Credit in America, New York, NY: Oxford Univeristy Press;

[34] Sullivan T.A., Warren E. and Westbrook J.L [2000], The Fragile Middle Class, New Haven: Yale Univeristy Press;

[35] Thomas J. and Worrall T. [1989], "Income Fluctuations and Asymmetric Information: an Example of a Repeated Principal Agent Problem", Journal of Economic Theory, vol. 51, pp. 367-390;

[36] Zame W.R. [1993], "Efficiency and the Role of Default when Security Markets are Incomplete", The American Economic Review, vol. 83-5, pp. 11421164 . 
Table 1 (to be continued in next page): Exemption Levels*

\begin{tabular}{|c|c|c|c|c|}
\hline U.S. State & $\begin{array}{l}\text { Exemption in } 1984 \\
(\$)\end{array}$ & $\begin{array}{l}\text { Exemption in } 1992 \\
(\$, 1984 \text { real value })\end{array}$ & $\begin{array}{c}\text { Average exemption } \\
1984-1992(\$)\end{array}$ & Category** \\
\hline DELAWARE & 5,075 & 370 & 2,723 & 1 \\
\hline MARYLAND & 6,000 & 4,073 & 5,037 & 1 \\
\hline WEST VIRGINIA & 6,000 & 6,739 & 6,370 & 1 \\
\hline GEORGIA & 9,500 & 4,740 & 7,120 & 1 \\
\hline KENTUCKY & 11,000 & 6,295 & 8,647 & 1 \\
\hline MISSOURI & 11,500 & 7,220 & 9,360 & 1 \\
\hline TENNESSEE & 12,250 & 6,665 & 9,458 & 1 \\
\hline UTAH & 13,000 & 7,035 & 10,018 & 1 \\
\hline INDIANA & 11,600 & 8,590 & 10,095 & 1 \\
\hline VIRGINIA & 12,000 & 8,887 & 10,443 & 1 \\
\hline NEBRASKA & 12,000 & 9,257 & 10,628 & 1 \\
\hline SOUTH CAROLINA & 8,750 & 12,738 & 10,744 & 1 \\
\hline ALABAMA & 13,000 & 9,627 & 11,314 & 1 \\
\hline NORTH CAROLINA & 16,000 & 11,108 & 13,554 & 1 \\
\hline MAINE & 17,300 & 10,072 & 13,686 & 1 \\
\hline OHIO & 19,000 & 8,739 & 13,869 & 1 \\
\hline MICHIGAN & 19,000 & 9,516 & 14,258 & 1 \\
\hline ILLINOIS & 17,750 & 13,478 & 15,614 & 2 \\
\hline NEW HAMPSHIRE & 10,500 & 22,957 & 16,729 & 2 \\
\hline CONNECTICUT & 19,000 & 15,070 & 17,035 & 2 \\
\hline DIST OF COLUMBIA & 19,000 & 15,070 & 17,035 & 2 \\
\hline NEW JERSEY & 19,000 & 15,070 & 17,035 & 2 \\
\hline PENNSYLVANIA & 19,000 & 15,070 & 17,035 & 2 \\
\hline RHODE ISLAND & 19,000 & 15,070 & 17,035 & 2 \\
\hline HAWAII & 21,000 & 15,552 & 18,276 & 2 \\
\hline WYOMING & 23,000 & 16,292 & 19,646 & 2 \\
\hline OREGON & 22,650 & 17,551 & 20,101 & 2 \\
\hline LOUISIANA & 25,000 & 18,514 & 21,757 & 2 \\
\hline
\end{tabular}




\section{Table 1 (continued): Exemption Levels *}

\begin{tabular}{|c|c|c|c|c|}
\hline U.S. State & $\begin{array}{l}\text { Exemption in } 1984 \\
(\$)\end{array}$ & $\begin{array}{l}\text { Exemption in } 1992 \\
(\$, 1984 \text { real value })\end{array}$ & $\begin{array}{l}\text { Average exemption } \\
\text { 1984-1992(\$) }\end{array}$ & Category** \\
\hline NEW YORK & 25,600 & $\overline{18,440}$ & 222,020 & $\overline{2}$ \\
\hline COLORADO & 25,000 & 22,957 & 23,979 & 2 \\
\hline WISCONSIN & 25,900 & 31,251 & 28,576 & 2 \\
\hline WASHINGTON & 36,750 & 24,142 & 30,446 & 2 \\
\hline VERMONT & 40,000 & 30,067 & 35,033 & 2 \\
\hline MONTANA & 40,200 & 30,511 & 35,355 & 2 \\
\hline NEW MEXICO & 46,500 & 32,955 & 39,727 & 2 \\
\hline IDAHO $* * *$ & 6,400 & 75,166 & 40,783 & \\
\hline ALASKA & 55,500 & 42,212 & 48,856 & 3 \\
\hline MISSISSIPPI & 38,000 & 62,947 & 50,474 & 3 \\
\hline CALIFORNIA & 47,500 & 56,727 & 52,113 & 3 \\
\hline ARIZONA & 57,600 & 75,278 & 66,439 & 3 \\
\hline MASSACHUSETTS & 63,500 & 75,296 & 69,398 & 3 \\
\hline NORTH DAKOTA & 90,000 & 63,836 & 76,918 & 3 \\
\hline NEVADA & 99,000 & 74,944 & 86,972 & 3 \\
\hline ARKANSAS & unlimited & unlimited & unlimited & 4 \\
\hline FLORIDA & unlimited & unlimited & unlimited & 4 \\
\hline KANSAS & unlimited & unlimited & unlimited & 4 \\
\hline MINNESOTA & unlimited & unlimited & unlimited & 4 \\
\hline OKLAHOMA & unlimited & unlimited & unlimited & 4 \\
\hline TEXAS & unlimited & unlimited & unlimited & 4 \\
\hline IOWA *** & 4,500 & unlimited & & \\
\hline SOUTH DAKOTA*** & unlimited & 25,179 & & \\
\hline
\end{tabular}

Average (excluding unlimited)

$\begin{array}{rrr}25,451 & 23,938 & 24,923 \\ 11,940 & 7,745 & 9,843 \\ 25,269 & 20,557 & 22,913 \\ 64,443 & 64,463 & 64,453\end{array}$

Average category 1 Average category 2 Average category 3 64,443

64,453

\footnotetext{
*Exemptions are the sum of homestead exemption, exempted value of vehicles and wild card exemption

Source: Elias, Renauer and Leonard $(1986,1992)$

${ }^{* *}$ Category 1: average exemption $1984-1992$ below $\$ 15,000$

Category 2: average exemption 1984-1992 above $\$ 15,000$ and below $\$ 40,000$

Category 3: average exemption 1984-1992 above $\$ 40,000$

Category 4: unlimited exemption

***States eliminated from the sample (see text for details)
} 
Figure 1: Average Exemption 1984-1992 and Average Real GSP Per-Capita 1978-1983, United States

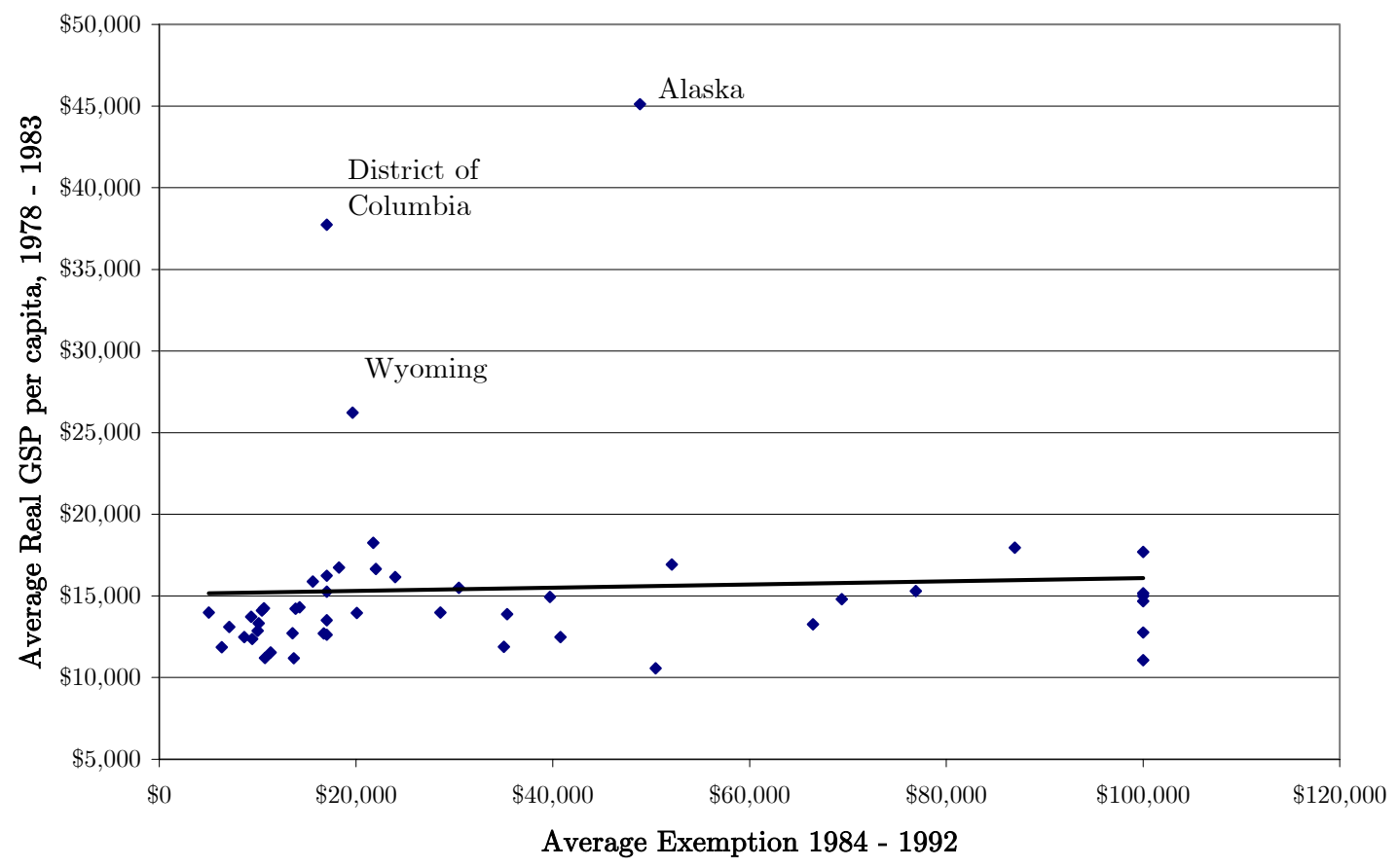

Figure 2: Average Exemption 1984-1992 and Average Real GSP Per-Capita 1978-1983, United States without three outliers

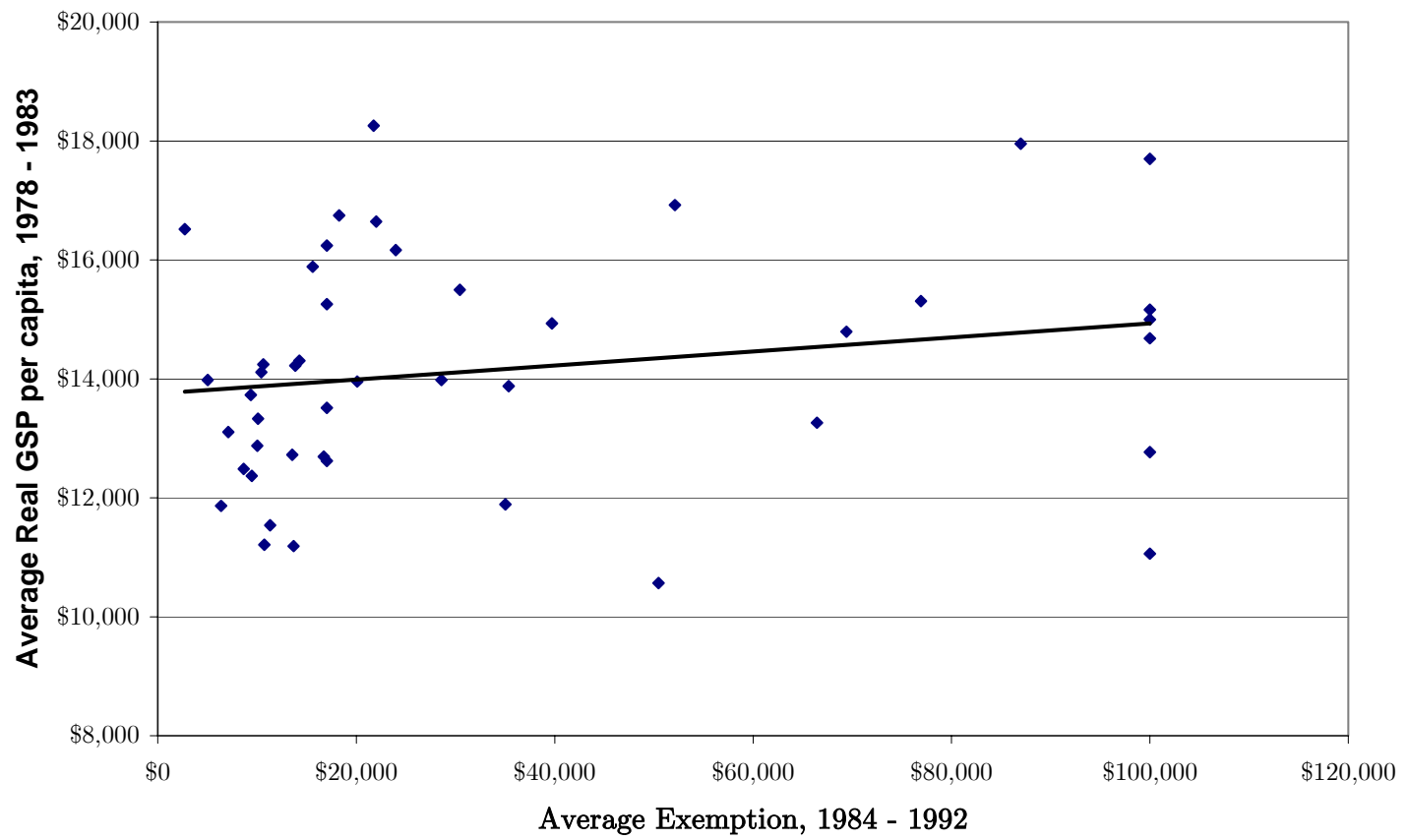


Table 2: PSID Sample Selection

1) PSID Heads of Households, total observations 1984-1994 9,983

2) Observations in 1) that are married

at least in one of the years 1984, 1989 or $1994 \quad 5,797$

3) Observations in 2) whose marriage history is observed $\quad 5,701$

4) Observations in 3) whose state of residence is observed $\quad 5,673$

5) Observations in 4) whose age is between 20 and $64 \quad 5,234$

6) Observations in 5) whose age at marriage is observed $\quad 4,974$

7) Observations in 6) whose education is observed $\quad 4,954$

8) Observations in 7) after eliminating outliers on earnings, durable and financial wealth

4,790 
Table 3: Composition of PSID Sub-Sample

\begin{tabular}{|c|c|c|c|}
\hline & & All sample & Defaulters \\
\hline \multirow[t]{8}{*}{ Distribution by Age } & $\% 20-24$ & 1.92 & 3.96 \\
\hline & $\begin{array}{ll}\% & 25-29 \\
\% & 30-34\end{array}$ & $\begin{array}{r}9.9 \\
17.15\end{array}$ & $\begin{array}{l}22.77 \\
18.81\end{array}$ \\
\hline & $\% 35-39$ & 19.57 & 26.73 \\
\hline & $\% 40-44$ & 16.21 & 13.86 \\
\hline & $\% 45-49$ & 11.56 & 6.93 \\
\hline & $\% 50-54$ & 8.21 & 4.95 \\
\hline & $\% 55-59$ & 7.98 & 1.98 \\
\hline & $\% 60-64$ & 7.5 & 0 \\
\hline Sex & $\%$ Male & 98.98 & 99.01 \\
\hline \multirow[t]{3}{*}{ Distribution by Race } & $\%$ White & 68.62 & 71.29 \\
\hline & $\%$ Black & 27.64 & 26.73 \\
\hline & $\%$ Other & 3.74 & 1.98 \\
\hline \multirow[t]{4}{*}{ Distribution by Education } & $\%$ No High School & 21.09 & 24.75 \\
\hline & $\%$ High School & 38.52 & 47.52 \\
\hline & $\%$ Some College & 19.95 & 21.78 \\
\hline & $\%$ College & 20.43 & 5.94 \\
\hline \multirow[t]{9}{*}{ Distribution by Age at Ma } & Before 20 y.o. & 7.95 & 16.83 \\
\hline & $\% 20-24$ & 41.52 & 45.54 \\
\hline & $\% 25-29$ & 25.72 & 24.75 \\
\hline & $\% 30-34$ & 11.32 & 6.93 \\
\hline & $\% 35-39$ & 5.74 & 1.98 \\
\hline & $\% 40-44$ & 3.4 & 0.99 \\
\hline & $\%$ 45-49 & 2.38 & 2.97 \\
\hline & $\% 50-54$ & 1.46 & 0 \\
\hline & $\% 55-59$ & 0.5 & 0 \\
\hline
\end{tabular}


Figure 3: Life-Cycle profiles of Labor Earnings, Durable and Non-durable wealth, PSID sub-sample

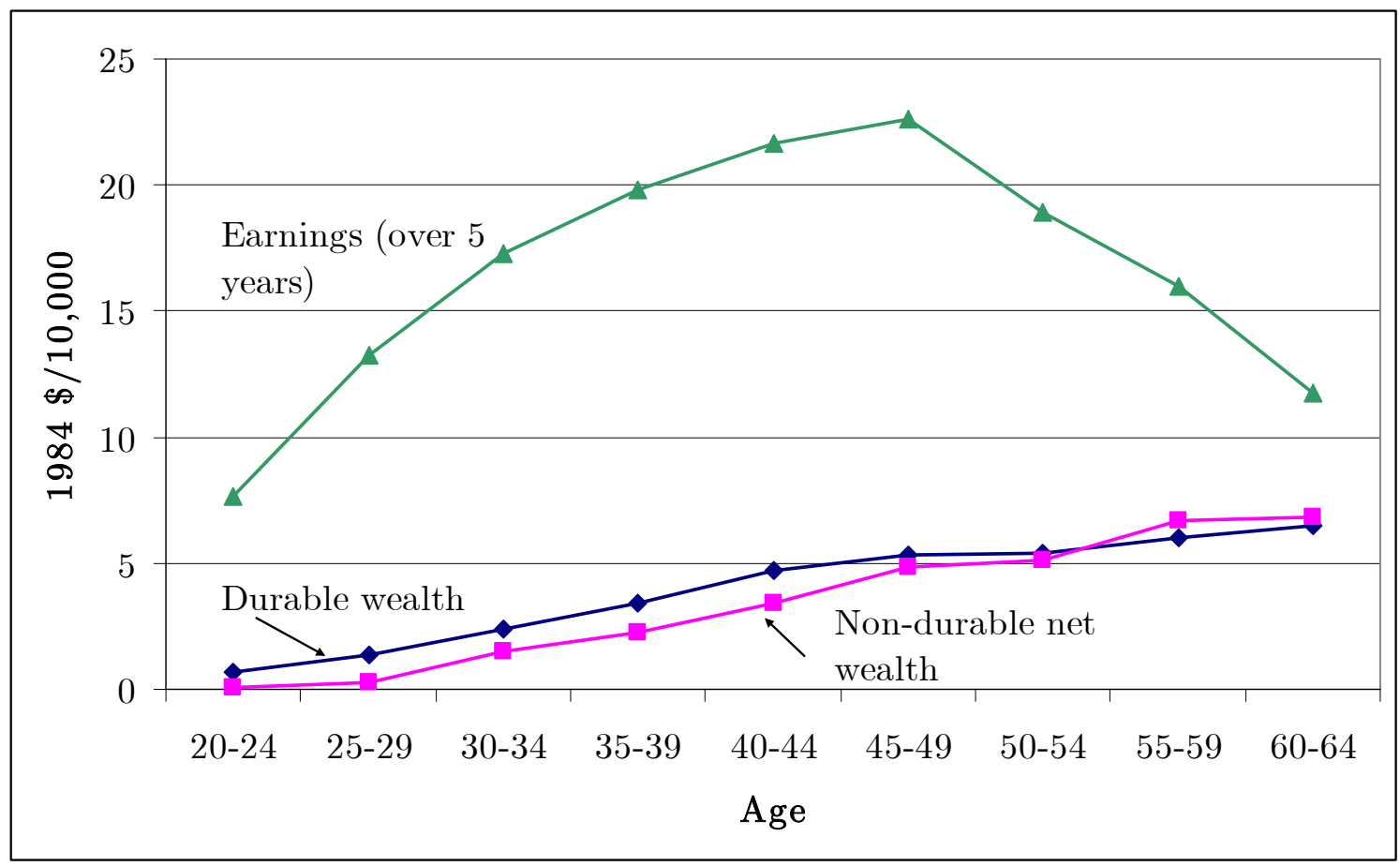


Table 4: Estimated Parameters

\begin{tabular}{|c|c|c|c|}
\hline & & $\begin{array}{l}\text { Point } \\
\text { Estimate }\end{array}$ & $\begin{array}{l}\text { Standard } \\
\text { Error }\end{array}$ \\
\hline Preference parameters & $\begin{array}{l}\text { beta (transformed in annual discount factor) } \\
\text { sigma (CRRA coeff.) type } 1 \\
\text { sigma (CRRA coeff.) type } 2 \\
\text { teta (consumption share) } \\
\text { st. deviation of shock to utility } \\
\text { ah (bequest motive) } \\
\text { ad (bequest motive) } \\
\text { cost of default (stigma) - type } 1 \\
\text { cost of default (stigma) - type } 2 \\
\end{array}$ & $\begin{array}{l}0.9321 \\
1.6481 \\
1.6519 \\
0.9784 \\
1.0232 \\
0.0437 \\
0.9512 \\
0.0201 \\
0.0049\end{array}$ & $\begin{array}{l}0.0003 \\
0.0048 \\
0.0051 \\
0.0002 \\
0.0003 \\
0.0003 \\
0.0028 \\
0.0003 \\
0.0001\end{array}$ \\
\hline $\begin{array}{l}\text { Parameters } \\
\text { that characterize the economy }\end{array}$ & $\begin{array}{l}\text { depreciation rate } \\
\text { interest rate (annual) }\end{array}$ & $\begin{array}{l}0.0035 \\
0.0178 \\
\end{array}$ & $\begin{array}{r}-0.0005 \\
0.0002 \\
\end{array}$ \\
\hline Earnings process & 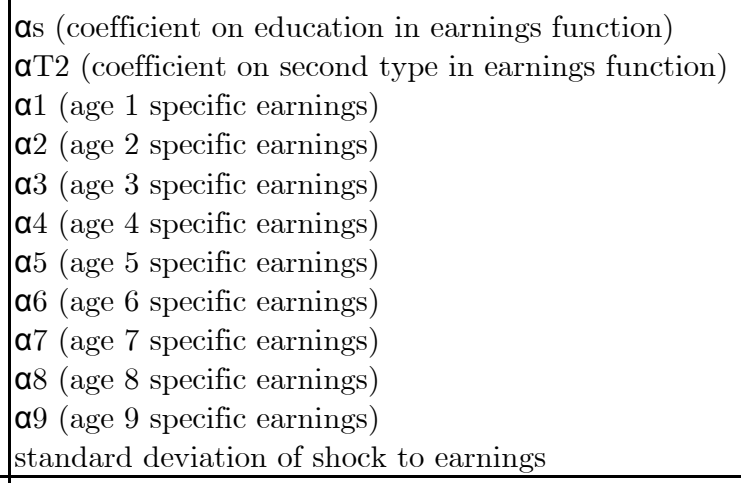 & $\begin{array}{r}0.1235 \\
-0.5346 \\
0.6529 \\
1.0803 \\
1.3359 \\
1.3812 \\
1.4513 \\
1.5240 \\
1.4459 \\
1.3782 \\
0.8467 \\
0.3774 \\
\end{array}$ & $\begin{array}{l}0.0004 \\
0.0033 \\
0.0233 \\
0.0076 \\
0.0061 \\
0.0064 \\
0.0061 \\
0.0070 \\
0.0073 \\
0.0076 \\
0.0062 \\
0.0021\end{array}$ \\
\hline Initial assets functions & $\begin{array}{l}\Psi 0 \text { (intercept in function of initial } \mathrm{h}) \\
\Psi \mathrm{a} \text { (coeff. on age at marriage) } \\
\Psi \mathrm{s} \text { (coeff. on education) } \\
\Psi 2 \text { (coeff. on type } 2) \\
\beta 0 \text { (intercept in function of initial d) } \\
\beta \mathrm{a} \text { (coeff. on age at marriage) } \\
\beta \mathrm{s} \text { (coeff. on education) } \\
\beta 2 \text { (coeff. on type } 2) \\
\sigma \mathrm{h} \text { (st. deviation random component of initial h) } \\
\sigma \mathrm{hd} \text { (correlation between initial d and initial h) } \\
\sigma \mathrm{d} \text { (st. deviation random component of initial d) }\end{array}$ & $\begin{array}{r}-15.2731 \\
2.0465 \\
0.2124 \\
-0.1503 \\
-0.7225 \\
0.1591 \\
0.1159 \\
-0.3126 \\
4.9003 \\
1.2134 \\
0.2377 \\
\end{array}$ & $\begin{array}{l}0.5186 \\
0.1151 \\
0.0091 \\
0.0694 \\
0.0154 \\
0.0084 \\
0.0021 \\
0.0132 \\
0.2620 \\
0.0280 \\
0.0144 \\
\end{array}$ \\
\hline Measurement error processes & $\begin{array}{l}\sigma_{-} \text {h0 } \\
\sigma_{-} \mathrm{h} 1 \\
\sigma_{-} \mathrm{b} 0 \\
\sigma_{-} \mathrm{b} 1 \\
\sigma_{-} \mathrm{y} 0 \\
\sigma_{-} \mathrm{y} 1 \\
\varphi 0 \\
\varphi 1\end{array}$ & $\begin{array}{r}0.0826 \\
0.5509 \\
0.0002 \\
0.9919 \\
0.6828 \\
-0.0318 \\
-4.7571 \\
3.0150 \\
\end{array}$ & $\begin{array}{l}0.0085 \\
0.0119 \\
0.0000 \\
0.0159 \\
0.0120 \\
0.0057 \\
0.1549 \\
0.2556 \\
\end{array}$ \\
\hline Type Probability & $\begin{array}{l}\text { Y01 (coeff. in type probability) } \\
\text { Ys1 (coeff. on education in type probability) } \\
\text { Y21 (coeff. on second exemption group in type prob.) } \\
\text { Y31 (coeff. on third exemption group in type prob.) } \\
\text { Y41 (coeff. on fourth exemption group in type prob.) }\end{array}$ & $\begin{array}{r}-1.3036 \\
0.0441 \\
1.1501 \\
3.0151 \\
-0.2230\end{array}$ & $\begin{array}{l}0.0153 \\
0.0008 \\
0.0460 \\
0.0757 \\
0.0192\end{array}$ \\
\hline
\end{tabular}


Table 5: Data Fit of the Model

\begin{tabular}{|c|c|c|c|c|}
\hline & \multicolumn{2}{|l|}{ Data $(1984 \$)$} & \multicolumn{2}{|l|}{ Model } \\
\hline & All economy & Defaulters & All economy & Defaulters \\
\hline $\begin{array}{l}\text { Mean household earnings (over } 5 \\
\text { years) }\end{array}$ & $\begin{array}{l}\$ 181,600 \text { (st.dev. } \\
\$ 109,800)\end{array}$ & $\$ 133,200$ & $\begin{array}{l}\$ 180,800 \text { (st.dev. } \\
\$ 144,900)\end{array}$ & $\$ 146,300$ \\
\hline Mean durable wealth & $\begin{array}{l}\$ 40,500 \text { (st.dev. } \\
\$ 43,600) \\
\text { median: } \$ 27,700\end{array}$ & $\$ 17,200$ & $\begin{array}{l}\$ 38,100 \text { (st.dev. } \\
\$ 43,500) \\
\text { median: } \$ 24,300\end{array}$ & $\$ 14,200$ \\
\hline Mean non-durable net wealth & $\begin{array}{l}\$ 32,600 \text { (st.dev. } \\
\$ 85,100) \\
\text { median: } \$ 2,900\end{array}$ & $\$ 3,400$ & $\begin{array}{l}\$ 45,800 \text { (st.dev. } \\
\$ 120,700) \\
\text { median: } \$ 4,200\end{array}$ & $(\$ 2,000)$ \\
\hline$\%$ Negative wealth in sample & $29.70 \%$ & & $32.70 \%$ & \\
\hline Mean durables at marriage & $\$ 10,400$ & & $\$ 9,100$ & \\
\hline $\begin{array}{l}\text { Mean non-durable net wealth at } \\
\text { marriage }\end{array}$ & $\$ 14,200$ & & $\$ 11,600$ & \\
\hline Mean Default Rate & $2.11 \%$ & & $2.82 \%$ & \\
\hline
\end{tabular}


Figure 4: Cumulative distribution of Earnings, Non-Durable Net Wealth and Durable Wealth, observed versus simulated data
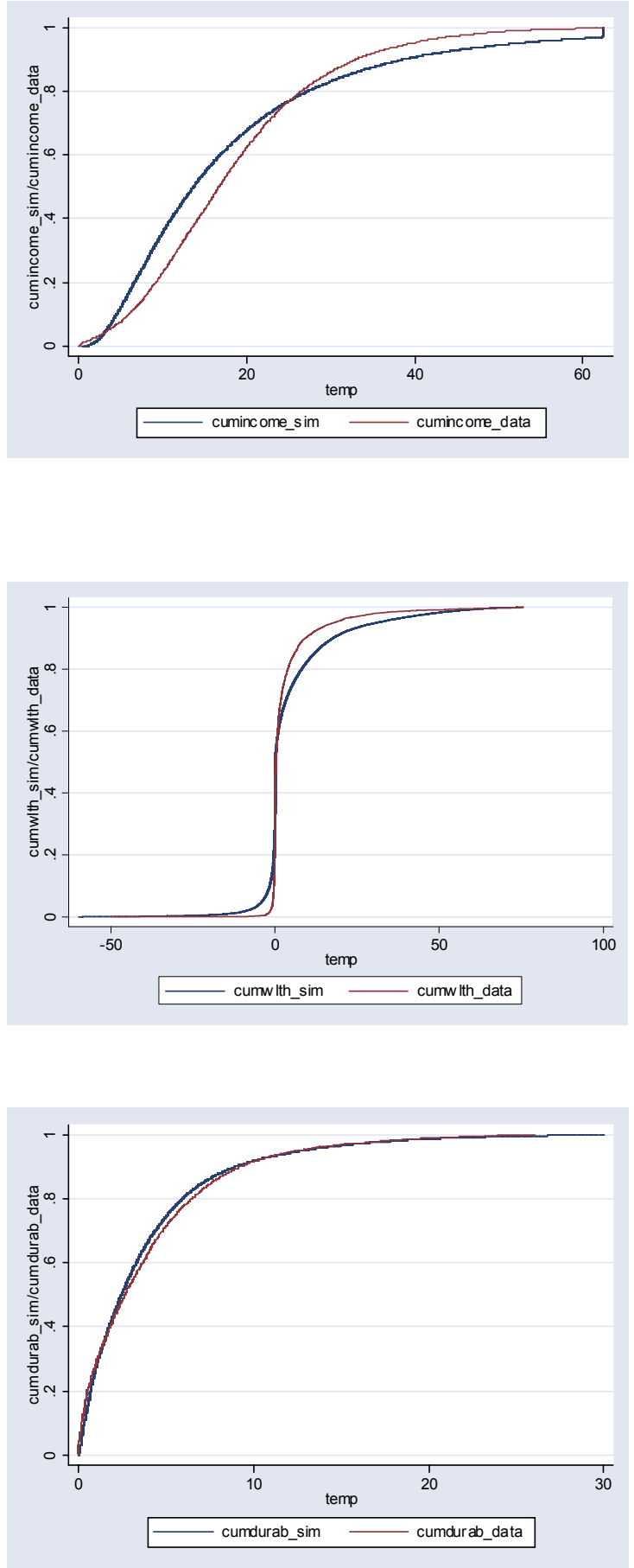
Figure 5: Actual and predicted mean durable and non-durable net wealth, labor earnings and default rates over the life cycle*
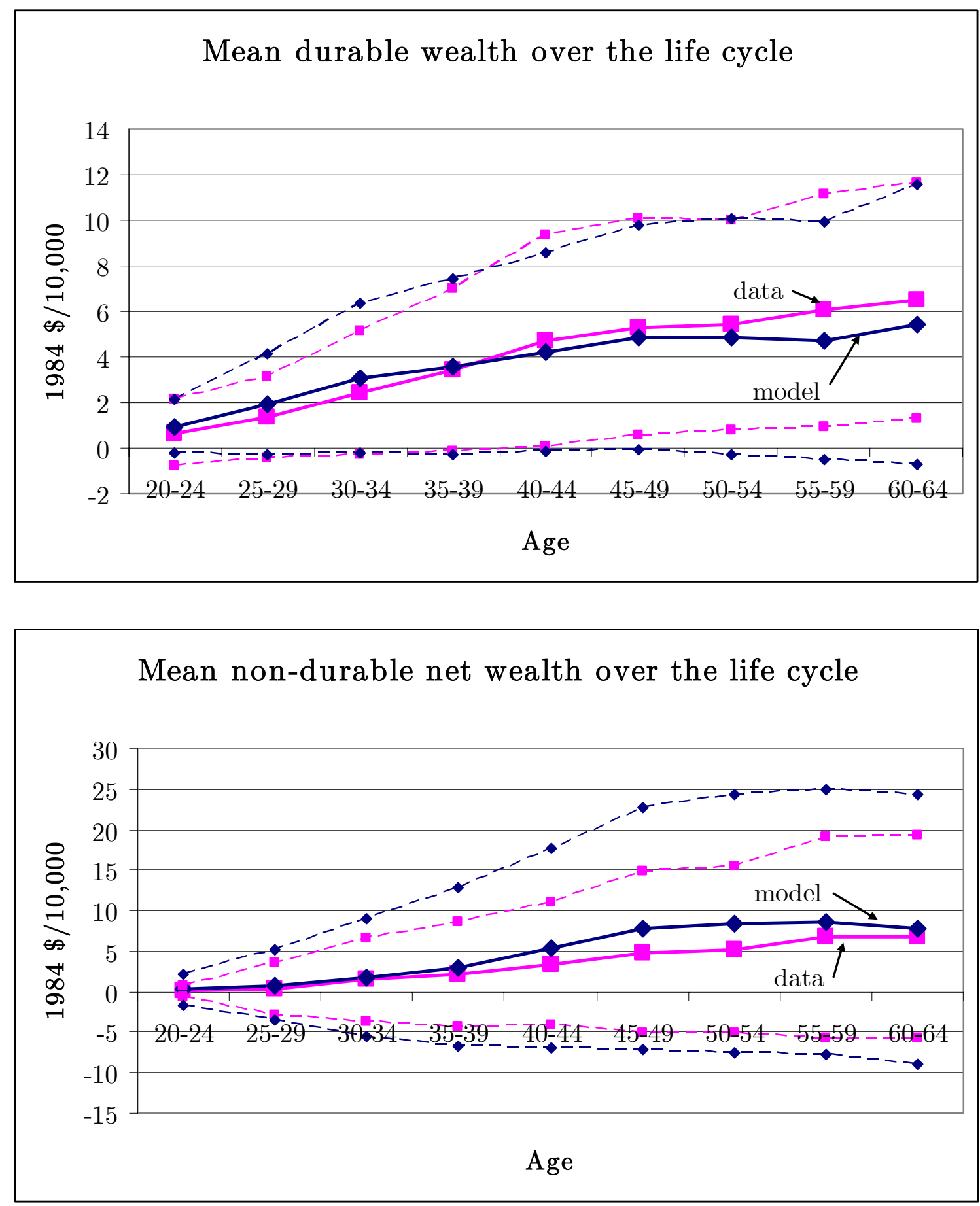

* the intervals are constructed adding and subtracting one standard deviation from the mean. 
Figure 5 (continued): Actual and predicted mean durable and non-durable net wealth, labor earnings and default rates over the life cycle*
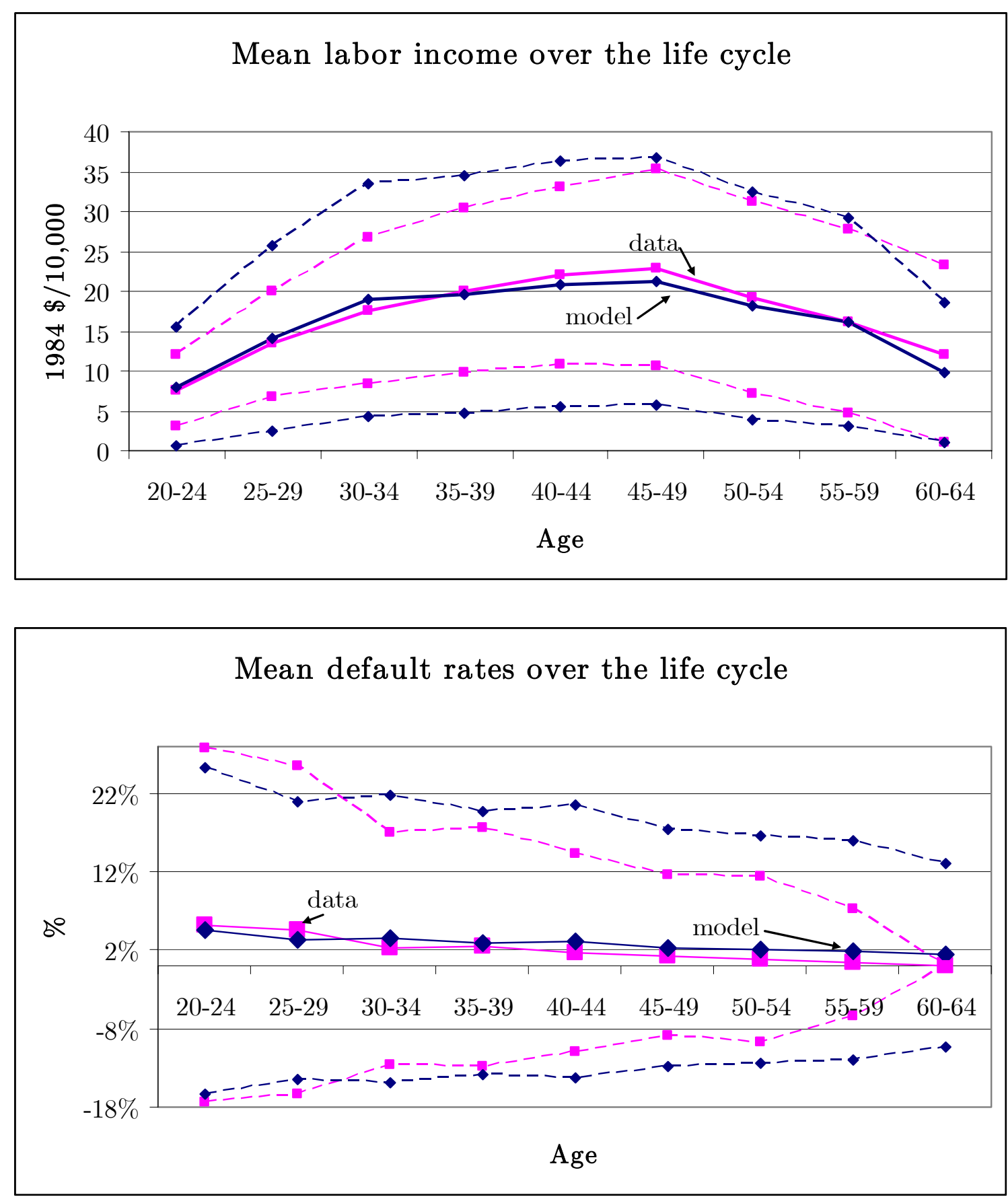

* the intervals are constructed adding and subtracting one standard deviation from the mean. 
Table 6: Data fit by education groups

Mean durable wealth $(\$ / 10,000,1984$ real value $)$

\begin{tabular}{|l|r|r|r|r|r|r|r|r|}
\hline \hline & \multicolumn{2}{l}{$\begin{array}{l}\text { High School } \\
\text { Drop-out }\end{array}$} & \multicolumn{2}{l|}{ High School } & \multicolumn{2}{l|}{ Some College } & \multicolumn{2}{l|}{ College or more } \\
\cline { 2 - 9 } A g e & \multicolumn{1}{|l|}{ D ata } & Model & D a ta & Model & D ata & Model & Data & Model \\
\hline \hline $20-29$ & 0.64 & 1.01 & 1.13 & 1.62 & $1.4^{*}$ & 2.20 & $1.16^{*}$ & 3.12 \\
$30-39$ & 1.46 & 1.87 & 2.51 & 2.83 & 3.31 & 3.62 & 4.17 & 4.88 \\
$40-49$ & 2.75 & 2.62 & 4.22 & 3.86 & 5.70 & 4.95 & 7.11 & 6.25 \\
$50-59$ & 3.61 & 3.09 & 5.40 & 4.78 & 6.95 & 6.36 & 8.43 & 7.41 \\
$60-64$ & 4.22 & 3.32 & 6.63 & 5.97 & $7.79 *$ & 7.73 & $11.07^{*}$ & 9.47 \\
\hline
\end{tabular}

Mean non-durable net wealth $(\$ / 10,000,1984$ real value $)$

\begin{tabular}{|c|c|c|c|c|c|c|c|c|}
\hline \multirow[b]{2}{*}{ A g e } & \multicolumn{2}{|c|}{$\begin{array}{l}\text { High School } \\
\text { Drop-out }\end{array}$} & \multicolumn{2}{|c|}{ High School } & \multicolumn{2}{|c|}{ Som e College } & \multicolumn{2}{|c|}{ College or more } \\
\hline & $\overline{\mathrm{D} \text { ata }}$ & $\overline{\mathrm{TM} \text { odel }}$ & D ata & $\overline{\mathrm{M} \text { odel }}$ & Data & M odel & Data & M odel \\
\hline $20-29$ & 0.04 & 0.58 & 0.11 & 0.76 & $0.81^{*}$ & 0.86 & $0.05^{*}$ & 0.83 \\
\hline $30-39$ & 0.44 & 1.50 & 1.35 & 2.14 & 2.44 & 2.80 & 3.15 & 3.22 \\
\hline $40-49$ & 1.34 & 3.16 & 3.10 & 5.09 & 3.76 & 7.57 & 7.57 & 9.63 \\
\hline $50-59$ & 2.27 & 4.56 & 5.27 & 8.44 & 7.70 & 11.89 & 12.15 & 14.68 \\
\hline $60-64$ & 2.77 & 3.53 & 6.64 & 8.58 & $9.66^{*}$ & 12.72 & $15.71^{*}$ & 16.31 \\
\hline
\end{tabular}

Mean earnings $(\$ / 10,000,1984$ real value $)$

\begin{tabular}{|c|c|c|c|c|c|c|c|c|}
\hline \multirow[b]{2}{*}{$\mathrm{Age}$} & \multicolumn{2}{|c|}{$\begin{array}{l}\text { High School } \\
\text { Drop-out }\end{array}$} & \multicolumn{2}{|c|}{ High School } & \multicolumn{2}{|c|}{ Som e College } & \multicolumn{2}{|c|}{ College or more } \\
\hline & D ata & M odel & D ata & M odel & Data & M odel & D ata & M odel \\
\hline $20-29$ & 8.63 & 8.17 & 111.47 & $\overline{12.36}$ & $113.34^{*}$ & 16.27 & $17.43^{*}$ & 20.61 \\
\hline $30-39$ & 12.03 & 12.05 & 16.20 & 16.86 & 19.62 & 21.29 & 25.55 & 26.77 \\
\hline $40-49$ & 13.70 & 12.98 & 19.55 & 18.70 & 24.05 & 23.55 & 31.06 & 27.98 \\
\hline $50-59$ & 11.77 & 11.88 & 16.49 & 17.09 & 21.10 & 21.67 & 28.35 & 25.49 \\
\hline $60-64$ & 8.25 & 7.17 & 11.87 & 10.07 & $15.07 *$ & 12.45 & $22.38^{*}$ & 15.36 \\
\hline
\end{tabular}

Mean Default

\begin{tabular}{|l|r|r|r|r|r|r|r|r|}
\hline \hline & \multicolumn{2}{l|}{$\begin{array}{l}\text { High School } \\
\text { D rop-out }\end{array}$} & \multicolumn{2}{l|}{ High School } & \multicolumn{2}{l|}{ Some College } & \multicolumn{2}{l|}{ College or more } \\
\cline { 2 - 8 } A ge & D ata & M odel & D a ta & Model & D ata & M odel & D a ta & M odel \\
\hline \hline $20-29$ & $7.9 \%$ & $5.0 \%$ & $5.1 \%$ & $3.5 \%$ & $2.1 \% *$ & $2.6 \%$ & $1.6 \% *$ & $1.9 \%$ \\
$30-39$ & $4.5 \%$ & $3.7 \%$ & $3.2 \%$ & $3.4 \%$ & $2.9 \%$ & $3.1 \%$ & $0.5 \%$ & $2.7 \%$ \\
$40-49$ & $2.1 \%$ & $3.2 \%$ & $1.4 \%$ & $2.9 \%$ & $1.7 \%$ & $2.6 \%$ & $0.0 \%$ & $2.5 \%$ \\
$50-59$ & $1.2 \%$ & $2.3 \%$ & $1.2 \%$ & $2.1 \%$ & $0.0 \%$ & $1.8 \%$ & $0.6 \%$ & $1.7 \%$ \\
$60-64$ & $0.0 \%$ & $1.6 \%$ & $0.0 \%$ & $1.4 \%$ & $0 \% *$ & $1.2 \%$ & $0 \% *$ & $1.0 \%$ \\
\hline
\end{tabular}

*Cell has less than 100 observations. 
Table 7: Data Fit by Exemption groups

Mean durable wealth $(\$ / 10,000,1984$ real value $)$

\begin{tabular}{|c|c|c|c|c|c|c|c|c|}
\hline \multirow[b]{2}{*}{ Age } & \multicolumn{2}{|c|}{ Exempt $<=\$ 15,000$} & \multicolumn{2}{|c|}{$\begin{array}{l}\text { Exempt }>\$ 15,000 \text { and } \\
<=\$ 40,000\end{array}$} & \multicolumn{2}{|c|}{ Exempt $>\$ 40,000$} & \multicolumn{2}{|c|}{$\begin{array}{l}\text { Unlimited } \\
\text { Exemption }\end{array}$} \\
\hline & Data & Model & Data & Model & Data & Model & Data & $\overline{\text { Model }}$ \\
\hline $20-29$ & $\mid 1.14$ & 1.80 & 1.29 & 1.84 & 1.68 & 1.96 & 1.05 & 1.43 \\
\hline $30-39$ & 2.54 & 3.23 & 3.04 & 3.46 & 3.89 & 3.69 & 2.64 & 2.81 \\
\hline $40-49$ & 4.10 & 4.11 & 5.63 & 4.77 & 6.93 & 5.44 & 4.34 & 3.98 \\
\hline $50-59$ & 4.89 & 4.27 & 6.82 & 5.33 & 7.11 & 5.95 & 4.70 & 4.35 \\
\hline $60-64$ & 5.09 & 4.50 & 7.63 & 6.12 & $8 *$ & 6.88 & $5.95^{*}$ & 4.89 \\
\hline
\end{tabular}

Mean non-durable net wealth $(\$ / 10,000,1984$ real value $)$

\begin{tabular}{|c|c|c|c|c|c|c|c|c|}
\hline \multirow[b]{2}{*}{ Age } & \multicolumn{2}{|c|}{ Exempt $<=\$ 15,000$} & \multicolumn{2}{|c|}{$\begin{array}{l}\text { Exempt }>\$ 15,000 \text { and } \\
<=\$ 40,000\end{array}$} & \multicolumn{2}{|c|}{ Exempt $>\$ 40,000$} & \multicolumn{2}{|c|}{$\begin{array}{l}\text { Unlimited } \\
\text { Exemption }\end{array}$} \\
\hline & Data & Model & Data & Model & Data & Model & Data & Model \\
\hline $20-29$ & 0.23 & 0.59 & -0.01 & 0.82 & 0.49 & 0.91 & 0.62 & 0.88 \\
\hline $30-39$ & 1.61 & 1.84 & 1.80 & 2.66 & 2.36 & 3.40 & 2.20 & 2.50 \\
\hline $40-49$ & 3.22 & 5.25 & 4.46 & 7.09 & 5.45 & 8.98 & 4.06 & 5.98 \\
\hline $50-59$ & 5.18 & 7.12 & 6.67 & 9.77 & 5.45 & 11.09 & 6.80 & 7.87 \\
\hline $60-64$ & 6.03 & 5.95 & 7.55 & 9.17 & $5.56^{*}$ & 10.61 & $8.64^{*}$ & 6.63 \\
\hline
\end{tabular}

Mean earnings $(\$ / 10,000,1984$ real value $)$

\begin{tabular}{|c|c|c|c|c|c|c|c|c|}
\hline \multirow[b]{2}{*}{ Age } & \multicolumn{2}{|c|}{ Exempt $<=\$ 15,000$} & \multicolumn{2}{|c|}{$\begin{array}{l}\text { Exempt }>\$ 15,000 \text { and } \\
<=\$ 40,000\end{array}$} & \multicolumn{2}{|c|}{ Exempt $>\$ 40,000$} & \multicolumn{2}{|c|}{$\begin{array}{l}\text { Unlimited } \\
\text { Exemption }\end{array}$} \\
\hline & Data & Model & Data & Model & Data & Model & Data & Model \\
\hline $20-29$ & 12.82 & 12.04 & 12.13 & 14.18 & 12.42 & 16.12 & 13.01 & 11.80 \\
\hline $30-39$ & 18.20 & 17.21 & 19.24 & 20.41 & 19.57 & 23.60 & 18.84 & 17.97 \\
\hline $40-49$ & 21.27 & 18.82 & 23.15 & 22.52 & 24.81 & 26.22 & 21.62 & 19.55 \\
\hline $50-59$ & 17.51 & 15.50 & 19.01 & 18.49 & 17.12 & 21.07 & 17.04 & 16.07 \\
\hline $60-64$ & 11.14 & 8.59 & 13.38 & 10.37 & $11.87^{*}$ & 12.04 & $12.32^{*}$ & 8.92 \\
\hline
\end{tabular}

Mean Default

\begin{tabular}{|c|c|c|c|c|c|c|c|c|}
\hline \multirow[b]{2}{*}{ Age } & \multicolumn{2}{|c|}{ Exempt $<=\$ 15,000$} & \multicolumn{2}{|c|}{$\begin{array}{l}\text { Exempt }>\$ 15,000 \text { and } \\
<=\$ 40,000\end{array}$} & \multicolumn{2}{|c|}{ Exempt $>\$ 40,000$} & \multicolumn{2}{|c|}{$\begin{array}{l}\text { Unlimited } \\
\text { Exemption }\end{array}$} \\
\hline & Data & Model & Data & Model & Data & Model & Data & $\overline{\text { Model }}$ \\
\hline $20-29$ & $6.05 \%$ & $3.95 \%$ & $2.16 \%$ & $3.09 \%$ & $4.00 \%$ & $2.07 \%$ & $6.12 \%$ & $3.91 \%$ \\
\hline $30-39$ & $2.50 \%$ & $3.56 \%$ & $2.60 \%$ & $2.99 \%$ & $2.18 \%$ & $1.73 \%$ & $1.30 \%$ & $4.31 \%$ \\
\hline $40-49$ & $0.98 \%$ & $3.06 \%$ & $1.21 \%$ & $2.53 \%$ & $1.26 \%$ & $1.36 \%$ & $3.07 \%$ & $3.95 \%$ \\
\hline $50-59$ & $0.27 \%$ & $2.18 \%$ & $0.92 \%$ & $1.92 \%$ & $1.52 \%$ & $1.24 \%$ & $1.36 \%$ & $2.76 \%$ \\
\hline $60-64$ & $0.00 \%$ & $1.31 \%$ & $0.00 \%$ & $1.43 \%$ & $0 \% *$ & $1.15 \%$ & $0 \% *$ & $1.78 \%$ \\
\hline
\end{tabular}

*Cell has less than 100 observations. 
Table 8: Regressions of Durable Wealth on Individual Characteristics and Exemption Levels, Model versus Data

Dependent variable: Durable wealth (1984 real \$/10,000)

\begin{tabular}{|l|r|r|r|r|}
\multicolumn{2}{|c}{ Data } & \multicolumn{3}{c|}{ Model } \\
\hline Independent variable & Coefficient & Std. Error & Coefficient & Std. Error \\
\hline \hline Intercept & -8.06 & 0.33 & -8.64 & 0.32 \\
Years of schooling & 0.53 & 0.02 & 0.63 & 0.02 \\
Age group at marriage & -0.44 & 0.04 & -0.38 & 0.03 \\
Age group & 1.38 & 0.10 & 1.78 & 0.10 \\
Age group squared & -0.04 & 0.01 & -0.11 & 0.01 \\
Exemption(1-dummy) & 0.30 & 0.02 & 0.11 & 0.02 \\
dummy unlimited & 0.02 & 0.13 & -0.42 & 0.13 \\
\hline R-Squared & 0.26 & & 0.16 & \\
\hline F-value & 414.84 & & 332.76 & \\
\hline
\end{tabular}




\begin{tabular}{|c|c|c|c|c|c|}
\hline 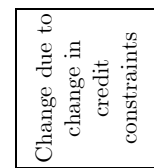 & 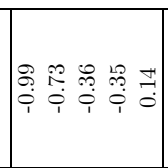 & 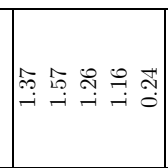 & | & 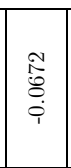 & $\begin{array}{l}\text { 递 } \\
\text { is }\end{array}$ \\
\hline 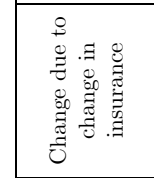 & 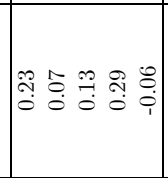 & 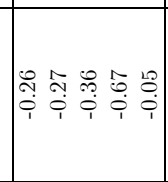 & | & 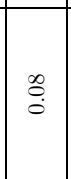 & 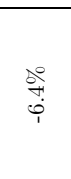 \\
\hline 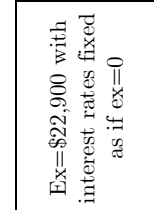 & 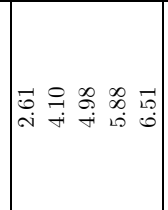 & 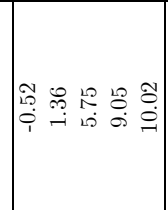 & $\mid$ & 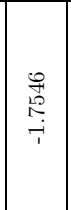 & 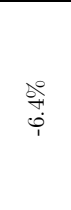 \\
\hline 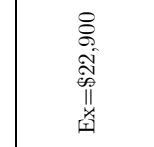 & 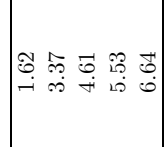 & 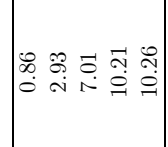 & $\mid$ & 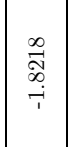 & 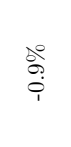 \\
\hline $\begin{array}{l}\text { II } \\
\text { 苗 }\end{array}$ & 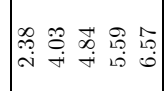 & 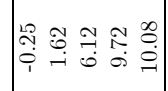 & 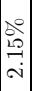 & 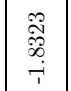 & \\
\hline 总 & 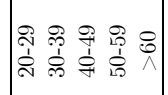 & 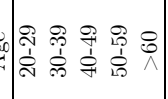 & $\mid$ & & \\
\hline & 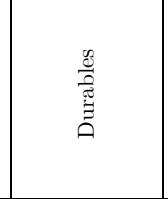 & 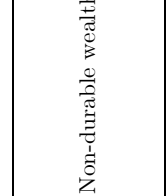 & 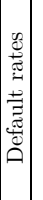 & 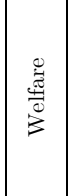 & $\begin{array}{ll}0 \\
0\end{array}$ \\
\hline 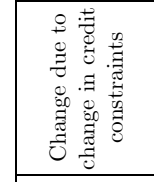 & 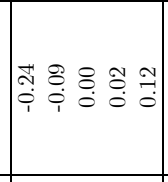 & 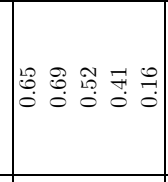 & 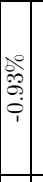 & $\begin{array}{l}\stackrel{8}{0} \\
\stackrel{0}{0} \\
\stackrel{i}{i}\end{array}$ & 兽 \\
\hline 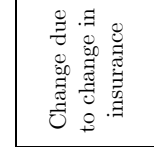 & 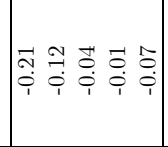 & 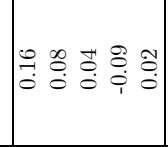 & $\mid$ & $\begin{array}{l}\stackrel{\infty}{9} \\
\stackrel{0}{0} \\
\stackrel{0}{0}\end{array}$ & बू. \\
\hline 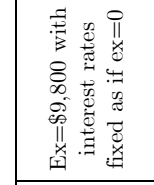 & 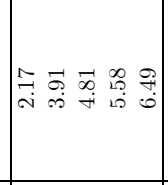 & 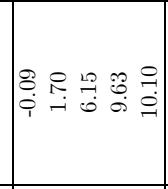 & 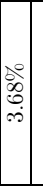 & 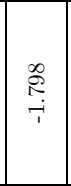 & ๙ু \\
\hline 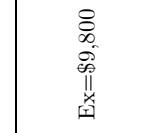 & 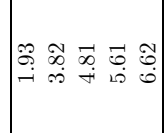 & 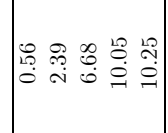 & 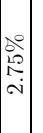 & 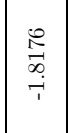 & $\stackrel{\circ}{\stackrel{\circ}{\dagger}}$ \\
\hline $\begin{array}{l}0 \\
\text { 崮 }\end{array}$ & 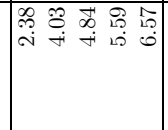 & 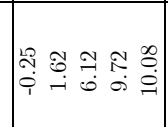 & 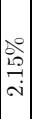 & 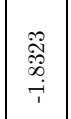 & \\
\hline 总 & 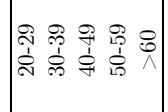 & 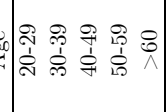 & 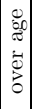 & & \\
\hline & 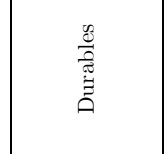 & 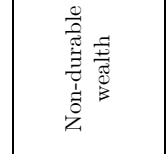 & $\mid$ & 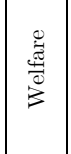 & 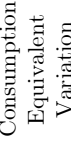 \\
\hline
\end{tabular}

\begin{tabular}{|c|c|c|c|c|c|}
\hline 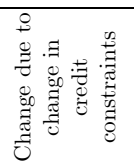 & 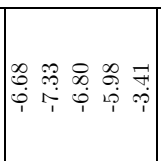 & 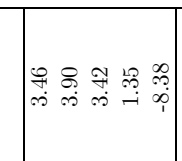 & $\mid$ & 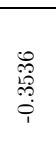 & 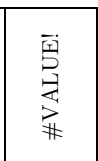 \\
\hline 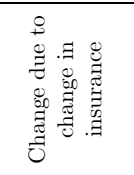 & 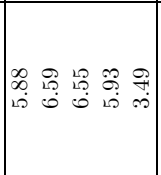 & 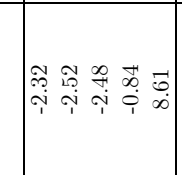 & $\left|\begin{array}{cc}0 \\
0 \\
12 \\
120\end{array}\right|$ & 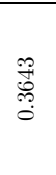 & 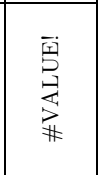 \\
\hline 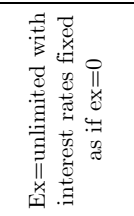 & $\mid$ & 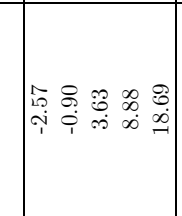 & : & 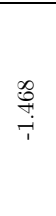 & 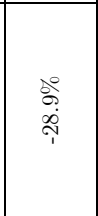 \\
\hline 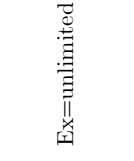 & 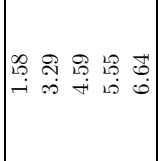 & 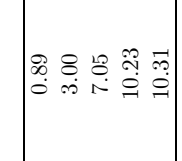 & 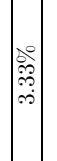 & 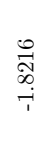 & 总 \\
\hline 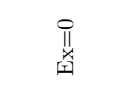 & 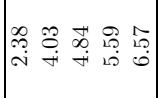 & 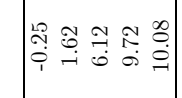 & 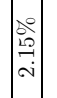 & 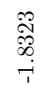 & \\
\hline 总 & 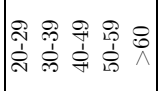 & 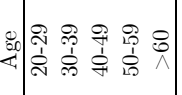 & $\mid$ & & \\
\hline & 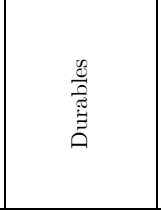 & 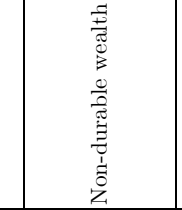 & 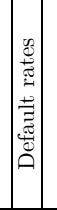 & 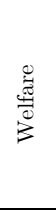 & 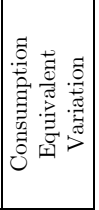 \\
\hline 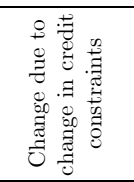 & 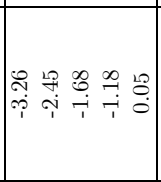 & 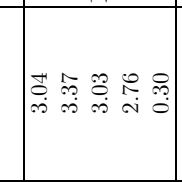 & $\mid$ & $\begin{array}{c}\stackrel{\infty}{0} \\
\stackrel{0}{\infty} \\
\stackrel{+}{i}\end{array}$ & 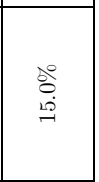 \\
\hline 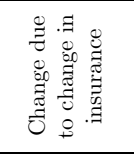 & 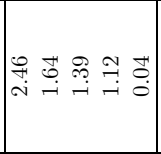 & 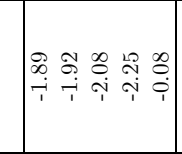 & $\mid$ & $\begin{array}{l}\vec{H} \\
\stackrel{9}{0} \\
0\end{array}$ & 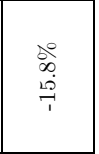 \\
\hline 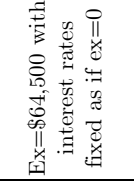 & 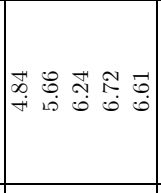 & 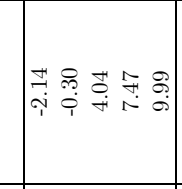 & 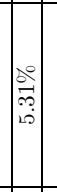 & 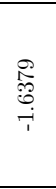 & 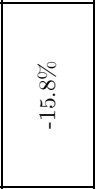 \\
\hline 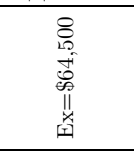 & 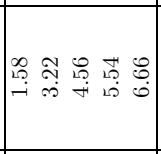 & $\mid$ & $\mid$ & 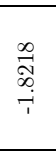 & 产 \\
\hline $\begin{array}{l}0 \\
\text { 畄 }\end{array}$ & 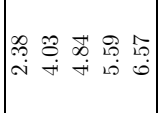 & 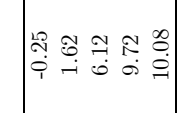 & 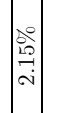 & 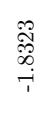 & \\
\hline \multirow[t]{2}{*}{ 遂 } & 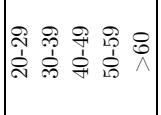 & 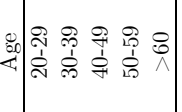 & $\mid$\begin{tabular}{l|} 
\\
0 \\
0 \\
0 \\
0 \\
$\vdots$ \\
$\vdots$
\end{tabular} & & \\
\hline & 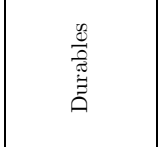 & 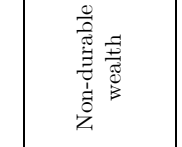 & 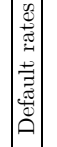 & 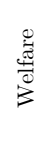 & 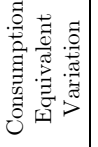 \\
\hline
\end{tabular}




\begin{tabular}{|c|c|c|c|c|c|}
\hline 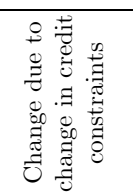 & 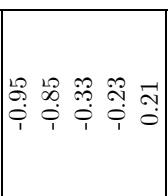 & 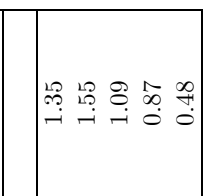 & $\mid$ & 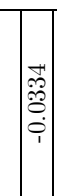 & 离 \\
\hline 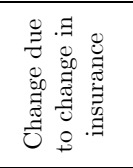 & 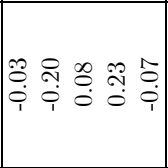 & 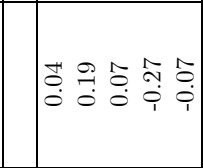 & $\mid$ & 章 & 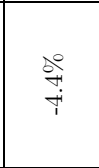 \\
\hline 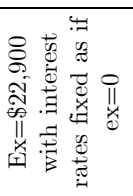 & 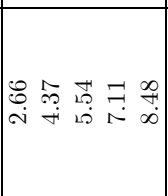 & 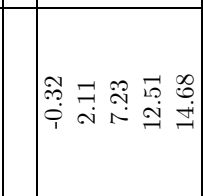 & $\left|\begin{array}{c}0 \\
0 \\
0 \\
\infty \\
\infty\end{array}\right|$ & 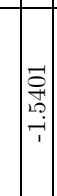 & 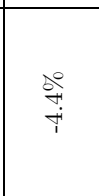 \\
\hline 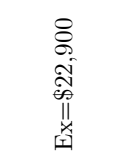 & 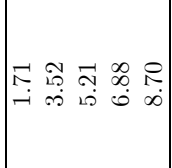 & 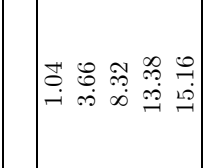 & $\left|\begin{array}{c}0 \\
0 \\
0 \\
\hdashline \\
-1\end{array}\right|$ & 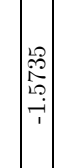 & 总 \\
\hline $\begin{array}{l}0 \\
\text { 离 } \\
\text { I }\end{array}$ & 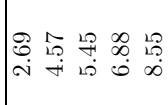 & 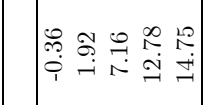 & 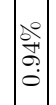 & 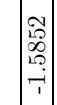 & $\stackrel{8}{\circ}$ \\
\hline$\frac{8}{4}$ & 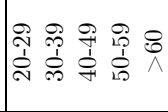 & 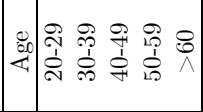 & $\left|\begin{array}{c}0 \\
0 \\
0 \\
\vdots \\
\vdots \\
\vdots \\
\vdots \\
\vdots\end{array}\right|$ & 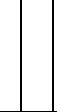 & \\
\hline & 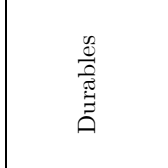 & 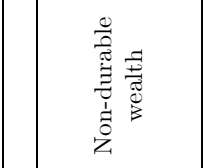 & 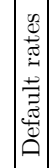 & 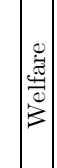 & 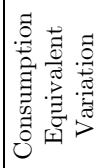 \\
\hline 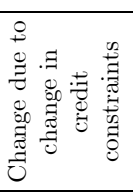 & 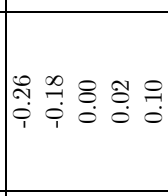 & 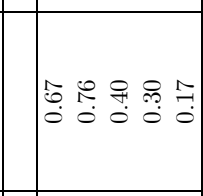 & 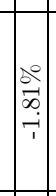 & $\begin{array}{l}\overrightarrow{1} \\
\overrightarrow{0} \\
0 \\
\dot{1}\end{array}$ & $\frac{5}{3}$ \\
\hline 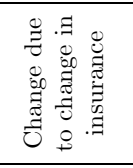 & 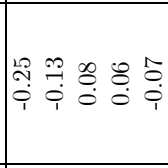 & 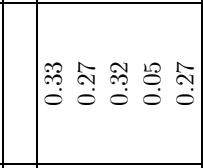 & 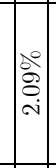 & : & 空 \\
\hline 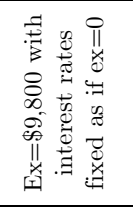 & 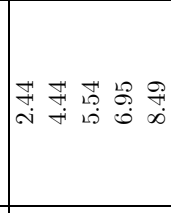 & 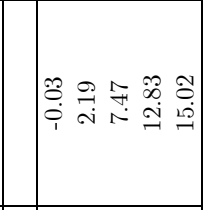 & 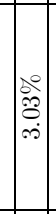 & $\mid$ & 究 \\
\hline $\begin{array}{l}8 \\
\infty \\
\infty \\
0 \\
0 \\
11 \\
1 \times 1 \\
0\end{array}$ & 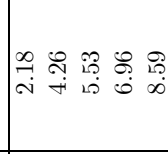 & 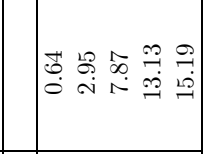 & 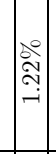 & 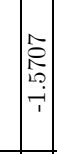 & 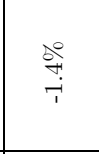 \\
\hline 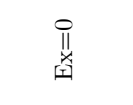 & 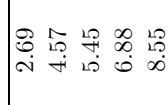 & 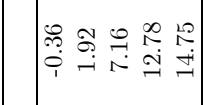 & $\mid$\begin{tabular}{c}
0 \\
\hdashline \\
$\vdots$ \\
0 \\
0 \\
0
\end{tabular} & $\mid \begin{array}{c}2 \\
2 \\
0 \\
2 \\
2 \\
-1 \\
-1\end{array}$ & : \\
\hline$\frac{8}{4}$ & 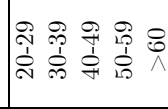 & 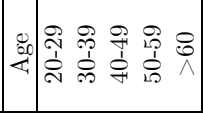 & 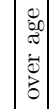 & & \\
\hline & 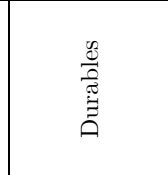 & 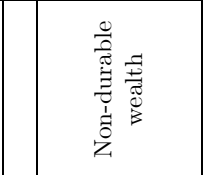 & 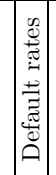 & 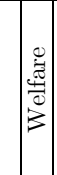 & 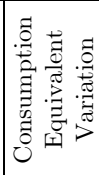 \\
\hline
\end{tabular}

\begin{tabular}{|c|c|c|c|c|c|}
\hline 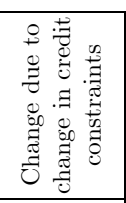 & 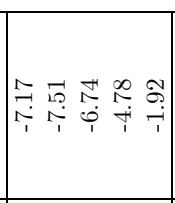 & 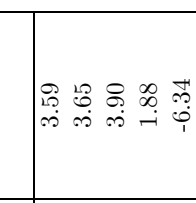 & 然 & $\left|\begin{array}{c}1 \\
1 \\
0 \\
0 \\
0 \\
i \\
1\end{array}\right|$ & 离 \\
\hline 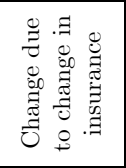 & 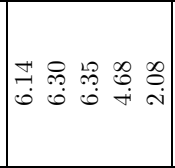 & 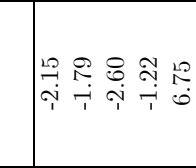 & $\left|\begin{array}{c}0 \\
0 \\
10 \\
0 \\
0\end{array}\right|$ & $\mid$ & 乲 \\
\hline 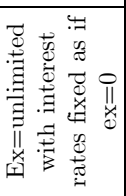 & 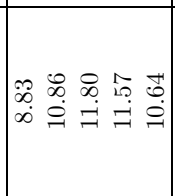 & 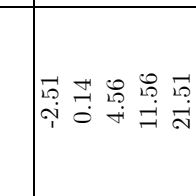 & $\mid$\begin{tabular}{c}
8 \\
7 \\
\hdashline \\
$i$
\end{tabular} & 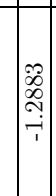 & 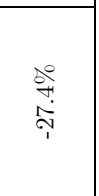 \\
\hline 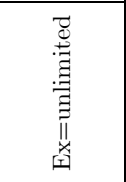 & 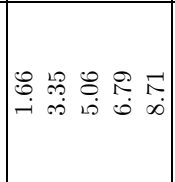 & 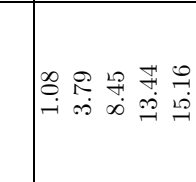 & $\mid$ & 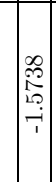 & $\stackrel{\text { so }}{\rightarrow}$ \\
\hline 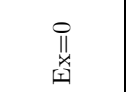 & 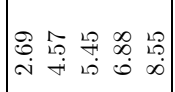 & 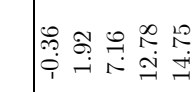 & 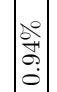 & $\mid$ & 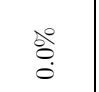 \\
\hline$\stackrel{8}{\stackrel{8}{4}}$ & 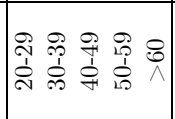 & 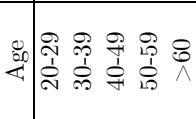 & $\mid \begin{array}{l}0 \\
0 \\
0 \\
0 \\
0 \\
0 \\
0 \\
0\end{array}$ & & \\
\hline & 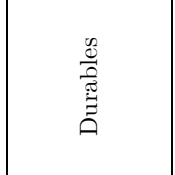 & 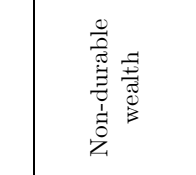 & 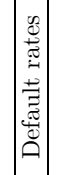 & 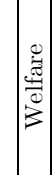 & 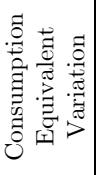 \\
\hline 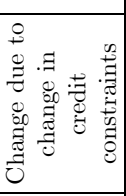 & 色 & 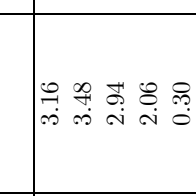 & $\left|\begin{array}{c}0 \\
0 \\
0 \\
\hdashline \\
\hdashline \\
\hdashline\end{array}\right|$ & 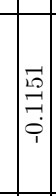 & $\stackrel{\circ}{\stackrel{\circ}{9}}$ \\
\hline 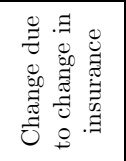 & 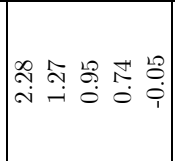 & 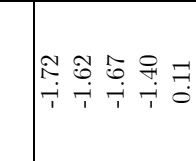 & $\mid \begin{array}{c}0 \\
\infty \\
\infty \\
\infty \\
\infty \\
\infty\end{array}$ & $\mid$ & 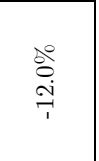 \\
\hline 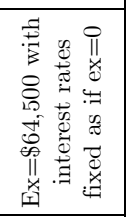 & 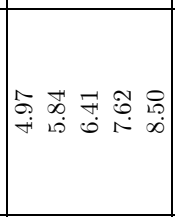 & 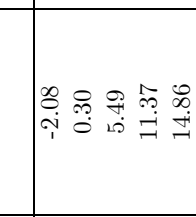 & 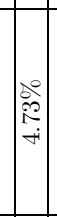 & $\mid$ & 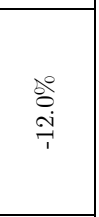 \\
\hline 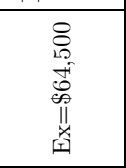 & 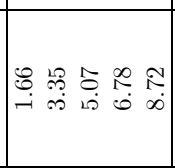 & 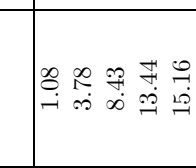 & $\mid$ & 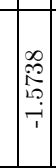 & $\stackrel{5}{\rightarrow}$ \\
\hline 䎡 & 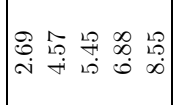 & 吊 & 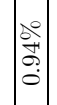 & 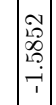 & 总 \\
\hline \multirow[t]{2}{*}{$\stackrel{8}{4}$} & 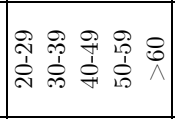 & 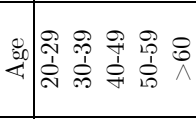 & $\mid \begin{array}{l}0 \\
0 \\
0 \\
0 \\
0 \\
\vdots \\
0 \\
\end{array}$ & & \\
\hline & 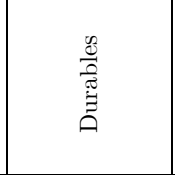 & 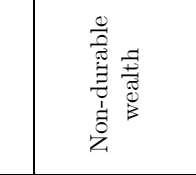 & 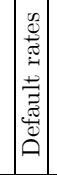 & 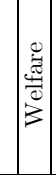 & 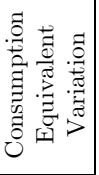 \\
\hline
\end{tabular}




\begin{tabular}{|c|c|c|c|c|c|}
\hline 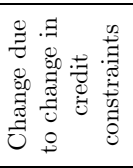 & 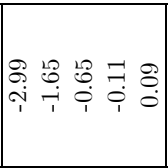 & 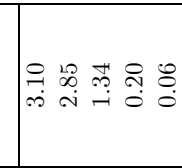 & $\mid$ & $\mid \begin{array}{c}0 \\
0 \\
0 \\
0 \\
0 \\
i\end{array}$ & $\stackrel{50}{i}$ \\
\hline 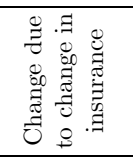 & 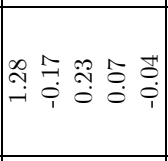 & 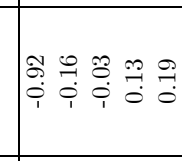 & 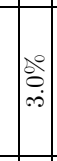 & 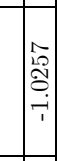 & $\begin{array}{l}b_{0}^{\circ} \\
\dot{0} \\
\dot{p}\end{array}$ \\
\hline 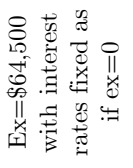 & 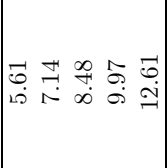 & 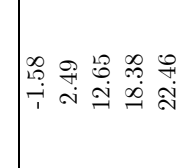 & 递 & 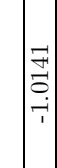 & $\begin{array}{l}\stackrel{8}{0} \\
\dot{\phi}\end{array}$ \\
\hline 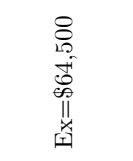 & 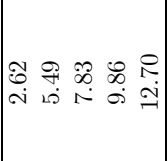 & 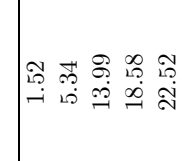 & 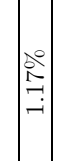 & $\begin{array}{l}\vec{H} \\
\stackrel{d}{0} \\
\dot{\rightarrow}\end{array}$ & 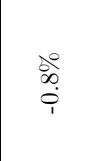 \\
\hline 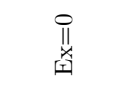 & 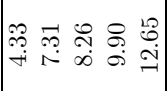 & 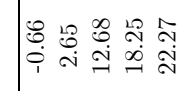 & $\mid$ & \begin{tabular}{|l}
$\overrightarrow{0}$ \\
0 \\
0 \\
$i$
\end{tabular} & g̊ \\
\hline$\frac{8}{4}$ & 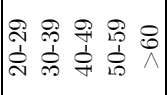 & 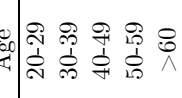 & 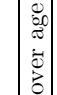 & 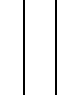 & \\
\hline & 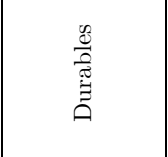 & 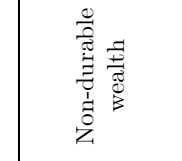 & 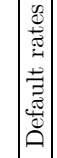 & 苛 & 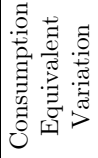 \\
\hline 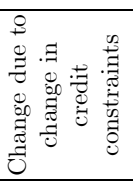 & 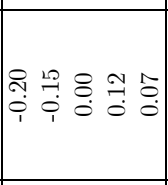 & 象 & $\left|\begin{array}{c}0 \\
\vdots \\
0 \\
\vdots \\
\vdots\end{array}\right|$ & 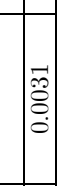 & $\begin{array}{l}\stackrel{b}{\circ} \\
\stackrel{i}{i}\end{array}$ \\
\hline 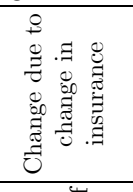 & 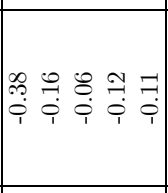 & 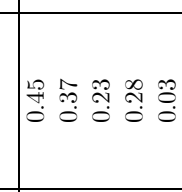 & $\mid$\begin{tabular}{c}
0 \\
\hdashline \\
\hdashline \\
\hdashline
\end{tabular} & 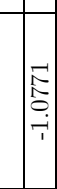 & $\begin{array}{l}\text { so } \\
\text { ì } \\
\text { i }\end{array}$ \\
\hline 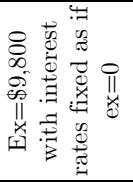 & 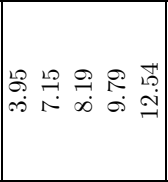 & 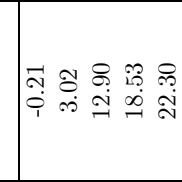 & $\mid$ & 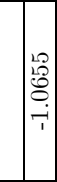 & $\begin{array}{l}\text { 余 } \\
\text { i }\end{array}$ \\
\hline 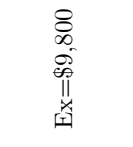 & 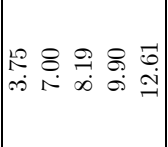 & 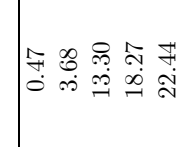 & $\mid$ & 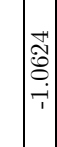 & $\stackrel{\Delta}{\rightarrow}$ \\
\hline 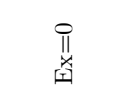 & 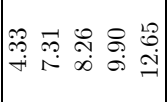 & 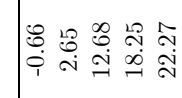 & $\mid$ & 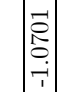 & 官 \\
\hline$\stackrel{\substack{0 \\
4}}{2}$ & 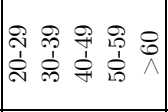 & 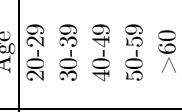 & 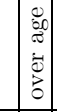 & & \\
\hline & 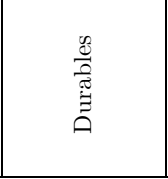 & 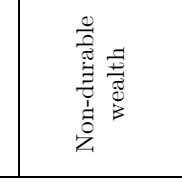 & 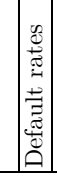 & 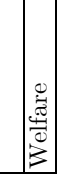 & 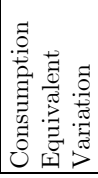 \\
\hline
\end{tabular}

\begin{tabular}{|c|c|c|c|c|c|}
\hline 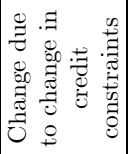 & 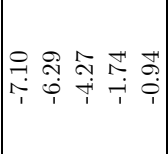 & $\mid$ & 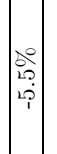 & 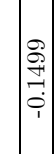 & 总 \\
\hline 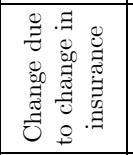 & 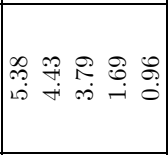 & 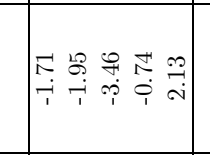 & $\mid$ & 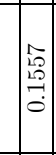 & 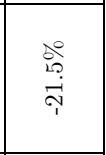 \\
\hline 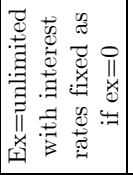 & 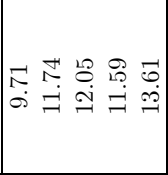 & 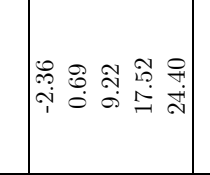 & $\mid$ & 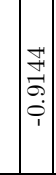 & 萬 \\
\hline 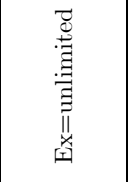 & 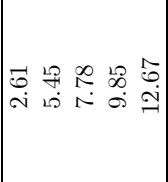 & 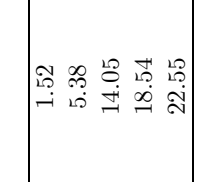 & $\mid$ & $\mid$ & $\begin{array}{l}\infty^{\circ} \\
\infty \\
i \\
i\end{array}$ \\
\hline 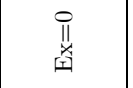 & 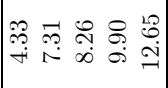 & 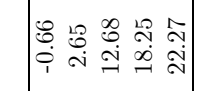 & $\mid$ & 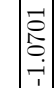 & $\stackrel{8}{0}$ \\
\hline$\frac{80}{4}$ & 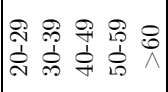 & 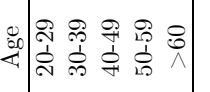 & | & 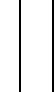 & \\
\hline & 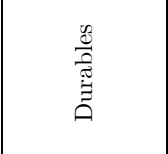 & 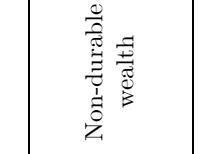 & 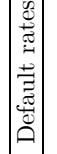 & 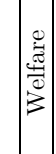 & 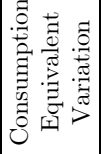 \\
\hline 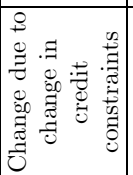 & 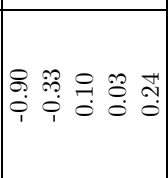 & 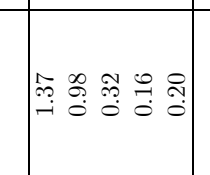 & 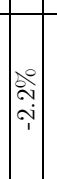 & $\left|\begin{array}{ll}0 \\
0 \\
\vdots \\
\vdots \\
1 \\
1\end{array}\right|$ & 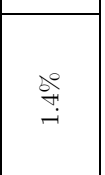 \\
\hline 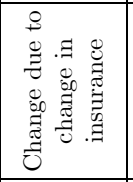 & 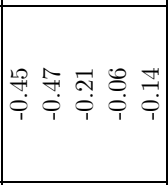 & 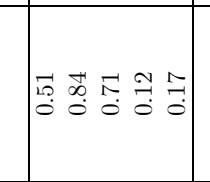 & $\mid$ & $\mid \begin{array}{l}0 \\
: \\
0 \\
0 \\
0 \\
0\end{array}$ & 命 \\
\hline 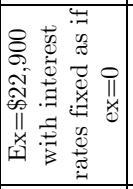 & 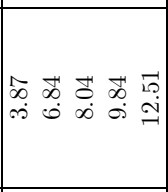 & 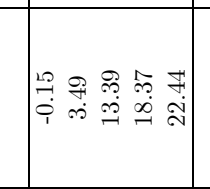 & 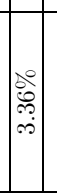 & $\mid$ & 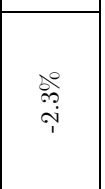 \\
\hline 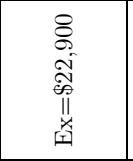 & 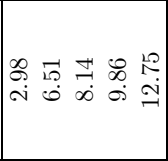 & 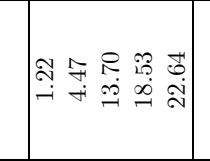 & $\mid$ & 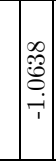 & so \\
\hline 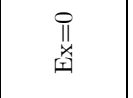 & 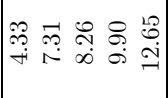 & 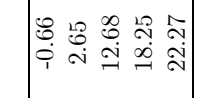 & 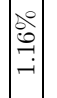 & 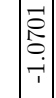 & : \\
\hline \multirow[t]{2}{*}{$\underset{\square}{\stackrel{8}{4}}$} & 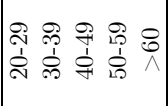 & 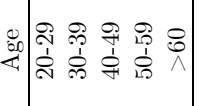 & $\mid \begin{array}{l}0 \\
0 \\
0 \\
0 \\
\vdots \\
\vdots \\
0\end{array}$ & & \\
\hline & 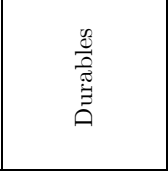 & 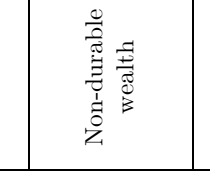 & 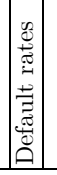 & 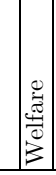 & 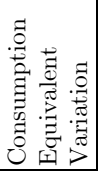 \\
\hline
\end{tabular}




\begin{tabular}{|c|c|c|c|c|c|}
\hline 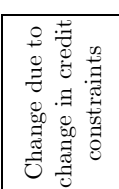 & 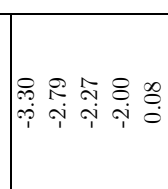 & 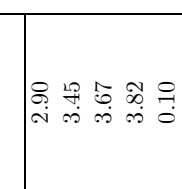 & 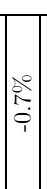 & $\mid$ & 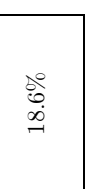 \\
\hline 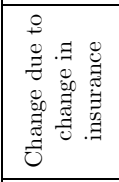 & 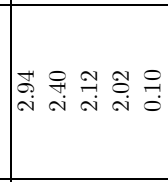 & 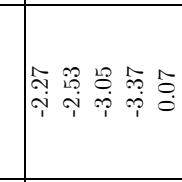 & 总 & | & 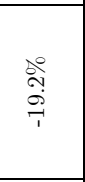 \\
\hline 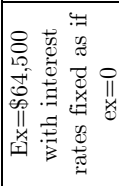 & 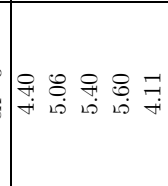 & 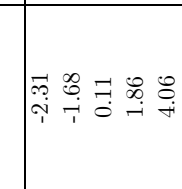 & 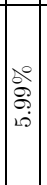 & $\left|\begin{array}{c}0 \\
0 \\
0 \\
0 \\
\hdashline \\
-1\end{array}\right|$ & 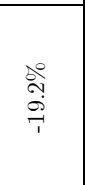 \\
\hline 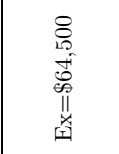 & 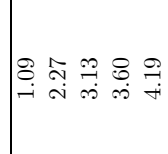 & 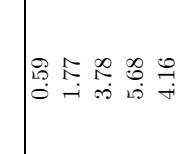 & $\mid$ & 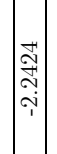 & 量 \\
\hline $\begin{array}{l}\prod_{1} \\
\text { 爻 }\end{array}$ & 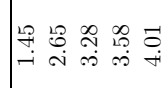 & 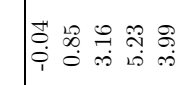 & 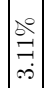 & 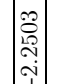 & : \\
\hline 离 & 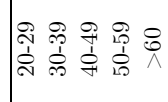 & 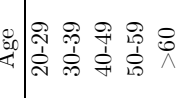 & 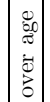 & & \\
\hline & 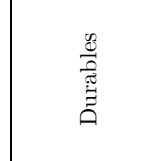 & 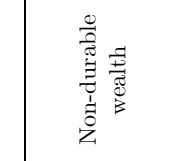 & 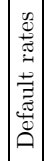 & 焉 & 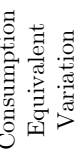 \\
\hline 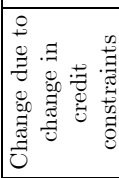 & $\mid$\begin{tabular}{lll}
0 \\
\hdashline
\end{tabular} & 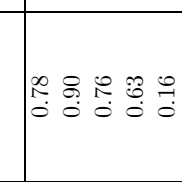 & 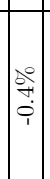 & 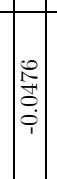 & 商 \\
\hline 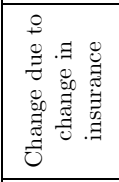 & 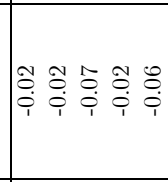 & 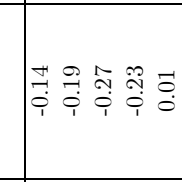 & $\mid$ & $\mid \begin{array}{l} \\
\infty \\
0 \\
0 \\
0 \\
0 \\
0\end{array}$ & 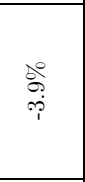 \\
\hline 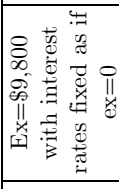 & 萧 & 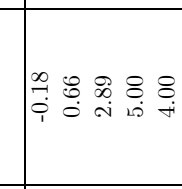 & 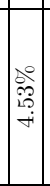 & $\mid$ & $\begin{array}{l}\text { बे } \\
\text { के }\end{array}$ \\
\hline 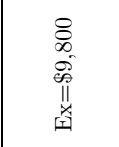 & 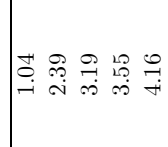 & 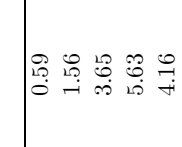 & $\mid$ & 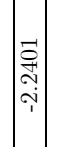 & 产 \\
\hline $\begin{array}{l}0 \\
\text { 崮 } \\
\text { 学 }\end{array}$ & 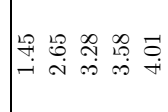 & 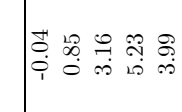 & 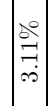 & 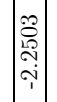 & : \\
\hline$\stackrel{\substack{\infty \\
\hdashline}}{0}$ & 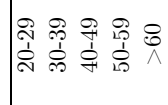 & 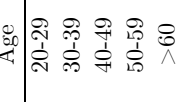 & 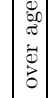 & & \\
\hline & 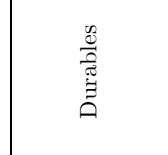 & 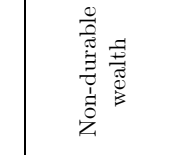 & 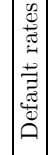 & . & $\begin{array}{ll}0 \\
0 \\
0\end{array}$ \\
\hline
\end{tabular}

\begin{tabular}{|c|c|c|c|c|c|}
\hline 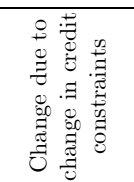 & 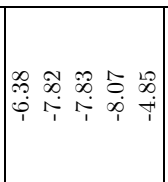 & 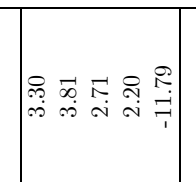 & $\mid$ & $\mid$ & 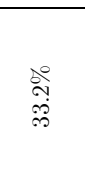 \\
\hline 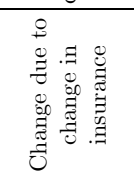 & 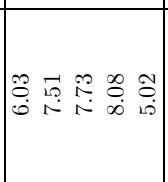 & 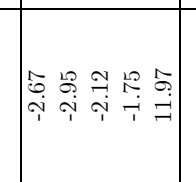 & $\mid \begin{array}{c}50 \\
25 \\
25\end{array}$ & 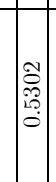 & $\begin{array}{l}\infty \\
\infty \\
\infty \\
\stackrel{p}{\rho}\end{array}$ \\
\hline 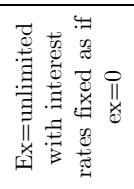 & 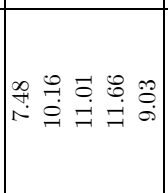 & 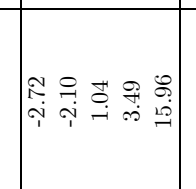 & $\mid$ & 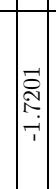 & $\begin{array}{l}\infty \\
\infty \\
\infty \\
\stackrel{p}{i}\end{array}$ \\
\hline 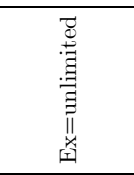 & 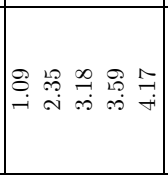 & 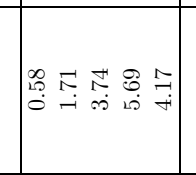 & 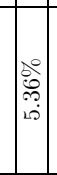 & 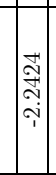 & 突 \\
\hline 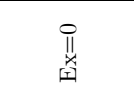 & $\mid$ & 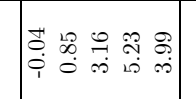 & $\mid$ & $\mid$ & : \\
\hline$\stackrel{8}{4}$ & 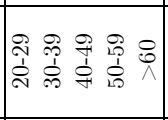 & 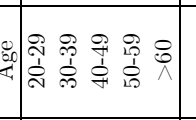 & 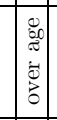 & 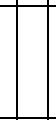 & \\
\hline & 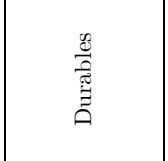 & 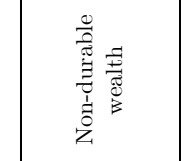 & 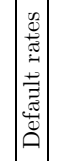 & 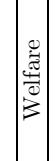 & 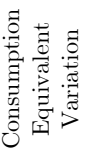 \\
\hline 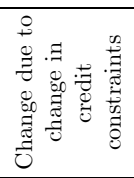 & 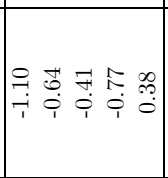 & 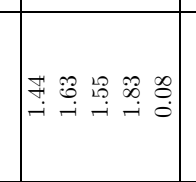 & $\left|\begin{array}{c}0 \\
0 \\
\vdots \\
i \\
i\end{array}\right|$ & 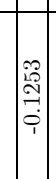 & $\underset{\infty}{\infty}$ \\
\hline 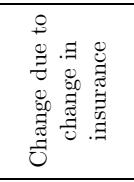 & 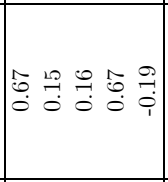 & 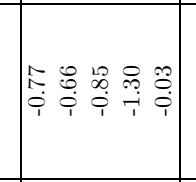 & 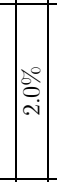 & $\overrightarrow{\mid r}$ & $\begin{array}{l}\dot{c}^{\circ} \\
\vdots \\
\text { o. } \\
1\end{array}$ \\
\hline 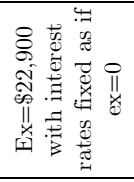 & 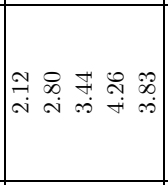 & 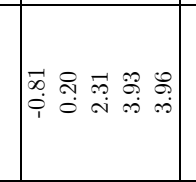 & $\mid \begin{array}{c}0 \\
10 \\
20 \\
10\end{array}$ & $\mid$ & $\begin{array}{c}\text { so } \\
\text { के } \\
\text { i }\end{array}$ \\
\hline 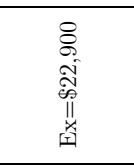 & 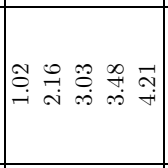 & 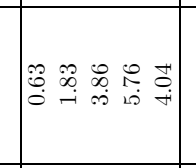 & 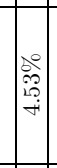 & $\mid$ & $\begin{array}{c}0^{\circ} \\
\text { in } \\
i\end{array}$ \\
\hline 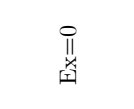 & 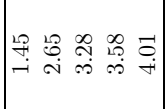 & 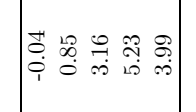 & $\mid \begin{array}{c}\stackrel{0}{\circ} \\
\vec{\infty} \\
\infty\end{array}$ & 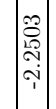 & : \\
\hline \multirow[t]{2}{*}{ 遂 } & 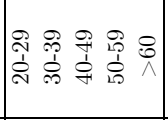 & 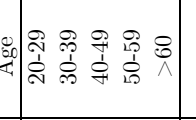 & 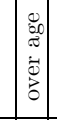 & & \\
\hline & 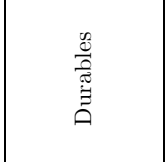 & 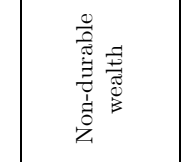 & 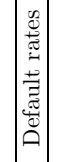 & 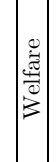 & 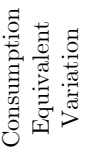 \\
\hline
\end{tabular}




\begin{tabular}{|c|c|c|c|c|c|}
\hline 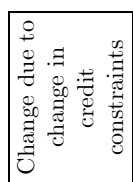 & 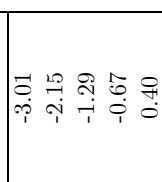 & 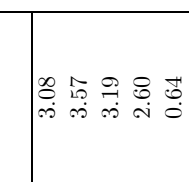 & $\mid$ & 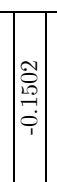 & $\stackrel{\stackrel{\circ}{ \pm}}{\square}$ \\
\hline 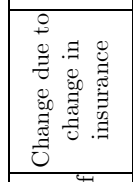 & 謀 & 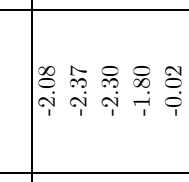 & 吾 & 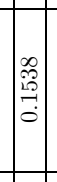 & 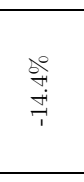 \\
\hline 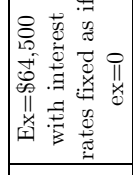 & 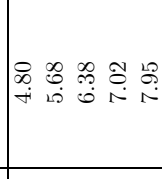 & 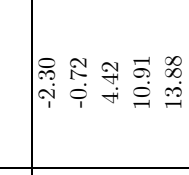 & 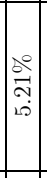 & $\mid$\begin{tabular}{c}
$\sharp$ \\
\hdashline \\
\hdashline
\end{tabular} & 总 \\
\hline 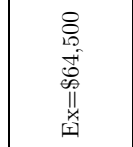 & 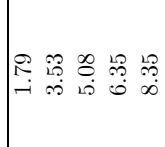 & 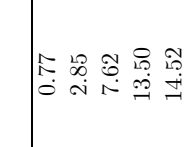 & $\mid$ & 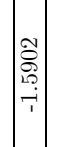 & 愈 \\
\hline 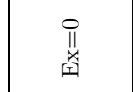 & 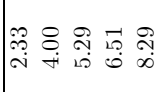 & تُ & 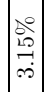 & 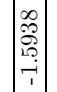 & 总 \\
\hline 造 & 解 & 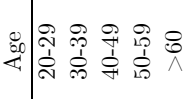 & 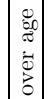 & & \\
\hline & 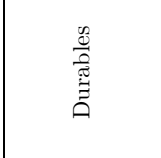 & 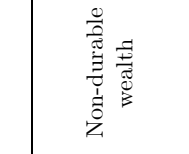 & 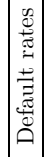 & . & 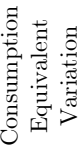 \\
\hline 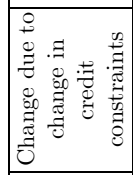 & 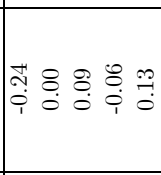 & 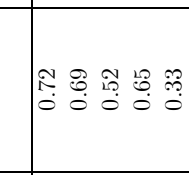 & $\mid$ & 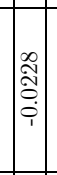 & ๙ั๊ \\
\hline 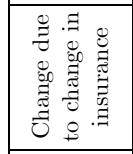 & 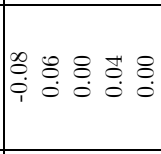 & 苗 & $\left|\begin{array}{c}0 \\
\infty \\
\infty \\
0\end{array}\right|$ & $\mid$ & 啇 \\
\hline 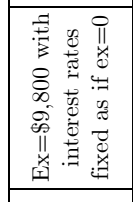 & 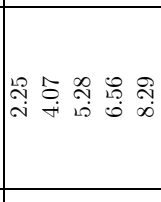 & 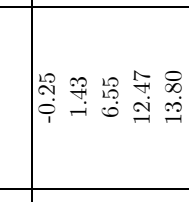 & $\mid$ & $\mid$ & 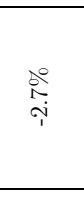 \\
\hline 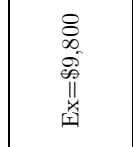 & 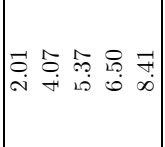 & 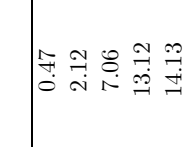 & 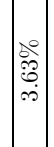 & 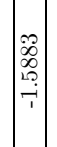 & 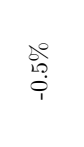 \\
\hline 䎡 & 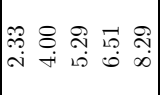 & 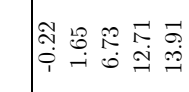 & $\left|\begin{array}{c}0 \\
0 \\
0 \\
0 \\
0 \\
0\end{array}\right|$ & 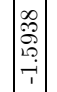 & 递 \\
\hline 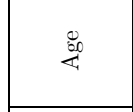 & 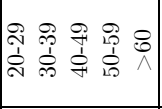 & 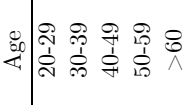 & 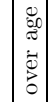 & & \\
\hline & 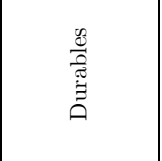 & 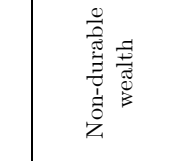 & 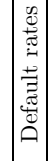 & . & 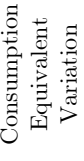 \\
\hline
\end{tabular}

\begin{tabular}{|c|c|c|c|c|c|}
\hline 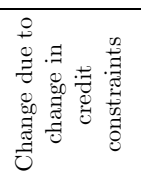 & 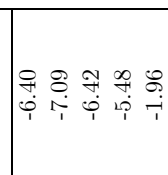 & 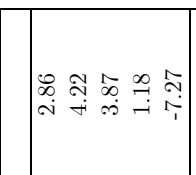 & $\mid$ & 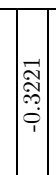 & 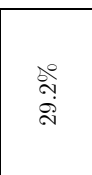 \\
\hline 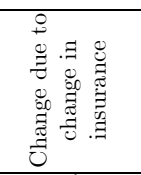 & 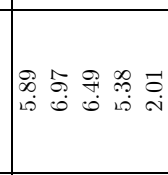 & 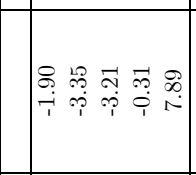 & 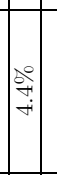 & 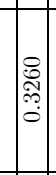 & 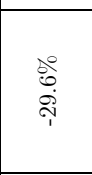 \\
\hline 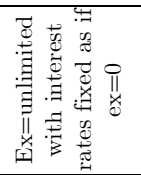 & 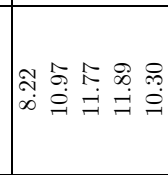 & 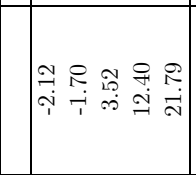 & $\mid \begin{array}{c}0 \\
0 \\
0 \\
0 \\
1 \\
1\end{array}$ & 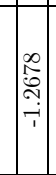 & 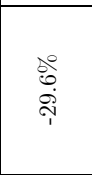 \\
\hline 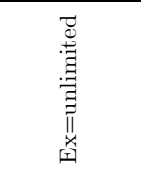 & 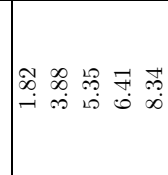 & 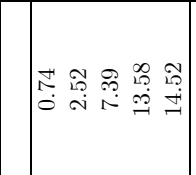 & $\left|\begin{array}{c}0 \\
\dot{0} \\
\infty \\
+\end{array}\right|$ & 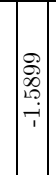 & 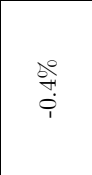 \\
\hline $\begin{array}{l}0 \\
\text { 尚 } \\
\text { 甾 }\end{array}$ & 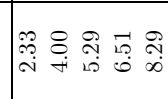 & 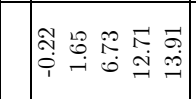 & 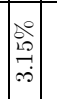 & $\mid$\begin{tabular}{c}
$\infty$ \\
0 \\
0 \\
$\vdots$ \\
\hdashline \\
\hdashline \\
\hdashline
\end{tabular} & $\stackrel{8}{\circ}$ \\
\hline$\underset{4}{4}$ & 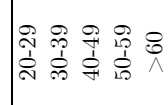 & 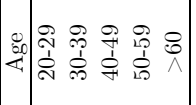 & 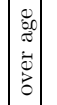 & & \\
\hline & 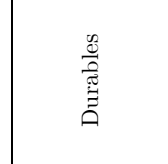 & 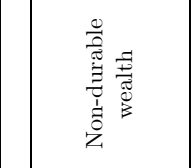 & 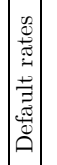 & 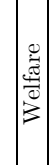 & 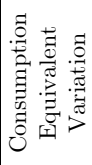 \\
\hline 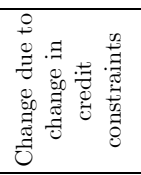 & 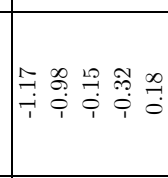 & 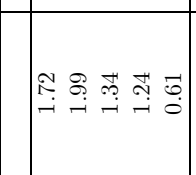 & $\mid$ & 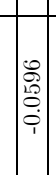 & $\begin{array}{l}\text { 永 } \\
\text { is }\end{array}$ \\
\hline 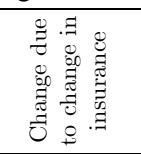 & 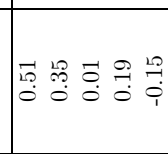 & 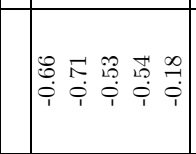 & $\mid$ & 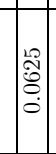 & $\begin{array}{l}\text { ò } \\
\text { i }\end{array}$ \\
\hline 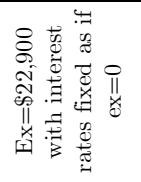 & 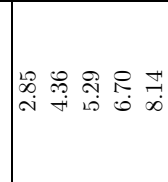 & 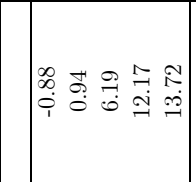 & $\mid$ & 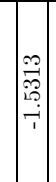 & 总 \\
\hline 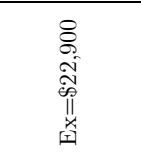 & 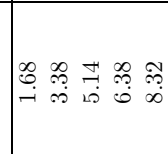 & 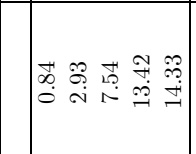 & $\mid \begin{array}{l}0 \\
0 \\
0 \\
5 \\
0\end{array}$ & $\mid$ & 宛 \\
\hline 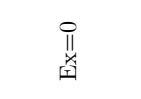 & 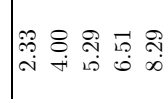 & 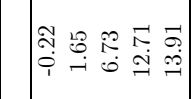 & $\mid$\begin{tabular}{c|c}
0 \\
0 \\
0 \\
0 \\
$\infty$ \\
$\infty$
\end{tabular} & 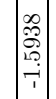 & $\stackrel{8}{0}$ \\
\hline \multirow[t]{2}{*}{$\frac{⿱ 亠 凶}{4}$} & 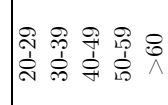 & 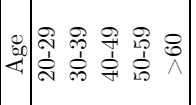 & 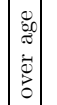 & & \\
\hline & 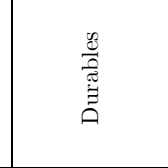 & 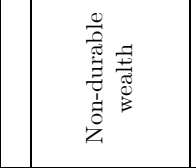 & 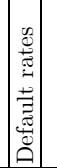 & 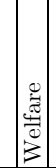 & 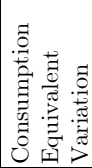 \\
\hline
\end{tabular}


Table 14: Comparison between regimes

\begin{tabular}{|c|c|c|c|c|c|}
\hline & Benchmark & Exempt. $=\$ 0$ & Exempt. $=\$ 5,000$ & Exempt.=\$10,000 & Exempt. $=\$ 60,000$ \\
\hline Default rate & $2.8 \%$ & $2.0 \%$ & $2.5 \%$ & $2.7 \%$ & $3.2 \%$ \\
\hline $\begin{array}{c}\text { Borrowing } \\
\text { Interest Rate }\end{array}$ & $13.7 \%$ & $3.3 \%$ & $5.9 \%$ & $10.5 \%$ & $19.7 \%$ \\
\hline $\begin{array}{c}\text { Percentage } \\
\text { negative } \\
\text { wealth }\end{array}$ & $32.7 \%$ & $38.7 \%$ & $34.5 \%$ & $32.8 \%$ & $33.1 \%$ \\
\hline $\begin{array}{c}\text { Equivalent } \\
\text { Consumption } \\
\text { Variation }\end{array}$ & $-0.3 \%$ & $-0.7 \%$ & $-0.3 \%$ & $-0.2 \%$ \\
\hline
\end{tabular}

